\title{
Baseline household survey: Dera Ghazi Khan district
}

Pakistan Initiative for Mothers and Newborns (PAIMAN)

Follow this and additional works at: https://knowledgecommons.popcouncil.org/departments_sbsr-rh

Part of the Family, Life Course, and Society Commons, and the Maternal and Child Health Commons How does access to this work benefit you? Let us know!

\section{Recommended Citation}

Pakistan Initiative for Mothers and Newborns (PAIMAN). 2006. "Baseline household survey: Dera Ghazi Khan district." Islamabad: Population Council. 


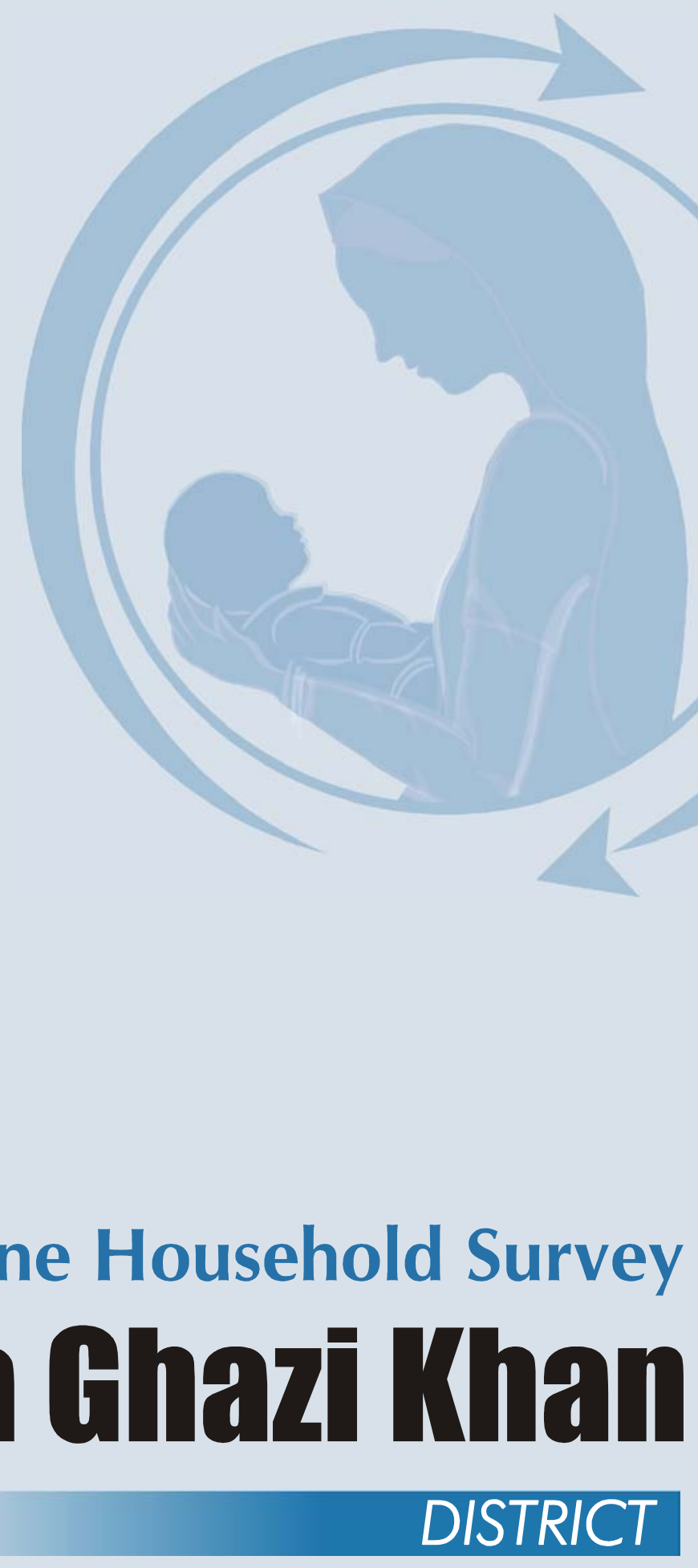

Baseline Household Survey Dera Ghazi Khan DISTRICT 



\section{Pakistan Initiative for Mothers and Newborns (PAIMAN)}

\section{Dera Ghazi Khan Baseline Household Survey}




\section{(1) Population Council}

The Population Council, an international, non-profit, non-governmental organization established in 1952, seeks to improve the well-being and reproductive health of current and future generations around the world and to help achieve a humane, equitable, and sustainable balance between people and resources.

The Council analyzes population issues and trends; conducts research in the reproductive sciences; develops new contraceptives; works with public and private agencies to improve the quality and outreach of family planning and reproductive health services; helps governments design and implement effective population policies; communicates the results of research in the population field to diverse audiences; and helps strengthen professional resources in developing countries through collaborative research and programs, technical exchanges, awards, and fellowships.

\section{For inquiries, please contact:}

Population Council

\#7, Street 62, F-6/3, Islamabad, Pakistan

Tel: 92512277439

Fax: 92512821401

Email: info@pcpak.org

web: http://www.popcouncil.org

Layout \& Design : Ali Ammad

Printed by: Crystal Printers, Islamabad

Disclaimer:

"This study/report is made possible by the generous support of the American people through the United States Agency for International Development (USAID). The contents are the responsibility of JSI Research \& Training Institute, Inc. and do not necessarily reflect the views of USAID or the United States Government." 


\section{Contents}

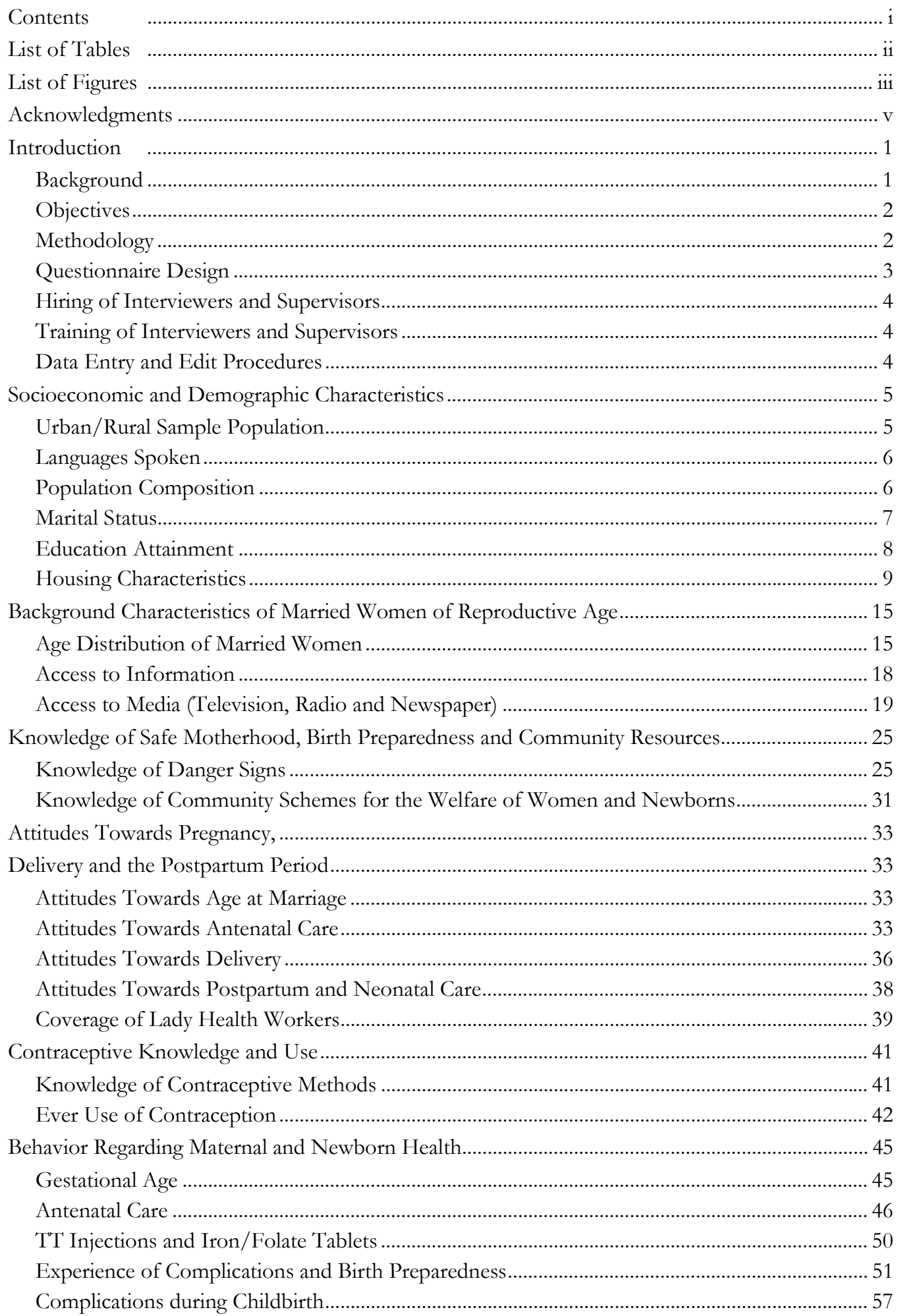


Newborn/Infant Care 60

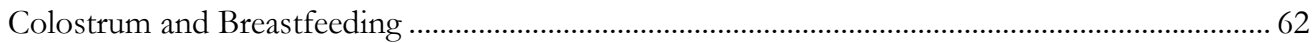

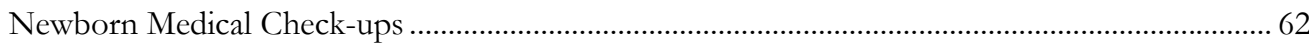

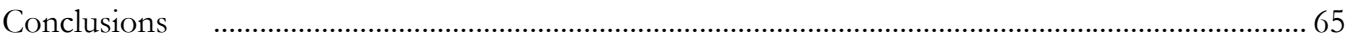

References

\section{List of Tables}

Table 1.1: Number of blocks/villages and households selected for the sample population.......... 2

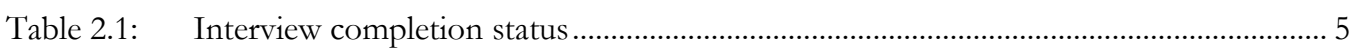

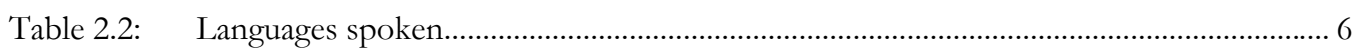

Table 2.3: Age-sex distribution of population ................................................................................... 6

Table 2.4: Household population by age (15 years and above), sex and marital status.................. 7

Table 2.5: Household population by age (10 years and above), sex and educational level............ 8

Table 2.6: Main source of drinking water...................................................................................... 9

Table 2.7: Type of toilet facility used by household members ........................................................ 10

Table 2.8: Main type of fuel used for cooking ................................................................................ 10

Table 2.9: $\quad$ Number of rooms used for sleeping.............................................................................. 11

Table 2.10: Ownership of household commodities/land .............................................................. 12

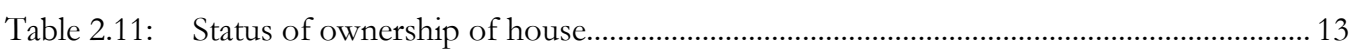

Table 3.1: Current age and age at marriage ................................................................................. 15

Table 3.2: $\quad$ Education level and literacy of married women and their husbands............................ 17

Table 3.3: Percentage distribution of married women by number of children ever born, mean number of children ever born, living children and age group, compared to the 1998

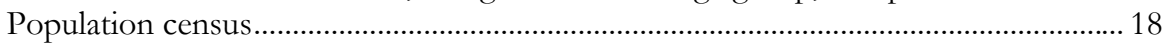

Table 3.4: Percentage distribution of married women by length of preceding birth interval....... 18

Table 3.5: Place where respondent usually watches television ..................................................... 19

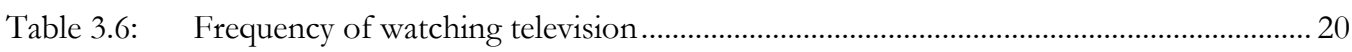

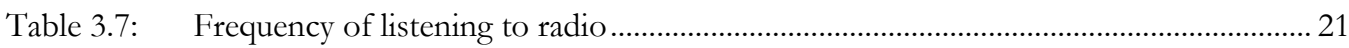

Table 4.1: Knowledge of existence and importance of transport, blood and finances by the community at the time of delivery .............................................................................. 31

Table 5.1: Belief that women should get married soon after puberty ............................................ 33

Table 5.2: Importance of antenatal check-up ...................................................................................... 34

Table 5.3: $\quad$ Month of pregnancy when women should obtain antenatal care ................................ 34

Table 5.4: Number of antenatal visits considered necessary by respondents ................................ 35

Table 5.5: Respondents who believe that women should receive delivery services from health professional ........................................................................................................... 36

Table 5.6: Person who should make decisions regarding the health of pregnant women............. 37

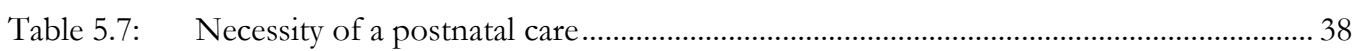

Table 5.8: Presence of lady health worker in the community ............................................................ 39

Table 5.9: $\quad$ LHW ever visited home during last three months............................................................. 39

Table 6.1: $\quad$ Ever used of specific contraceptive method................................................................. 42

Table 6.2: Current use of specific contraceptive method ................................................................ 43 
Table 6.3: Distribution of contraceptive users by source of supply ............................................. 44

Table 7.1: Pregnancy outcome by gestational age ........................................................................... 46

Table 7.2: Gestational age at first antenatal check-up/number of antenatal check-ups obtained 47

Table 7.3: Status of last delivery....................................................................................................... 53

Table 7.4: Type of complications experienced during the last delivery .......................................... 57

Table 7.5: Person who made decision to seek health care / mode of transport used to reach

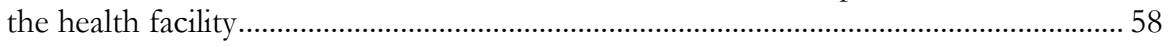

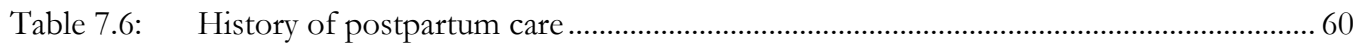

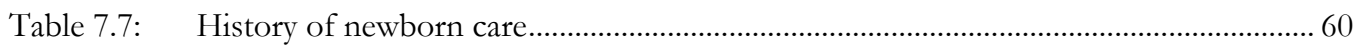

\section{List of Figures}

Figure 2.1: Material used for construction of roof by place of residence....................................... 11

Figure 3.1: Age distribution by place of residence............................................................................ 16

Figure 3.2: $\quad$ Percentage of women who watch TV or listen to radio by place of residence, ........... 19

Figure 3.3: Influence of TV programs on health behaviors of people by place of residence........ 20

Figure 3.4: Attitudes regarding influence of radio on health behaviors by place of residence ...... 21

Figure 3.5: Frequency of reading newspaper by place of residence ................................................. 22

Figure 3.6: Exposure to media (radio, TV or newspaper) ……………............................................ 22

Figure 3.7: $\quad$ Most trustworthy media by place of residence, ............................................................... 23

Figure 3.8: Percentage of married women who had heard/read maternal and newborn messages during the last 3 months by place of residence ............................................. 23

Figure 4.1: Knowledge of danger signs during pregnancy, which require medical attention ........ 26

Figure 4.2: $\quad$ Percentage of married women by status of knowledge of danger signs during

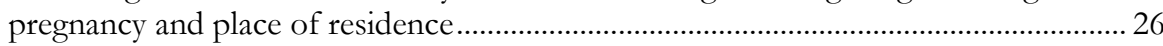

Figure 4.3: Distribution of respondents who had knowledge about complications during delivery by place of residence.

Figure 4.4: Percentage of married women by status of knowledge of danger signs during delivery and place of residence

Figure 4.5: Distribution of married women who had knowledge about complication during postpartum period by place of residence

Figure 4.6: Percentage of married women by status of knowledge of danger signs during postpartum period and place of residence.....

Figure 4.7: Distribution of respondents who had knowledge about danger signs in newborns by place of residence.

Figure 4.8: Percentage of married women by status of knowledge of danger signs in newborn and place of residence.

Figure 4.9: Source of information about pregnancy, delivery and the postpartum period by place of residence

Figure 5.1: Percentage of married women who thought having TT shots and take iron/folate during pregnancy by place of residence. 35

Figure 5.2: Percentage of women who thought in their community the women go for health professional for their delivery by place of residence........................................................ 36

Figure 5.3: Percentage of women by their perception where should delivery take place............... 37 
Figure 5.4: Percentage of married women by mode of transport they would use to reach health

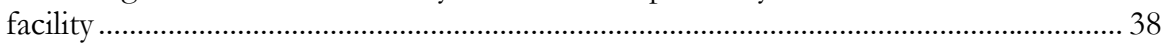

Figure 5.5: Number of postnatal care visits women should have in the community by place of

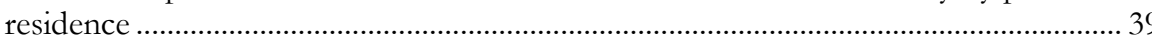

Figure 6.1: Percentage of married women by knowledge of specific contraceptive method in

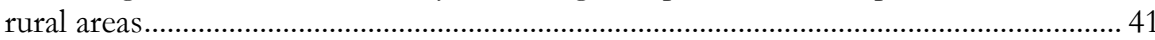

Figure 6.2: $\quad$ Percentage of married women by knowledge of specific contraceptive method in

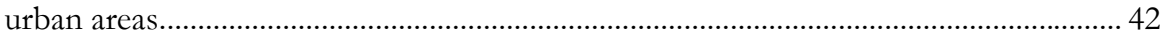

Figure 6.3: $\quad$ Percentage of married women by future intention to use contraceptives .................. 44

Figure 7.1: Percentage of pregnant women by their antenatal care status for the pregnancy

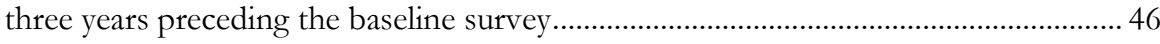

Figure 7.2: Percentage distribution of married women by persons accompanied for ANC to

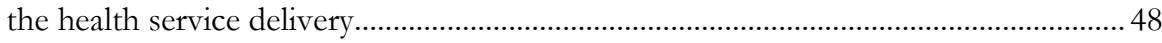

Figure 7.3: $\quad$ Services performed/asked during antenatal check-up by place of residence ............... 49

Figure 7.4: Percentage of pregnant women by issues discussed during antenatal check-up and

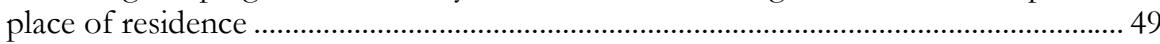

Figure 7.5: Percentage of marred women by status of T'T injections during the last pregnancy

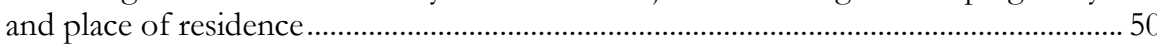

Figure 7.6: Percentage of married women by status of iron/folate tablets during the last pregnancy and place of residence ...................................................................................... 51

Figure 7.7: Percentage of married women who experienced complications during their last

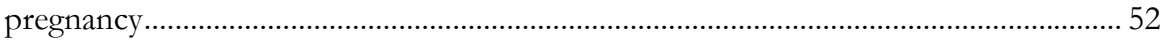

Figure 7.8: Percentage of married women who made arrangements for their last delivery by

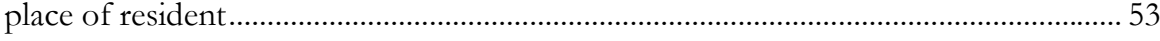

Figure 7.9: $\quad$ Percentage of pregnancies by outcome and place of residence ................................... 54

Figure 7.10: Percentage of women by place of delivery..................................................................... 54

Figure 7.11: Percentage of married women by delivery attendant.................................................... 55

Figure 7.12: Percentage of married women by reported main reason to choose a dai as delivery

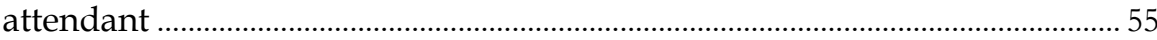

Figure 7.13: Percentage of delivery attendants who reported washed hands before conducting the delivery and type of thread used to tie the cord ........................................................ 56

Figure 7.14: Percentage of delivery attendants reported instruments for cutting the cord..............56

Figure: 7.15: Time taken to reach the health facility for childbirth .................................................. 58

Figure 7.16: Median time to reach the health facility ......................................................................... 59

Figure 7.17: Percentage of live birth by their size (small, normal and big) at birth........................ 61

Figure 7.18: Percentage of babies by time of given bath after birth.............................................. 61

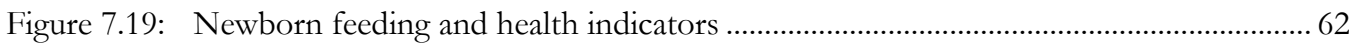

Figure 7.20: Percentage of newborns with appeared signs/symptoms soon after deliver by place of residence 63

Figure 7.21: Percentage of newborns with appeared signs/symptoms within 7-days after last delivery by place of residence

Figure 7.22: Percentage of newborn with measures taken to have complications treated, place of residence

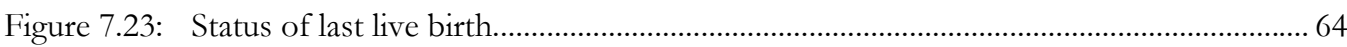




\section{Acknowledgments}

The PAIMAN Baseline Household Survey is a collaborative effort involving many partners, and will be the foundation of the PAIMAN project as a whole. Firstly, we would like to acknowledge our major partners. The United States Agency for International Development (USAID), in particular Mr. Chris McDermott, made funding available for this activity. Dr. Nabeela Ali, Chief of Party for PAIMAN, encouraged the study in general, and greatly facilitated the partnership between the Population Council and NIPS. The role of NIPS was supported under a separate agreement with PAIMAN. The comments, suggestions and feedback received from PAIMAN partners with regard to the design of this activity greatly contributed towards the success of the household survey.

The National Institute of Population Studies (NIPS) ably carried out the fieldwork for this study and was responsible for the completion of a clean dataset. We would like to appreciate the efforts of the Executive Director, Dr. Saeed Shafqat; and the Director Mr. Mahboob Sultan for the execution of the fieldwork; Computer Programmer, Mr. Fateh-ud-din, who managed the entry and cleaning of the data and the numerous NIPS staff members who carried out the study.

The Population Council was primarily responsible for designing the study, overseeing the data collection, analysis of data, and writing the reports. Dr. Arshad Mahmood, Director of Monitoring and Evaluation for PAIMAN, used his capable technical and managerial skills to oversee the entire study with enthusiasm and energy. Mr. Peter Miller, Deputy Country Director, contributed substantially in the design phase, and Dr. Zeba Sathar and Mr. Miller contributed towards the report preparation. The essential work of the study was carried out by several Council staff members at all phases. During the design and pre-testing phases, we would particularly like to acknowledge Shagufta Naheed, Bushra Bano, Irfan Masood, Tayyaba Gul, and Saima Pervaiz for monitoring field work and ensuring quality data collection in the field. Muhammad Ashraf and Saman Naz assisted in preparing graphs and tables as well as with the writing process. Dr. Arshad Mahmood and Reem Khan jointly prepared the first draft of the baseline survey report, which served as the template for all ten district reports. Shafique Arif, Azeema Faizunisa and Nadia Abid also contributed to the report writing and reviewing process. Reem Khan completed the initial editing of the baseline reports, Mehdi Ali Khan designed their layout, Ali Ammad was responsible for the formatting, and Ms. Mary DeSouza carried out the final proofreading of the district reports.

Finally, we must express our gratitude to the women of DG Khan, who gave their time freely and cooperated with us in order to make this study possible. We hope to repay them by using the information obtained from them to improve maternal and neonatal health services in the district of DG Khan. 



\section{Chapter}

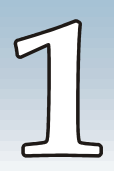

\section{Introduction}

\section{Background}

The Pakistan Initiative for Mothers and Newborns (PAIMAN) is a five-year project funded by the United States Agency for International Development (USAID). PAIMAN is committed to assisting the Government of Pakistan (GoP) in the implementation of the full spectrum of interventions necessary to address maternal and neonatal health $(\mathrm{MNH})$ issues.

The consortium is led by John Snow Incorporated (JSI), with partners from Pakistani and international organizations including Aga Khan University, Contech, Greenstar Social Marketing, Johns Hopkins University Center for Communication Program (JHU), PAVHNA, Population Council and Save the Children USA.

USAID has provided a grant to implement PAIMAN in 10 districts of Pakistan's four provinces. These districts are: Rawalpindi, Jehlum, Khanewal, and DG Khan in Punjab; Dadu and Sukkur in Sindh; Jafarabad and Lasbela in Balochistan; and Upper Dir and Bunner in the North West Frontier Province. The goal of the project is to reduce maternal, newborn and child mortality in Pakistan. The project is based on the "Pathway to Care and Survival" framework. The five major strategic objectives are to:

1) Increase awareness and promote positive maternal and neonatal health behaviors

2) Increase access (including essential obstetric care) to and community involvement in maternal and child health services, while ensuring that services are successfully delivered through health and ancillary health services

3) Improve service quality in both the public and private sectors, particularly related to management of obstetrical complications

4) Increase the capacity of Maternal and Newborn Health $(\mathrm{MNH})$ managers and care providers

5) Improve the management and integration of services at all levels

The PAIMAN Project will promote skilled attendants as the long-term goal for all deliveries in Pakistan, while acknowledging that maternal and neonatal health outcomes are influenced by factors other than health care. The PAIMAN Project calls for a multi-pronged and integrated strategic approach, combining individual health care with public health and community-based interventions. 
To ensure that the success of PAIMAN is properly ascertained and that the appropriate lessons are learned, PAIMAN has developed a Monitoring and Evaluation Plan. Included in this plan is the establishment of baseline measures for a set of indicators which will be used to evaluate the success of the project. This baseline report explores the level of knowledge of, as well as the attitudes and behaviors towards, maternal and newborn health in the DG Khan district. The specific objectives of the baseline survey were as follows:

\section{Objectives}

- To measure the Intermediate Result 7 indicators necessary as part of PAIMAN's obligation to USAID.

- To measure PAIMAN indicators for which household survey data are appropriate for measurement, and for which sample sizes are feasible.

- To obtain information on maternal and neonatal health along with related issues, which may be of use to district Departments of Health for health management purposes.

- To obtain information needed for the detailed design of the PAIMAN project and, in particular, behavior change communication, public/private partnerships, and health systems strengthening.

\section{Methodology}

\section{Study Population}

PAIMAN is primarily a district-level project, intended to improve the health of all pregnant women, women with neonatal children, as well as all neonates of the district over the course of the project. To this end, the study covers community residents - notably mothers and prospective mothers - in order to understand and measure general knowledge and practice in relation to pregnancy, delivery, obstetric and neonatal emergencies etc.

Hence, the study population for the baseline includes all currently married women of reproductive age (15-49 years) living in the selected districts. More specifically, it includes women who have experienced a pregnancy during the last three years.

\section{Sample Design}

The sampling design adopted for the survey is a stratified, systematic sample of households. The universe consists of all urban and rural areas of the district. The number of blocks selected in urban areas, along with the number of villages selected in rural areas, are presented in table 1.1. The selection procedure for is described below:

Table 1.1:Number of blocks/villages and households selected for the sample population

\begin{tabular}{lrrr} 
& Area & Number of Sample & \multicolumn{2}{c}{ Number of Households } \\
\cline { 2 - 4 } & Blocks/Villages & Selected \\
\hline Urban & & 7 & 144 \\
\hline Rural & & 33 & 816 \\
Total & 40 & 960 \\
\hline
\end{tabular}




\section{Urban Sample}

The required numbers of enumeration blocks were selected with probability proportional to size (number of circles). The "Enumeration Circle" was the smallest unit available in the 1998 Population District Census Reports as demarcated by the Population Census organizations. The maps of these circles were obtained from the Population Census Organization. The areas were already divided into blocks of approximately 250-300 households depending upon the number of households in each circle. Later, blocks were randomly selected with probability proportional to size from the list of total blocks in that circle. The listing of each block was then updated by the enumeration teams before selecting the sampled households. A fixed number of 24 households have been drawn from each sample enumeration block by using systematic random technique.

\section{Rural Sample}

The 1998 Population Census list of villages was used as the sampling frame for the selection of the rural sample. Villages in rural areas have been treated as primary sampling units (PSU). Sample PSUs have been selected with probability proportional to size (number of households). Households within the sample PSUs were considered secondary sampling units. The enumeration teams then updated the listing of each village before selecting the sampled households. A fixed number of 24 households have been drawn from each sample enumeration village by the systematic random technique.

\section{Questionnaire Design}

The questionnaire has been developed by the Population Council, based on a combination of current general Demographic and Health Survey methodologies and the questionnaire developed by the Population Council for the Safe Motherhood Applied Research and Training (SMART) Project. The questionnaire contains data sufficient to estimate all PAIMAN indicators.

Information on the following is included in the questionnaire:

- Households Information

- Socio-economic status of women

- Fertility, pregnancy history and reproductive intentions

- Attitude towards, as well as knowledge and practice of contraceptive methods

- Attitude towards pregnancy, delivery and the postpartum period

- Current Birth Preparedness/Complications Readiness (BP/CR) and knowledge of newborn care

- Current birth practices

- Health seeking behaviors

- $\quad$ Future BP/CR intentions

- Personal beliefs regarding pregnancy, delivery and the postpartum period

- Common perceptions pertaining to women who are pregnant, delivering or in their postpartum period

- Facilities regarding BP/CR available in the community

- Factors that facilitate or hinder behaviors related to BP/CR

- Media habits 


\section{Pre-testing of Questionnaire}

The questionnaire was reviewed by the PAIMAN's M\&E thematic group as well as by other interested stakeholders, and was pre-tested in non-PAIMAN districts. The main objective of the pretesting was to examine the suitability and effectiveness of questions in eliciting adequate responses, and to find out if there were any linguistic problems faced either by interviewers or by respondents. Finally, the pre-testing also helped determine the approximate time required to complete a questionnaire. The pre-tests were carried out by the Population Council's female staff members, who recorded their experiences with regard to each question. These records were then used to revise and finalize the questionnaire.

\section{Hiring of Interviewers and Supervisors}

Since the respondents in the baseline were to be MWRA and married men, it was decided that female interviewers would be used to interview women and male interviewers for men. Based on the constitution of each team, the required number of female interviewers were hired by NIPS according to its own internal procedures.

\section{Training of Interviewers and Supervisors}

The quality of training received by interviewers is reflected in the quality of data they record. In order to ensure that interviews were of a high and uniform quality, and that interviewers understood the definitions and concepts behind the language of the questions, training was conducted by the Population Council in collaboration with NIPS. The training took place in Islamabad over a two week period, and interviewers were schooled in questionnaire and survey procedures. Interviewers visited 3-4 households to conduct practice interviews.

It was very important for the interviewers to thoroughly understand the methodology and statistical importance of the sampled households. Training regarding the importance of the criterion of selection of primary sampling units, mapping and listing procedure, sample selection, field operation procedures, as well as the selection of the particular households and respondents was also provided by experts.

\section{Data Entry and Edit Procedures}

Data processing was started from the field level with the checking of the questionnaires. Each team leader completed on-the-spot checks and preliminary editing of questionnaires during the enumeration period. Editing instructions were provided to the team leaders, and emphasis was laid on the importance of completing each questionnaire, correctly identifying each eligible respondent, and the completeness of household composition.

Quality Assurance

To ensure the quality of the data, Population Council staff monitored the fieldwork accompanying the field teams. While supervising the fieldwork, the Population Council supervisory staff was also available to provide on-the-spot guidance to interviewers in the event that any part of the questionnaire was unclear to them. This ensured the completeness and accuracy of each questionnaire. 


\section{Chapter}

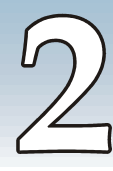

\section{Socioeconomic and Demographic Characteristics}

This chapter presents the demographic and socioeconomic characteristics of the population in the sampled households of Dera Ghazi Khan. Information was collected on some demographic and socioeconomic characteristics such as the condition of the households, including the source of drinking water, sanitation facilities, building materials, and possession of household durable goods. This information on the characteristics of the households is essential for the interpretation of survey findings. The definition of the household used for the baseline survey was "a person or a group of persons, related or unrelated, who live together in the same dwelling unit and share a common source of food".

\section{Urban/Rural Sample Population}

Table 2.1 shows the number of households selected in both urban and rural areas of DG Khan, as well as the interview status upon completion. A total sample of 960 households was selected from DG Khan. This number includes 816 households from rural areas along with 144 households from urban areas. One selected village was out of reach and could not be covered. Table 2.1 indicates a slightly higher interview completion rate in urban areas as compared to rural areas of DG Khan. Only 0.3 percent of households refused to participate in the survey.

Table 2.1: $\quad$ Interview completion status

\begin{tabular}{lrrrrrr}
\multirow{2}{*}{ Result } & \multicolumn{2}{c}{ Rural } & \multicolumn{2}{c}{ Urban } & \multicolumn{2}{c}{ Total } \\
\cline { 2 - 7 } Completed & Percent & Number & Percent & Number & Percent & Number \\
\hline Incomplete & 98.7 & 782 & 99.3 & 143 & 98.8 & 925 \\
\hline Refused & 0.1 & 1 & & & 0.1 & 1 \\
\hline Others & 0.3 & 2 & 0.7 & 1 & 0.3 & 3 \\
\hline Total & 0.9 & 7 & & & 0.7 & 7 \\
\hline
\end{tabular}




\section{Languages Spoken}

Table 2.2 presents the distribution of households with respect to the languages spoken by their inhabitants. Saraiki is the most widely spoken language in both rural and urban areas of Dera Ghazi Khan. Urdu is the second most spoken language in urban areas, whereas in rural areas, Balochi is the second most popular language after Saraiki, due to the settlement of Baloch tribes in the rural areas of DG Khan

Table 2.2: $\quad$ Languages spoken

\begin{tabular}{|c|c|c|c|c|c|c|}
\hline \multirow{2}{*}{ Language } & \multicolumn{2}{|c|}{ Rural } & \multicolumn{2}{|c|}{ Urban } & \multicolumn{2}{|c|}{ Total } \\
\hline & Percent & Number & Percent & Number & Percent & Number \\
\hline Urdu & 5.8 & 45 & 14.0 & 20 & 7.0 & 65 \\
\hline Punjabi & 0.9 & 7 & 3.5 & 5 & 1.3 & 12 \\
\hline Sindhi & & & 0.7 & 1 & 0.1 & 1 \\
\hline Pushto & & & 0.7 & 1 & 0.1 & 1 \\
\hline Hindko & & & 0.7 & 1 & 0.1 & 1 \\
\hline Balochi & 11.3 & 88 & 2.1 & 3 & 9.8 & 91 \\
\hline Barahvi & 0.4 & 3 & & & 0.3 & 3 \\
\hline Saraiki & 81.7 & 639 & 78.3 & 112 & 81.2 & 751 \\
\hline Total & 100.0 & 782 & 100.0 & 143 & 100.0 & 925 \\
\hline
\end{tabular}

\section{Population Composition}

Table 2.3 shows the distribution of population in the baseline survey with regard to age and sex composition. Age and sex are important demographic variables as these are the primary basis of demographic analysis. They are also the important variables in the study of reproductive health, mortality and fertility.

Table 2.3: $\quad$ Age-sex distribution of population

\begin{tabular}{lrrrrrr} 
& \multicolumn{2}{c}{ Males } & \multicolumn{2}{c}{ Females } & \multicolumn{2}{c}{ Both Sexes } \\
Age-group & Number & \multicolumn{1}{c}{ Percent } & Number & Percent & Number & \multicolumn{2}{c}{ Percent } \\
$<5$ & 595 & 15.4 & 582 & 15.6 & 1177 & 15.5 \\
\hline $5-9$ & 640 & 16.5 & 564 & 15.2 & 1204 & 15.9 \\
\hline $10-14$ & 551 & 14.2 & 510 & 13.7 & 1061 & 14.0 \\
\hline $15-19$ & 458 & 11.8 & 433 & 11.6 & 891 & 11.7 \\
\hline $20-24$ & 311 & 8.0 & 350 & 9.4 & 661 & 8.7 \\
\hline $25-29$ & 253 & 6.5 & 311 & 8.4 & 564 & 7.4 \\
\hline $30-34$ & 214 & 5.5 & 216 & 5.8 & 430 & 5.7 \\
\hline $35-39$ & 209 & 5.4 & 183 & 4.9 & 392 & 5.2 \\
\hline $40-44$ & 120 & 3.1 & 124 & 3.3 & 244 & 3.2 \\
\hline $45-49$ & 114 & 2.9 & 83 & 2.2 & 197 & 2.6 \\
\hline $50-54$ & 103 & 2.7 & 142 & 3.8 & 245 & 3.2 \\
\hline $55-59$ & 107 & 2.8 & 68 & 1.8 & 175 & 2.3 \\
\hline $60-64$ & 68 & 1.8 & 56 & 1.5 & 124 & 1.6 \\
\hline 65 and older & 126 & 3.3 & 99 & 2.7 & 225 & 3.0 \\
\hline Total & 3869 & 100.0 & 3721 & 100.0 & 7590 & 100.0 \\
\hline
\end{tabular}


In table 2.3, the age-sex distribution shows that 45.4 percent of population in DG Khan is under the age of 15 years, which is a result of high fertility in the recent past. The sex ratio in the baseline survey is 104 males per 100 females. The sex ratio obtained in the 1998 Population Census was 108 males per 100 females. The marked difference between the two could be a result of improved overall enumeration of the female population in individual households.

\section{Marital Status}

The data on the marital status of respondents is shown in table 2.4. The proportion of married women between the age of 15 and 19 is much higher than the proportion of married men within the same age group (21.7 percent versus 3.5 percent). This comparison clearly shows a change from the 1998 Population Census results. The results clearly demonstrate a delay in female marriages, which is an improvement in the status of women. However, women still tend to get married earlier than men. Also, a greater percentage of women show signs of early widowhood compared to men. This trend has not changed since the 1998 Population Census.

Table 2.4: $\quad$ Housebold population by age (15 years and above), sex and marital status

\begin{tabular}{|c|c|c|c|c|c|c|}
\hline & & Males & & & Females & \\
\hline Age & Never & Currently & Widow/ & Never & Currently & Widow/ \\
\hline Group & Married & Married & Divorced & Married & Married & Divorced \\
\hline PAIMAN Base & & & & & & \\
\hline $15-19$ & 95.6 & 3.5 & 0.7 & 77.4 & 21.7 & 0.7 \\
\hline $20-24$ & 73.6 & 25.7 & 0.0 & 38.6 & 59.4 & 0.3 \\
\hline $25-29$ & 31.6 & 68.0 & 0.4 & 14.8 & 83.6 & 1.0 \\
\hline $30-34$ & 12.1 & 86.9 & 0.5 & 1.9 & 94.0 & 3.7 \\
\hline $35-39$ & 3.3 & 95.7 & 0.5 & 1.1 & 95.1 & 3.8 \\
\hline $40-44$ & 0.8 & 98.3 & 0.0 & 2.4 & 89.5 & 6.5 \\
\hline $45-49$ & 0.0 & 97.4 & 2.6 & 0.0 & 80.7 & 18.1 \\
\hline $50-54$ & 0.0 & 92.2 & 7.8 & 0.7 & 81.0 & 16.2 \\
\hline $55-59$ & 0.0 & 94.4 & 5.6 & 1.5 & 70.6 & 26.5 \\
\hline $60-64$ & 1.5 & 91.2 & 7.4 & 0.0 & 62.5 & 37.5 \\
\hline 65 and older & 1.6 & 82.5 & 15.9 & 2.0 & 33.3 & 64.6 \\
\hline Total & 37.7 & 59.8 & 2.3 & 25.6 & 65.3 & 8.3 \\
\hline Population cen & & & & & & \\
\hline $15-19$ & 88.4 & 11.3 & 0.3 & 60.6 & 38.9 & 0.5 \\
\hline $20-24$ & 50.8 & 48.7 & 0.5 & 18.7 & 80.4 & 0.8 \\
\hline $25-29$ & 23.6 & 75.6 & 0.8 & 7.4 & 91.3 & 1.3 \\
\hline $30-34$ & 10.5 & 88.4 & 1.1 & 4.2 & 93.8 & 2.1 \\
\hline $35-39$ & 5.3 & 93.3 & 1.4 & 2.6 & 94.1 & 3.3 \\
\hline $40-44$ & 3.9 & 94.5 & 1.6 & 2.1 & 92.9 & 5.0 \\
\hline $45-49$ & 2.5 & 95.3 & 2.2 & 1.4 & 90.9 & 7.7 \\
\hline $50-54$ & 2.8 & 93.2 & 3.9 & 2.2 & 83.6 & 14.3 \\
\hline $55-59$ & 2.1 & 92.5 & 5.3 & 2.0 & 80.2 & 17.7 \\
\hline $60-64$ & 3.0 & 89.0 & 8.0 & 3.3 & 66.1 & 30.6 \\
\hline 65 and older & 3.7 & 80.9 & 15.4 & 5.3 & 47.4 & 47.3 \\
\hline Total & 29.7 & 67.8 & 2.6 & 16.1 & 76.8 & 7.1 \\
\hline
\end{tabular}




\section{Education Attainment}

Education is a major factor influencing social status. Education is important for the social and economic development of a country.

Males tend to be better educated than females for all age groups in DG Khan. Table 2.5 shows the distribution of males and females by their educational levels. It shows the overall percentage of uneducated males and females, which comes to 33 percent and 61 percent respectively. According to table 2.5 , the proportion of females who never go to school has significantly declined over time whereas the trend in males is not pronounced.

Table 2.5: $\quad$ Household population by age (10 years and above), sex and educational level

\begin{tabular}{|c|c|c|c|c|c|}
\hline $\begin{array}{c}\text { Age } \\
\text { Group }\end{array}$ & $\begin{array}{c}\text { No } \\
\text { Schooling }\end{array}$ & $\begin{array}{c}1-5 \\
\text { Years }\end{array}$ & $\begin{array}{c}6-10 \\
\text { Years }\end{array}$ & $\begin{array}{c}11 \text { and } \\
\text { More years }\end{array}$ & Total \\
\hline $10-14$ & 27.4 & 57.4 & 15.2 & 0.0 & 551 \\
\hline $15-19$ & 26.0 & 20.5 & 45.9 & 7.6 & 458 \\
\hline $20-24$ & 22.8 & 19.0 & 39.9 & 18.3 & 311 \\
\hline $25-29$ & 23.7 & 19.8 & 37.5 & 19.0 & 253 \\
\hline $30-34$ & 32.2 & 16.8 & 32.7 & 18.2 & 214 \\
\hline $35-39$ & 44.5 & 11.0 & 29.2 & 15.3 & 209 \\
\hline $40-44$ & 40.0 & 14.2 & 33.3 & 12.5 & 120 \\
\hline $45-49$ & 44.7 & 17.5 & 28.9 & 8.8 & 114 \\
\hline $50-54$ & 45.6 & 19.4 & 30.1 & 4.9 & 103 \\
\hline $55-59$ & 57.0 & 20.6 & 16.8 & 5.6 & 107 \\
\hline $60-64$ & 54.4 & 14.7 & 26.5 & 4.4 & 68 \\
\hline 65 and older & 56.3 & 22.2 & 19.0 & 2.4 & 126 \\
\hline Total & 33.3 & 26.4 & 30.7 & 9.6 & 2634 \\
\hline \multicolumn{6}{|l|}{ Females } \\
\hline $10-14$ & 43.3 & 41.4 & 15.3 & 0.0 & 510 \\
\hline $15-19$ & 43.4 & 16.9 & 32.3 & 7.4 & 433 \\
\hline $20-24$ & 50.3 & 11.1 & 23.4 & 15.1 & 350 \\
\hline $25-29$ & 62.7 & 9.6 & 17.7 & 10.0 & 311 \\
\hline $30-34$ & 73.1 & 12.0 & 9.3 & 5.6 & 216 \\
\hline $35-39$ & 77.0 & 12.0 & 7.1 & 3.8 & 183 \\
\hline $40-44$ & 75.0 & 12.9 & 10.5 & 1.6 & 124 \\
\hline $45-49$ & 78.3 & 8.4 & 8.4 & 4.8 & 83 \\
\hline $50-54$ & 88.7 & 7.7 & 3.5 & 0.0 & 142 \\
\hline $55-59$ & 89.7 & 8.8 & 1.5 & 0.0 & 68 \\
\hline $60-64$ & 91.1 & 1.8 & 5.4 & 1.8 & 56 \\
\hline 65 and older & 92.9 & 6.1 & 1.0 & 0.0 & 99 \\
\hline Total & 60.9 & 17.4 & 16.2 & 5.5 & 2575 \\
\hline
\end{tabular}




\section{Housing Characteristics}

\section{Source of Drinking Water}

In order to obtain a clear understanding of the living conditions of the population of DG Khan, it is necessary to record the source of drinking water available to respondents and their families. The source of drinking water has a close bearing on a household's socio-economic status. By determining the source of drinking water, the level of hygiene of the household can also be assessed. With regard to pregnancy and neonatal care, the source of drinking water indicates the level of hygiene and comfort available to an expectant mother or a newborn child.

Table 2.6 presents the types of water sources available to the residents of DG Khan. Overall, about 59 percent of households obtain their drinking water from indoor motorized hand pumps. About 3.5 percent remain dependent on open sources such as rivers/canals/streams/pond/pooled water. Government supply of tap water is available mostly in urban areas, where about 83 percent of the households surveyed have access to it inside their homes. The proportion of such households in rural areas is 11 percent.

Table 2.6:

Main source of drinking water

\begin{tabular}{lrrrrrr}
\multirow{2}{*}{ Source } & \multicolumn{2}{c}{ Rural } & \multicolumn{2}{c}{ Urban } & \multicolumn{2}{c}{ Total } \\
& Percent & Number & Percent & Number & Percent & Number \\
\hline Govt. supply (tap water inside) & 11.4 & 89 & 82.5 & 118 & 22.4 & 207 \\
\hline Govt. supply (communal) & 4.6 & 36 & 2.1 & 3 & 4.2 & 39 \\
\hline Motorized/hand pump (inside) & 67.4 & 527 & 9.8 & 14 & 58.5 & 541 \\
\hline Motorized/hand pump (outside) & 7.0 & 55 & 0.7 & 1 & 6.1 & 56 \\
\hline Well (inside) & 0.1 & 1 & & & 0.1 & 1 \\
\hline Well (outside) & 0.3 & 2 & & & 0.2 & 2 \\
\hline Tube-well & 3.6 & 28 & & & 3.0 & 28 \\
\hline River/canal/stream & 3.6 & 28 & & & 3.0 & 28 \\
\hline Pooled/pond water & 0.6 & 5 & & & 0.5 & 5 \\
\hline Other & 1.4 & 11 & 4.9 & 7 & 1.9 & 18 \\
Total & 100.0 & 782 & 100.0 & 143 & 100.0 & 925
\end{tabular}

\section{Toilet Facilities}

Along with the source of drinking water, toilet facilities are a major indicator of a household's socioeconomic status, and therefore the level of hygiene, sanitation and comfort available to an expectant or new mother and her newborn children. The residents of households with open-concept toilet facilities or no toilet facilities altogether are at a higher risk of catching diseases than households with closed flush systems. According to table 2.7, in rural areas of DG Khan, 44 percent of the sampled households have no toilet facilities and are therefore forced to use fields. Only 3 percent have access to a flush system connected to the sewerage system, while 35 percent have access to a flush connected to a septic tank, and 16 percent have access to a flush connected to an open drain. In urban areas 53 percent of sampled households have access to a flush connected to sewerage system, 38 percent have access to a flush connected to a septic tank, and 9 percent have access to a flush connected to an open drain. 
Table 2.7: $\quad$ Type of toilet facility used by bousehold members

\begin{tabular}{lrrrrrr}
\multirow{2}{*}{ Toilet facility } & \multicolumn{2}{c}{ Rural } & \multicolumn{2}{c}{ Urban } & \multicolumn{2}{c}{ Total } \\
\cline { 2 - 7 } & Percent & Number & Percent & Number & Percent & Number \\
\hline Flush to sewerage & 3.1 & 24 & 53.1 & 76 & 10.8 & 100 \\
\hline Flush connected to septic tank & 34.5 & 270 & 37.8 & 54 & 35.0 & 324 \\
\hline Flush connected to open drain & 16.0 & 125 & 9.1 & 13 & 14.9 & 138 \\
\hline Raised latrine & 1.4 & 11 & & & 1.2 & 11 \\
\hline Pit latrine & 0.4 & 3 & & & 0.3 & 3 \\
\hline In fields & 43.7 & 342 & & & 37.0 & 342 \\
\hline Others & 0.9 & 7 & & & 0.8 & 7 \\
Total & 100.0 & 782 & 100.0 & 143 & 100.0 & 925
\end{tabular}

\section{Fuel Used for Cooking}

The fuel used in a household for cooking purpose is another important indicator which may be used to measure the socio-economic status of that household. In rural areas of DG Khan, more than 95 percent of the sampled households use firewood for the purpose of cooking. In urban areas, over 83 percent of the sample population uses natural gas, while 16 percent use firewood for cooking purposes (Table 2.8).

Table 2.8: $\quad$ Main type of fuel used for cooking

\begin{tabular}{lrrrrrrr}
\multirow{2}{*}{ Type of fuel } & \multicolumn{2}{c}{ Rural } & \multicolumn{2}{c}{ Urban } & \multicolumn{2}{c}{ Total } \\
\cline { 2 - 7 } Fire wood & Percent & Number & Percent & Number & Percent & Number \\
\hline Kerosene oil & 95.4 & 746 & 16.1 & 23 & 83.1 & 769 \\
\hline Gas cylinder & 0.1 & 1 & 0.7 & 1 & 0.2 & 2 \\
\hline Natural gas (Sui gas) & 2.6 & 20 & & & 2.2 & 20 \\
\hline Dry dung & 0.1 & 1 & 83.2 & 119 & 13.0 & 120 \\
Total & 1.8 & 14 & & & 1.5 & 14 \\
\hline
\end{tabular}

\section{Materials used for the Roof}

The materials used for the construction of the roof and walls of a household are major indicators of the socio-economic status of that household, as well as of the living standards of the people residing there. The more secure the materials, the higher the level of comfort and living standard of residents, and the lower the risk of disease and infection.

According to figure 2.1, 73 percent of the households in urban areas of DG Khan have roofs made from girders and T-iron. In rural areas, about 52 percent of the households have roofs of the same material, while 47 percent of the households use wood/bamboo and mud. In urban areas, 13 percent of the households have roofs made of wood/bamboo and mud. 
Figure 2.1: $\quad$ Material used for construction of roof

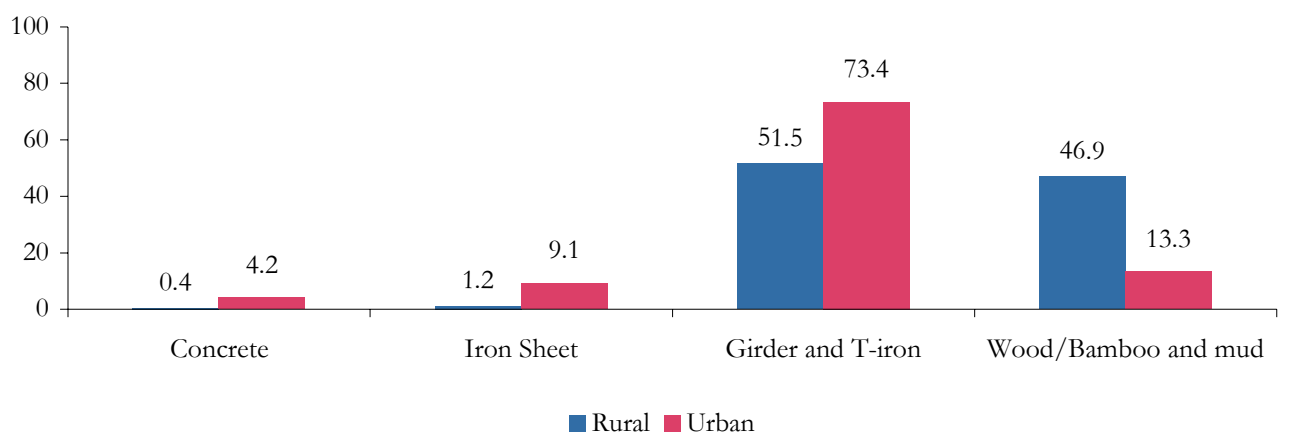

\section{Number of Rooms for Sleeping}

The number of separate rooms available for sleeping in each household is an important indicator of sanitation and hygiene levels. Overcrowding in households may lead to the spread of infection and disease, which puts the lives of expectant/young mothers and of their newborn children at risk.

According to table 2.9, about 34 percent of the population in rural DG Khan has access to only one room for sleeping, while 44 percent of the population has access to two rooms for the same purpose. In urban areas, 20 percent indicated that they have only one room used for sleeping, whereas nearly half the population (49.7 percent) indicated that they have two rooms. Approximately 14 percent of the sampled population in rural areas and 21 percent of the sample population in urban areas have access to 3 rooms for the purpose of sleeping. Findings show that in urban areas, there is an average of 3.7 persons per room, compared to 4.6 persons per room in rural areas.

Table 2.9: $\quad$ Number of rooms used for sleeping

\begin{tabular}{lrrrrrr}
\multirow{2}{*}{ Number of rooms } & \multicolumn{2}{c}{ Rural } & \multicolumn{2}{c}{ Urban } & \multicolumn{2}{c}{ Total } \\
\cline { 2 - 7 } 1 & Percent & Number & Percent & Number & Percent & Number \\
\hline 2 & 34.0 & 266 & 20.3 & 29 & 31.9 & 295 \\
\hline 3 & 44.0 & 344 & 49.7 & 71 & 44.9 & 415 \\
\hline 4 & 14.1 & 110 & 21.0 & 30 & 15.1 & 140 \\
\hline $5+$ & 5.1 & 40 & 7.7 & 11 & 5.5 & 51 \\
\hline Total & 2.8 & 22 & 1.4 & 2 & 2.6 & 24 \\
& 100.0 & 782 & 100.0 & 143 & 100.0 & 925
\end{tabular}




\section{Household possessions}

Household possessions are perhaps one of the most effective ways of determining the socioeconomic status of a household. Often, it is easier to obtain information regarding household possessions than to ask for details regarding household income, which respondents may be less willing to provide for various reasons.

According to table 2.10, 78 percent of the people surveyed in rural areas and 99 percent in urban areas owned electric fans. However, a higher proportion of urban households reported ownership of midrange possessions such as an electric iron, sewing machines, clocks, radios etc., along with high-range possessions such as televisions, air conditioners, refrigerators etc. than rural households.

Table 2.10 also shows that 43 percent of the rural households surveyed own agricultural land, compared to 21 percent of the households in urban areas. Agriculture was reported as being a major source of livelihood for approximately 17 percent of the households in rural DG Khan, compared to only 3 percent of the households in urban areas that draw their income from agriculture.

Table 2.10: $\quad$ Ownership of household commodities/land

\begin{tabular}{lrrrr} 
& Household items & & \multicolumn{2}{c}{ Total } \\
& Rural & Urban & Percentage & Number \\
\hline Electric iron & 55.2 & 89.5 & 60.5 & 560 \\
\hline Electric fan & 77.7 & 99.3 & 81.1 & 750 \\
\hline Sewing machine & 46.4 & 86.0 & 52.5 & 486 \\
\hline Radio or cassette player & 37.7 & 62.9 & 41.6 & 385 \\
\hline Chair/table & 23.9 & 67.8 & 30.7 & 284 \\
\hline Television & 34.9 & 74.8 & 41.1 & 380 \\
\hline Telephone & 23.1 & 55.9 & 28.2 & 261 \\
\hline Watch/clock & 54.1 & 88.8 & 59.5 & 550 \\
\hline VCR/VCP/VCD/CD player & 6.6 & 20.3 & 8.8 & 81 \\
\hline Refrigerator/deep freezer & 19.2 & 57.3 & 25.1 & 232 \\
\hline Air cooler & 13.4 & 43.4 & 18.1 & 167 \\
\hline Air conditioner & 0.6 & 14.0 & 2.7 & 25 \\
\hline Computer & 2.7 & 18.2 & 5.1 & 47 \\
\hline Bicycle & 44.4 & 44.1 & 44.3 & 410 \\
\hline Motorcycle & 17.1 & 41.3 & 20.9 & 193 \\
\hline Car/jeep & 1.5 & 3.5 & 1.8 & 17 \\
\hline Tractor/truck & 3.8 & 0.7 & 3.4 & 31 \\
\hline HH owned any agriculture land & 43.1 & 21.0 & 39.7 & 367 \\
\hline Agriculture major source of livelihood & 17.1 & 2.8 & 14.9 & 138 \\
\hline
\end{tabular}




\section{Ownership of the House}

Table 2.11 shows the ownership status of the households in which the respondents reside. In rural areas of DG Khan, 95 percent of the sampled population owned the homes in which they lived. Only 3 percent indicated that they live in rented houses in rural areas. In urban areas, 85 percent of the sampled population indicated that they live in their own houses, while 13 percent live in rented houses.

Table 2.11: $\quad$ Status of ownership of house

\begin{tabular}{lrrrrrr}
\multicolumn{1}{c}{ Status } & \multicolumn{2}{c}{ Rural } & \multicolumn{2}{c}{ Urban } & \multicolumn{2}{c}{ Total } \\
\cline { 2 - 7 } Owner occupied & Percent & Number & Percent & Number & Percent & Number \\
\hline Rented & 95.1 & 744 & 85.3 & 122 & 93.6 & 866 \\
\hline Rent free & 2.9 & 23 & 12.6 & 18 & 4.4 & 41 \\
Total & 1.9 & 15 & 2.1 & 3 & 1.9 & 18 \\
\hline
\end{tabular}





\section{Chapter \\ 53}

\section{Background Characteristics of Married Women of Reproductive Age}

This chapter describes the basic background characteristics including age, education level, and place of residence of the respondents. It also describes detailed information on the educational status of respondents and their husbands, literacy levels, and exposure to mass media. Only married women aged 15-49 years were interviewed for this portion of the survey.

\section{Women's Characteristics}

\section{Age Distribution of Married Women}

Table 3.1 indicates the proportion of married women of reproductive age in each age group for the sampled households. In rural areas, the highest proportion of women interviewed was in the 25 to 29 year age group, whereas in urban areas the 30 to 34 year age group was the most interviewed. Overall, the mean age of respondents in DG Khan is 31.4 years.

Table 3.1: $\quad$ Current age and age at marriage

\begin{tabular}{|c|c|c|c|c|c|c|c|}
\hline \multirow{2}{*}{\multicolumn{2}{|c|}{ Background profile }} & \multicolumn{2}{|c|}{ Rural } & \multicolumn{2}{|c|}{ Urban } & \multicolumn{2}{|c|}{ Total } \\
\hline & & Percent & Number & Percent & Number & Percent & Number \\
\hline \multirow{7}{*}{$\begin{array}{l}\text { Age of } \\
\text { respondent }\end{array}$} & $15-19$ & 6.6 & 50 & 4.0 & 5 & 6.3 & 55 \\
\hline & $20-24$ & 20.2 & 152 & 12.9 & 16 & 19.1 & 168 \\
\hline & $25-29$ & 24.7 & 186 & 21.0 & 26 & 24.1 & 212 \\
\hline & $30-34$ & 20.0 & 151 & 22.6 & 28 & 20.4 & 179 \\
\hline & $35-39$ & 15.6 & 118 & 16.1 & 20 & 15.7 & 138 \\
\hline & $40-44$ & 8.8 & 66 & 12.9 & 16 & 9.3 & 82 \\
\hline & $45-49$ & 4.1 & 31 & 10.5 & 13 & 5.0 & 44 \\
\hline \multirow{4}{*}{ Age at marriage } & $<15$ & 34.6 & 261 & 14.5 & 18 & 31.8 & 279 \\
\hline & $15-19$ & 56.5 & 426 & 55.6 & 69 & 56.4 & 495 \\
\hline & $20-24$ & 7.3 & 55 & 21.8 & 27 & 9.3 & 82 \\
\hline & $25+$ & 1.6 & 12 & 8.1 & 10 & 2.5 & 22 \\
\hline
\end{tabular}

According to the data obtained, approximately 56 percent of the women in both urban and rural areas indicated that they were in the 15 to 19 year age cohort at the time of marriage. More than one-third (34.6 percent) of women got married before the age of 15 years in rural DG Khan. Overall the mean age at marriage in DG Khan is 15.5 years. 
Figure 3.1: $\quad$ Age distribution

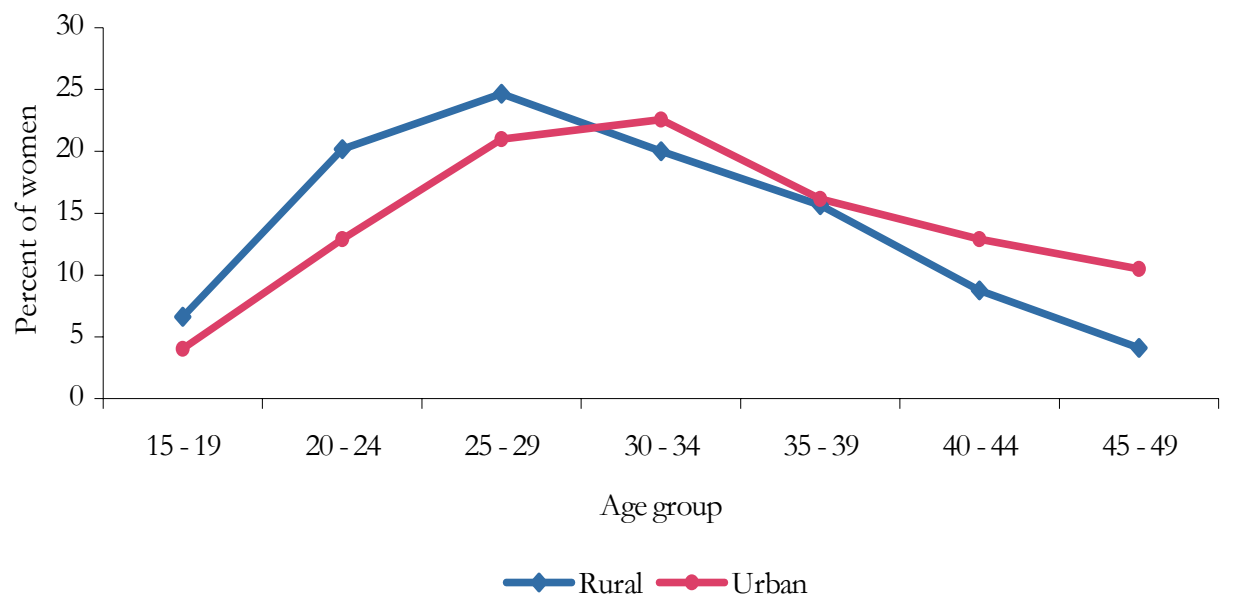

Figure 3.1 is a visual depiction of the age distribution amongst married women in rural and urban areas. The percentage of women married prior to the age of twenty-five was higher in rural areas compared to urban DG Khan.

\section{Education/Literacy level}

The level of education obtained by a woman can be a good indicator of her status in society as well as the independent decision-making power available to her. It is presumed that the higher the level of education obtained by a woman, the more say she has in matters concerning her health and that of her children. With regard to maternal health, a higher literacy rate in women can result in an increased use of contraceptives, higher awareness of complications during and after pregnancy, a strong understanding of neonatal and newborn health, and finally, a more complete understanding of safe birth practices.

It has also been shown that the mortality rates among children with mothers who have six or more years of education are considerably lower than the mortality rates among children with uneducated mothers (Martin, 1983). Educated women are more likely to recognize signs of illness in their children, actively seek assistance from a doctor, and administer the treatment in the manner required. Educated women are also more likely to return to a doctor in the event that the treatment administered failed to take effect. Therefore, the proactive nature of educated women with regard to the health of their children lowers the morbidity and mortality rates of infants and young children.

The level of education of fathers also affects the mortality rates amongst children. This is partly an indication of socio-economic level, as typically the more education the father of a child has, the higher his socio-economic status and standard of living are likely to be. However, the effect educated fathers have on the mortality rates of children is lower than the effect an educated mothers have (Mahmood, 1992). 
Education level and literacy of married women and their husbands

\begin{tabular}{|c|c|c|c|c|c|c|c|}
\hline \multirow{2}{*}{\multicolumn{2}{|c|}{ Background profile }} & \multicolumn{2}{|c|}{ Rural } & \multicolumn{2}{|c|}{ Urban } & \multicolumn{2}{|c|}{ Total } \\
\hline & & Percent & Number & Percent & Number & Percent & Number \\
\hline \multirow{5}{*}{$\begin{array}{l}\text { Level of } \\
\text { education }\end{array}$} & No education & 75.5 & 569 & 39.5 & 49 & 70.4 & 618 \\
\hline & Up to primary & 11.9 & 90 & 15.3 & 19 & 12.4 & 109 \\
\hline & Up to middle & 4.5 & 34 & 11.3 & 14 & 5.5 & 48 \\
\hline & Up to secondary & 5.8 & 44 & 17.7 & 22 & 7.5 & 66 \\
\hline & Secondary + & 2.3 & 17 & 16.1 & 20 & 4.2 & 37 \\
\hline \multirow{2}{*}{$\begin{array}{l}\text { Respondent's } \\
\text { literacy }\end{array}$} & Literate & 24.8 & 187 & 63.7 & 79 & 30.3 & 266 \\
\hline & Illiterate & 75.2 & 567 & 36.3 & 45 & 69.7 & 612 \\
\hline \multirow{6}{*}{$\begin{array}{l}\text { Husband's } \\
\text { Level of } \\
\text { education }\end{array}$} & No education & 43.0 & 324 & 19.4 & 24 & 39.6 & 348 \\
\hline & Up to primary & 17.1 & 129 & 10.5 & 13 & 16.2 & 142 \\
\hline & Up to middle & 11.7 & 88 & 15.3 & 19 & 12.2 & 107 \\
\hline & Up to secondary & 18.0 & 136 & 25.8 & 32 & 19.1 & 168 \\
\hline & Secondary + & 9.0 & 68 & 28.2 & 35 & 11.7 & 103 \\
\hline & Don't know & 1.2 & 9 & 0.8 & 1 & 1.1 & 10 \\
\hline \multirow{2}{*}{$\begin{array}{l}\text { Husband's } \\
\text { literacy }\end{array}$} & Literate & 56.8 & 428 & 79.8 & 99 & 60.0 & 527 \\
\hline & Illiterate & 43.2 & 326 & 20.2 & 25 & 40.0 & 351 \\
\hline
\end{tabular}

The ability to read is an important personal asset allowing women and their husbands increased access to various opportunities. By gathering information regarding the distribution of literacy among the respondents surveyed, maternal and newborn health communicators are better able to reach their target population with their messages. Table 3.2 shows that nearly 70 percent of the women interviewed in DG Khan were illiterate and had received no education. Only 12 percent received primary education, while about 4 percent obtained more than secondary level education. In urban areas of DG Khan, approximately 64 percent of the women interviewed were literate, whereas the same was true for only 25 percent of the women interviewed in rural areas. According to table 3.2, 60 percent of the women in DG Khan indicated that their husbands are literate. In urban areas, approximately 80 percent of the women interviewed indicated that their husbands were literate, while 57 percent of the women in rural areas made the same claim.

\section{Children Ever Born and Living}

Table 3.3 presents the distribution of married women by the number of children ever born (CEB). It shows the mean number of children ever born and the mean number of living children for each fiveyear age group. It is observed that overall in DG Khan there is an average of 4.4 children ever born and 3.9 surviving children. When these results are compared with the 1998 Population Census, some changes can be noted. The overall average number of children ever born has decreased from 4.8 to 4.4. This reduction is observed in all age groups. The number of living children however, has increased from 3.4 to 3.9 . 
Table 3.3: $\quad$ Percentage distribution of married women by number of children ever born, mean number of children ever born, living children and age group, compared to the 1998 Population census

\begin{tabular}{|c|c|c|c|c|c|c|c|c|c|c|}
\hline \multirow{3}{*}{$\begin{array}{l}\text { Age } \\
\text { Group }\end{array}$} & \multicolumn{5}{|c|}{ Number of Children Ever Born } & \multirow{3}{*}{$\begin{array}{c}\text { No. of } \\
\text { Women }\end{array}$} & \multicolumn{4}{|c|}{ Mean Number of Children } \\
\hline & \multirow[t]{2}{*}{0} & \multirow[t]{2}{*}{$1-2$} & \multirow[t]{2}{*}{$3-4$} & \multirow{2}{*}{$\begin{array}{l}5 \text { or } \\
\text { more }\end{array}$} & \multirow[t]{2}{*}{ Total } & & \multicolumn{2}{|c|}{ Baseline } & \multicolumn{2}{|c|}{1998 Population Census } \\
\hline & & & & & & & Ever born & Living & Ever born & Living \\
\hline $15-19$ & 50.9 & 38.2 & 5.5 & 5.5 & 100 & 55 & 1.2 & 0.6 & 1.7 & 0.9 \\
\hline $20-24$ & 12.5 & 51.8 & 30.4 & 5.4 & 100 & 168 & 2.1 & 1.9 & 2.9 & 1.7 \\
\hline $25-29$ & 6.1 & 21.2 & 41.5 & 31.1 & 100 & 212 & 3.6 & 3.2 & 4.1 & 3.0 \\
\hline $30-34$ & 3.9 & 12.3 & 25.7 & 58.1 & 100 & 179 & 5.0 & 4.3 & 5.6 & 4.0 \\
\hline $35-39$ & 2.9 & 4.3 & 16.7 & 76.1 & 100 & 138 & 6.5 & 5.7 & 6.6 & 4.9 \\
\hline $40-44$ & 2.4 & 2.4 & 13.4 & 81.7 & 100 & 82 & 7.2 & 6.2 & 7.0 & 5.4 \\
\hline $45-49$ & 4.5 & 4.5 & 6.8 & 84.1 & 100 & 44 & 7.1 & 6.3 & 7.0 & 5.3 \\
\hline Total & 8.8 & 21.1 & 25.6 & 44.5 & 100 & 878 & 4.4 & 3.9 & 4.8 & 3.4 \\
\hline
\end{tabular}

\section{Preceding Birth Interval}

The length of the preceding birth interval is very important, as it directly affects the health and mortality of both mother and child. A mother with repeated pregnancies, especially at short intervals, does not have sufficient time for recovery both physically and nutritionally and is therefore more likely to have pregnancy losses and babies of a lower birth weight. Table 3.4 shows that almost 22 percent of the births that occurred in the past three years, took place after a birth interval of less than 19 months. Furthermore, 21 percent of the respondents left a 19-24 month interval between their last two births, while 30 percent left a 25-36 month interval.

Table 3.4: $\quad$ Percentage distribution of married women by length of preceding birth interval

\begin{tabular}{lrr}
\hline Length of Preceding Birth Interval & Number & Percent \\
\hline Less than 12 Months & 15 & 3.5 \\
\hline 13-18 Months & 80 & 18.4 \\
\hline 19-24 Months & 92 & 21.2 \\
\hline 25-36 Months & 130 & 30.0 \\
\hline More than 36 Months & 117 & 27.0 \\
\hline Total & 434 & 100.0 \\
\hline
\end{tabular}

\section{Access to Information}

In the baseline survey, respondents were asked several questions regarding access and exposure to television, radio and newspapers. One of the main objectives of the baseline survey was to determine the knowledge of married women on different maternal and newborn health issues, as well as the source of that knowledge. This information is useful in determining which media channels should be employed in the dissemination of maternal and newborn health information to target audiences. Moreover it is important to measure the likelihood of reaching target audiences as well as to determine which media channels are most effective when it comes to reaching that audience. 


\section{Access to Media (Television, Radio and Newspaper)}

Mass media is regularly used to campaign various issues including those related to the health of mothers and newborns. In the past, radio was the most popular form of communication (Syed, 1979). However, according to the survey findings, television seems to have become a more popular source of information for a large portion of the population in DG Khan.

\section{Television}

Figure 3.2 shows the percentage of respondents who watch television and listen to the radio. In rural areas of DG Khan, 36.5 percent of the respondents watch television, whereas the figure for urban areas is 75 percent. This difference may be due to the socioeconomic disparities between urban and rural areas of DG Khan, urban areas typically being better off socio-economically. Since access to television is synonymous with access to information, women in urban areas often have better access to information through television due to socio-economic success. As a result, they are able to make informed decisions, based on the knowledge made available to them through television.

Figure 3.2: $\quad$ Percentage of women who watch television or listen to radio

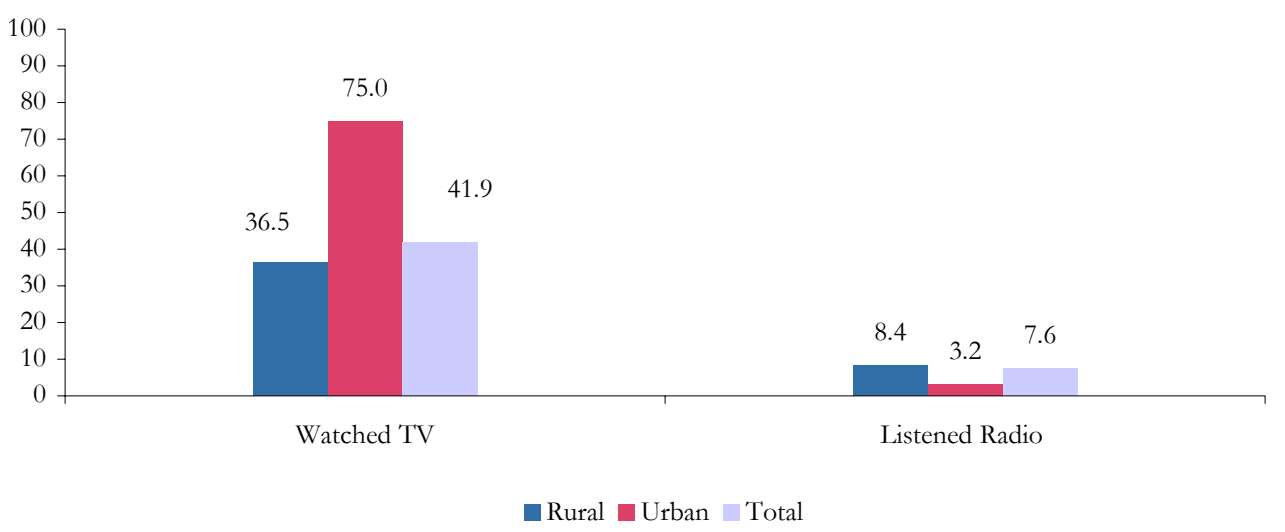

Table 3.5 indicates that 86 percent of the women interviewed in rural areas watch TV at home, while about 14 percent do so at a relative's house. In urban areas however, 98 percent reportedly watched TV at home. This would suggest that a majority of the population in DG Khan who watch TV have access to a television at home.

Table 3.5: $\quad$ Place where respondent usually watches television

\begin{tabular}{lrrrrrr}
\multirow{2}{*}{ Place } & \multicolumn{2}{c}{ Rural } & \multicolumn{2}{c}{ Urban } & \multicolumn{2}{c}{ Total } \\
\cline { 2 - 7 } At home & Percent & Number & Percent & Number & Percent & Number \\
\hline At relative's house & 86.2 & 237 & 97.8 & 91 & 89.1 & 328 \\
\hline At neighbor's house & 13.5 & 37 & 2.2 & 2 & 10.6 & 39 \\
\hline Total & 0.4 & 1 & & & 0.3 & 1 \\
\hline
\end{tabular}


Table 3.6 indicates the frequency with which people watch TV. In rural areas, 68 percent of the women interviewed indicated that they watch television on a daily basis, while 30 percent indicated that they rarely watch TV. In urban areas however, 84 percent indicated that they watch television on a daily basis.

Table 3.6: $\quad$ Frequency of watching television

\begin{tabular}{lrrrrrr}
\multicolumn{1}{c}{ Frequency } & \multicolumn{2}{c}{ Rural } & \multicolumn{2}{c}{ Urban } & \multicolumn{2}{c}{ Total } \\
& Percent & Number & Percent & Number & Percent & Number \\
\hline Almost daily & 68.4 & 188 & 83.9 & 78 & 72.3 & 266 \\
\hline At least once a week & 1.8 & 5 & 1.1 & 1 & 1.6 & 6 \\
\hline At least once a month & 0.4 & 1 & & & 0.3 & 1 \\
\hline Rarely & 29.5 & 81 & 15.1 & 14 & 25.8 & 95 \\
Total & 100.0 & 275 & 100.0 & 93 & 100.0 & 368
\end{tabular}

When asked if they thought television has an impact on the health behaviors of people, about 53 percent of respondents in urban areas and 42 percent in rural areas thought that television is very influential. A very low percentage of women both in urban and rural said that the television has no impact on the health behaviors of people (Figure 3.3).

Figure 3.3: $\quad$ Influence of television programs on health behaviors of people

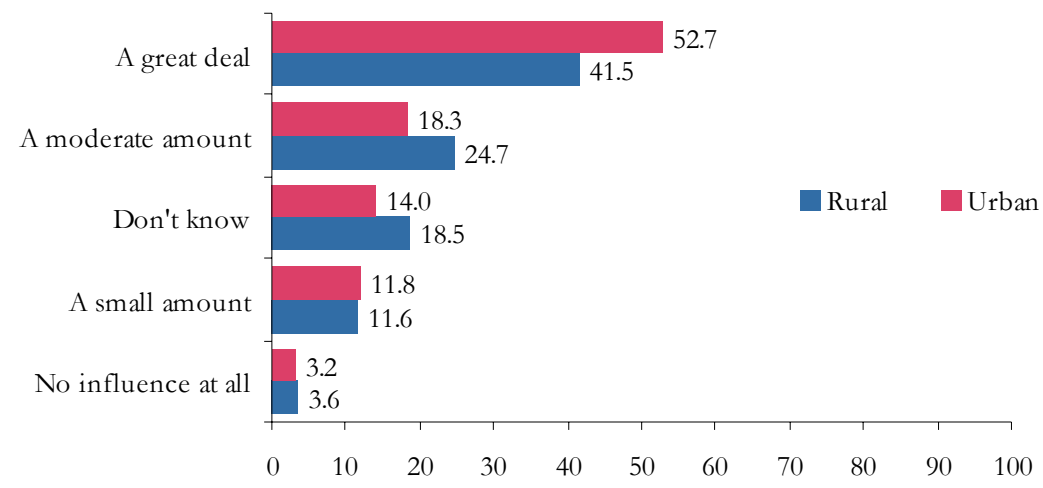

\section{Radio}

Much like television, radio is also a tool through which messages may be relayed to a relatively large audience. When asked to indicate if they listen to the radio, a very low percentage of respondents both in urban and rural areas ( 3 percent and 8 percent respectively) answered in the affirmative (Figure 3.2).

According to table 3.7, from those respondents who do listen to the radio, 41 percent of the in rural areas and 75 percent in urban areas listen to it on a daily basis. The remaining 56 percent in rural areas and 25 percent in urban areas indicated that they rarely listen to the radio. 
Table 3.7:

Frequency of listening to radio

\begin{tabular}{lrrrrrr}
\multirow{2}{*}{ Frequency } & \multicolumn{2}{c}{ Rural } & \multicolumn{2}{c}{ Urban } & \multicolumn{2}{c}{ Total } \\
\cline { 2 - 7 } Almost daily & Percent & Number & Percent & Number & Percent & Number \\
\hline Alt least once a week & 41.3 & 26 & 75.0 & 3 & 43.3 & 29 \\
\hline Rarely & 3.2 & 2 & & & 3.0 & 2 \\
\hline Total & 55.6 & 35 & 25.0 & 1 & 53.7 & 36 \\
\hline
\end{tabular}

Respondents were asked to indicate the place at which they usually listen to the radio, and the results are indicated in table 3.8. About 87 percent of the women surveyed in rural areas indicated that they listen to the radio at home, whereas all the women surveyed in urban areas claimed to have access to a radio at home.

Table 3.8: $\quad$ Place where respondent listens to the radio

\begin{tabular}{|c|c|c|c|c|c|c|}
\hline \multirow{2}{*}{ Place } & \multicolumn{2}{|c|}{ Rural } & \multicolumn{2}{|c|}{ Urban } & \multicolumn{2}{|c|}{ Total } \\
\hline & Percent & Number & Percent & Number & Percent & Number \\
\hline At home & 87.3 & 55 & 100.0 & 4 & 88.1 & 59 \\
\hline At work place & 1.6 & 1 & & & 1.5 & 1 \\
\hline At relative's house & 11.1 & 7 & & & 10.4 & 7 \\
\hline Total & 100.0 & 63 & 100.0 & 4 & 100.0 & 67 \\
\hline
\end{tabular}

According to figure 3.4, among those who listen to the radio, about 75 percent of the respondents in urban areas indicated that radio has a great deal of influence on the health behaviors of people, while about 37 percent felt the same in urban areas.

Figure 3.4: $\quad$ Influence of radio on health behaviors

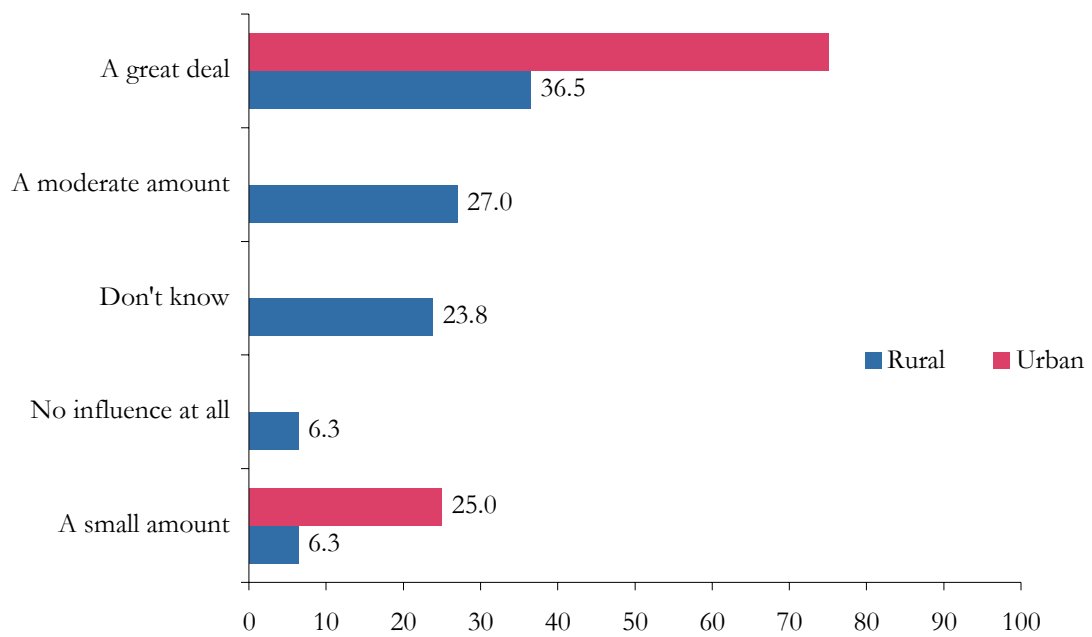




\section{Newspapers}

Respondents were questioned about how frequently they read the newspaper. About 88 percent of the women in rural areas indicated that they never read the newspaper, while 57 percent stated the same in urban areas of Dera Ghazi Khan. Only 6.5 percent in urban areas and less than 1 percent in rural areas read the newspaper on daily basis, while 27 percent women in urban and 10 percent women in rural areas indicated that they rarely read the newspaper.

Figure 3.5: $\quad$ Frequency of reading newspaper

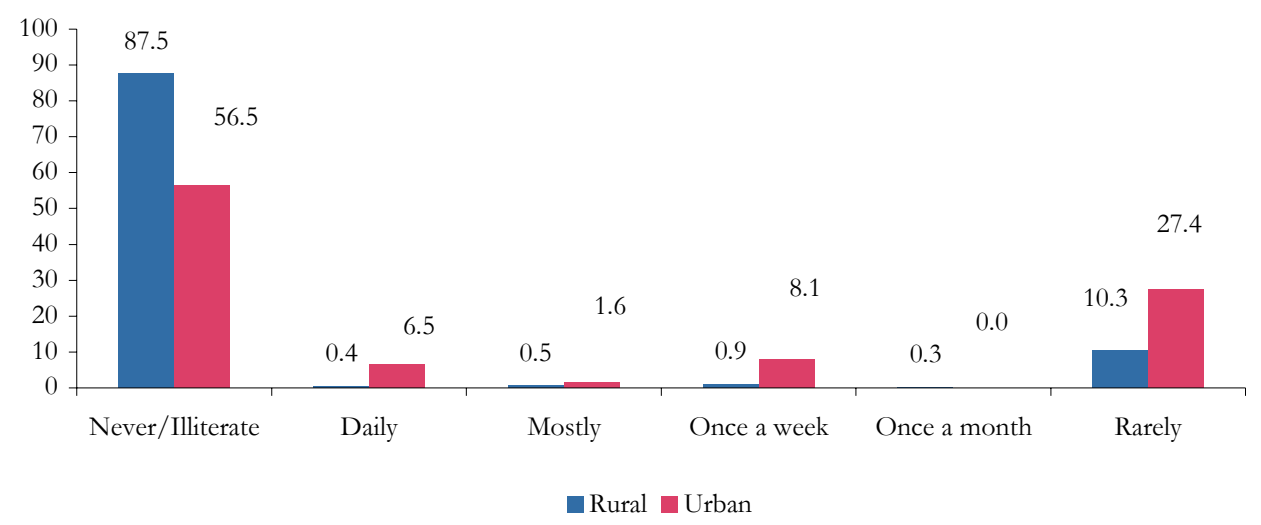

According to figure 3.6, about half (50.2 percent) of the respondents in DG Khan have access to some sort of media, whether it is television, radio or newspapers. While it may seem relatively easy to reach this portion of the population through one of the three main media channels, there are some obstacles that stand in the way including the lack of decision-making power for women and the infrequency of access to the media. As well, it is important to keep in mind the other half of the population of DG Khan that have no access to any one of the three media channels mentioned above. In order to educate and inform this segment of the population regarding maternal and infant mortality and birth preparedness, more grassroots methods must be adopted. These grassroots efforts may include inter-personal communication through community workers, community gatherings, speeches and health education sessions.

Figure 3.6: $\quad$ Exposure to mass media (radio, television or newspaper)

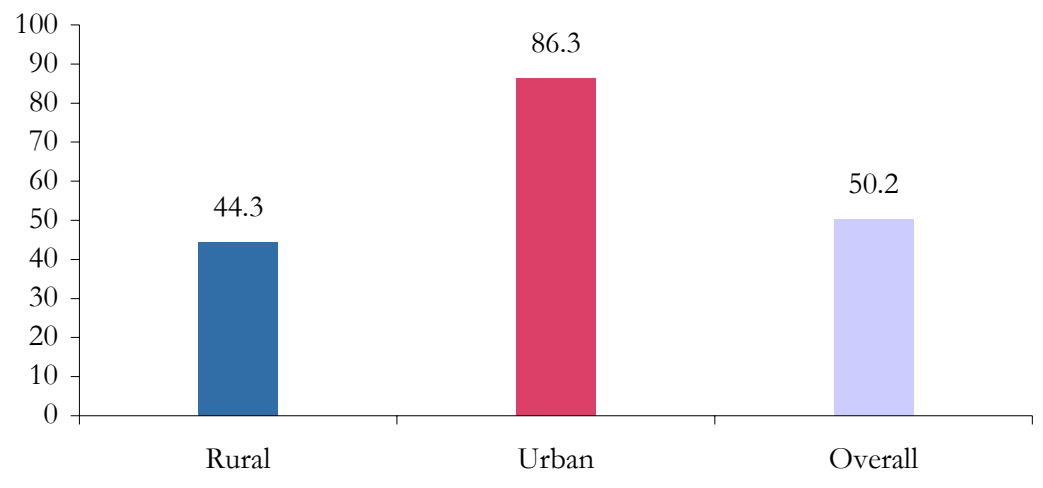


Television seems to be considered the most trustworthy form of media in both urban and rural areas as shown in figure 3.7. About 74 percent of the respondents in urban areas and 42 percent in rural areas indicated that they considered TV to be the most trustworthy form of media. Therefore, perhaps the most effective way to educate the married women of DG Khan with regards to maternal and neonatal health is through television, along with a more grassroots, community-based approach.

Figure 3.7: $\quad$ Most trustworthy form of media

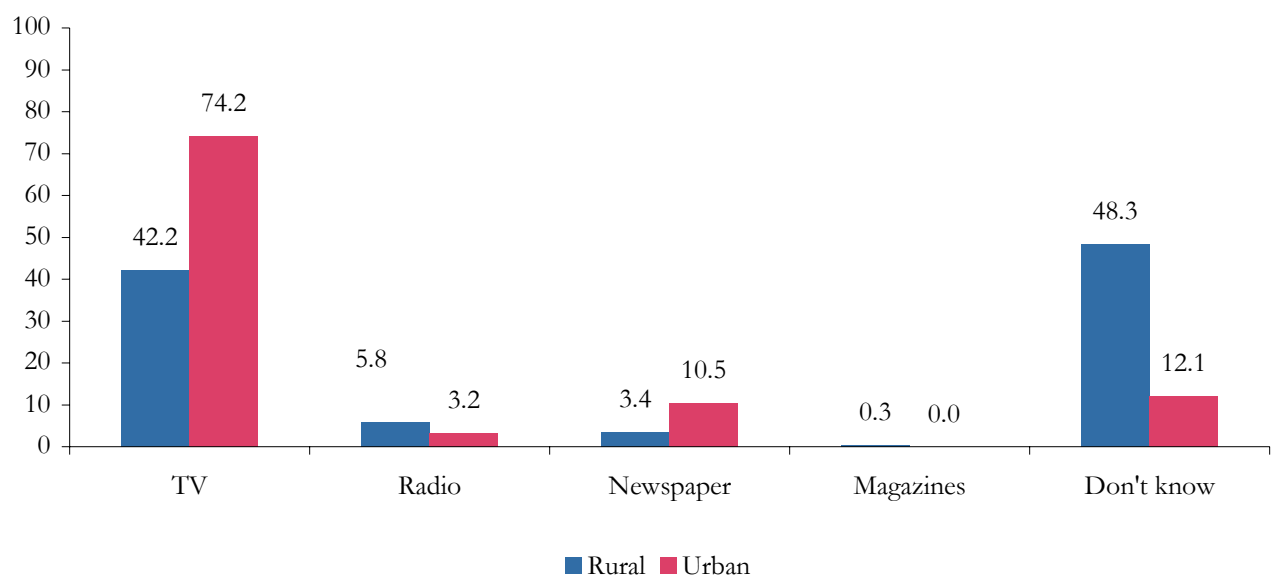

\section{Information/Education through Media}

Respondents were asked to indicate if they had heard/read anything about maternal and newborn health within the past three months preceding the survey.

Figure 3.8: $\quad$ Percentage of married women who had heard/ read maternal and newborn messages during the last 3 months

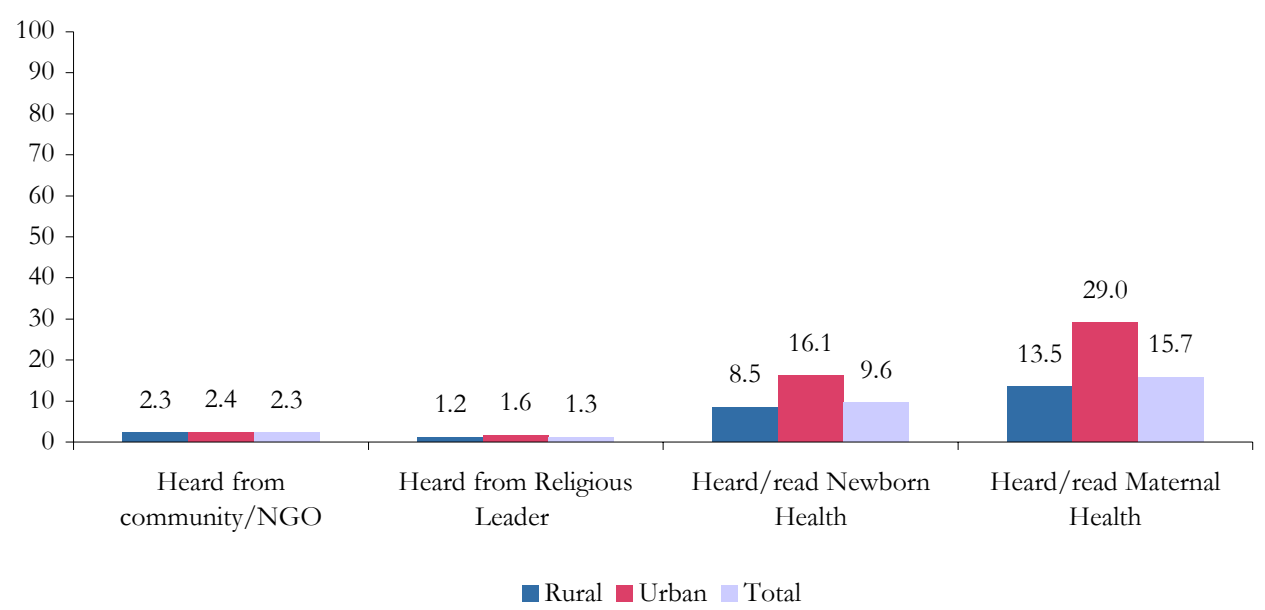


According to figure 3.8, only 29 percent of the married women in urban areas had heard/read something about maternal health within the past three months, while 14 percent said the same thing in rural areas. Overall, 84 percent of the married women in sampled households had not heard or read anything about maternal health in the past three months. Furthermore, more than 90 percent of the women surveyed said that they had not heard/read anything regarding newborn health in the past three months.

Respondents were then asked if they had heard anything about maternal or newborn health from religious leaders or community/NGO workers. Less than 3 percent overall answered in the affirmative. 


\section{Chapter 4}

\section{Knowledge of Safe Motherhood, Birth Preparedness and Community Resources}

This chapter explores the level of understanding women have of safe motherhood practices, birth preparedness and the use of community resources. It examines the level of health awareness women in the district possess and thus provides an explanation for the maternal and newborn mortality rates. Respondents were asked questions regarding knowledge of complications during pregnancy, delivery, the postpartum period and newborn health. They were also asked about the community resources available to them. The findings of those responses are presented in this chapter.

\section{Knowledge of Danger Signs}

\section{Knowledge of Danger Signs during Pregnancy}

Figure 4.1 outlines the various complications, which may occur during pregnancy. Respondents were asked to indicate which complications they believed were dangerous and required medical attention. Surprisingly, a very small percentage believed that most complications required a doctor's care, and agreed that medical attention must be provided only after being prompted.

About 47 percent of the respondents in urban areas, and 40 percent in rural areas said that 'heavy vaginal bleeding' during pregnancy was a danger sign, while 27 percent and 18 percent in urban and rural areas respectively said the same about 'spotting'.

According to figure 4.2, 25 percent of the respondents in urban areas, along with 22 percent of the respondents in rural areas were able to name three or more danger signs during pregnancy. About 29 percent and 26 percent of the respondents in urban and rural areas respectively were unable to name any danger signs at all. 
Figure 4.1: $\quad$ Knowledge of danger signs during pregnancy, which require medical attention

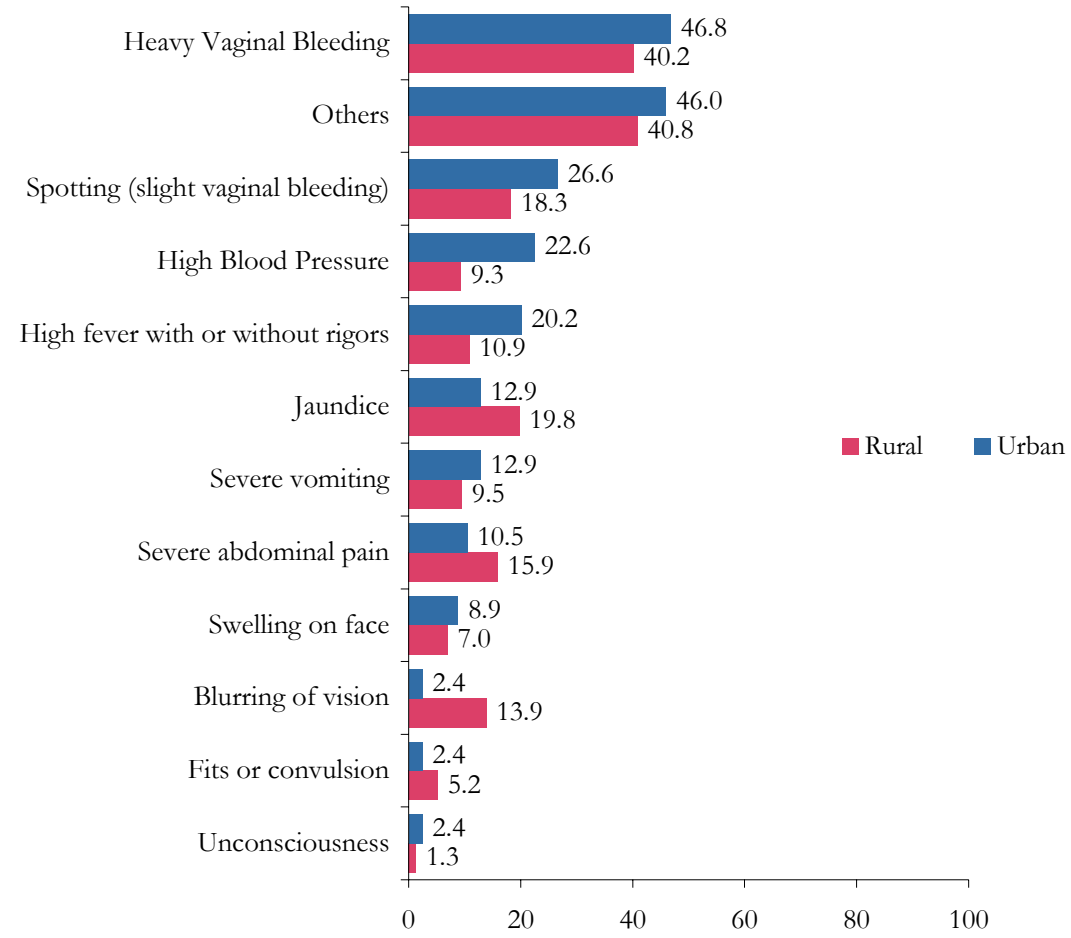

Figure 4.2: $\quad$ Percentage distribution of women by status of knowledge of danger signs of pregnancy

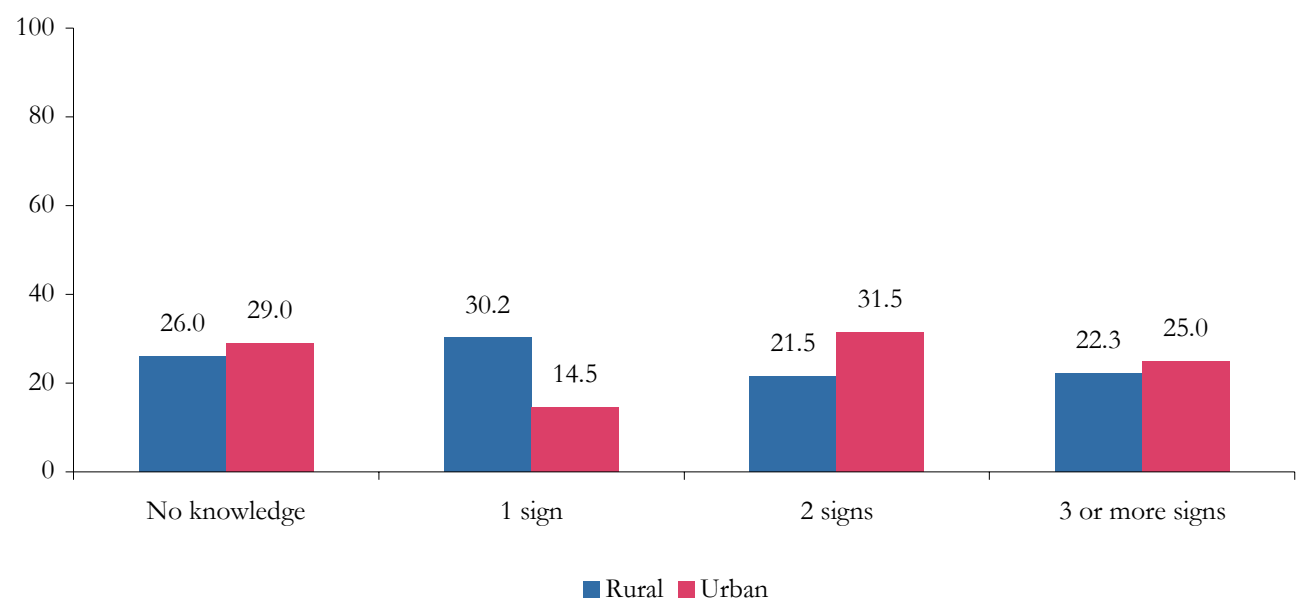




\section{Knowledge of Danger Signs during Childbirth/Delivery}

As in the case of pregnancy, many women are not aware of the complications that may arise during delivery. This lack of knowledge may eventually result in women not being taken to a hospital in the event that such a complication should occur. Figure 4.3 depicts the level of the respondents' understanding of complications during delivery. The highest proportion of women (45 percent and 48 percent in urban and rural areas respectively) recognized "prolonged labor/obstructed labor" as a complication. More than one-fifth of the respondents in both urban and rural indicated that "bleeding before labor began" was a danger sign during delivery. Finally, about 18 percent of the women in urban areas and 20 percent in rural areas believed that "excessive vaginal bleeding" was a sign of danger during delivery.

Figure 4.3: $\quad$ Percentage distribution of respondents who had knowledge about complications during delivery

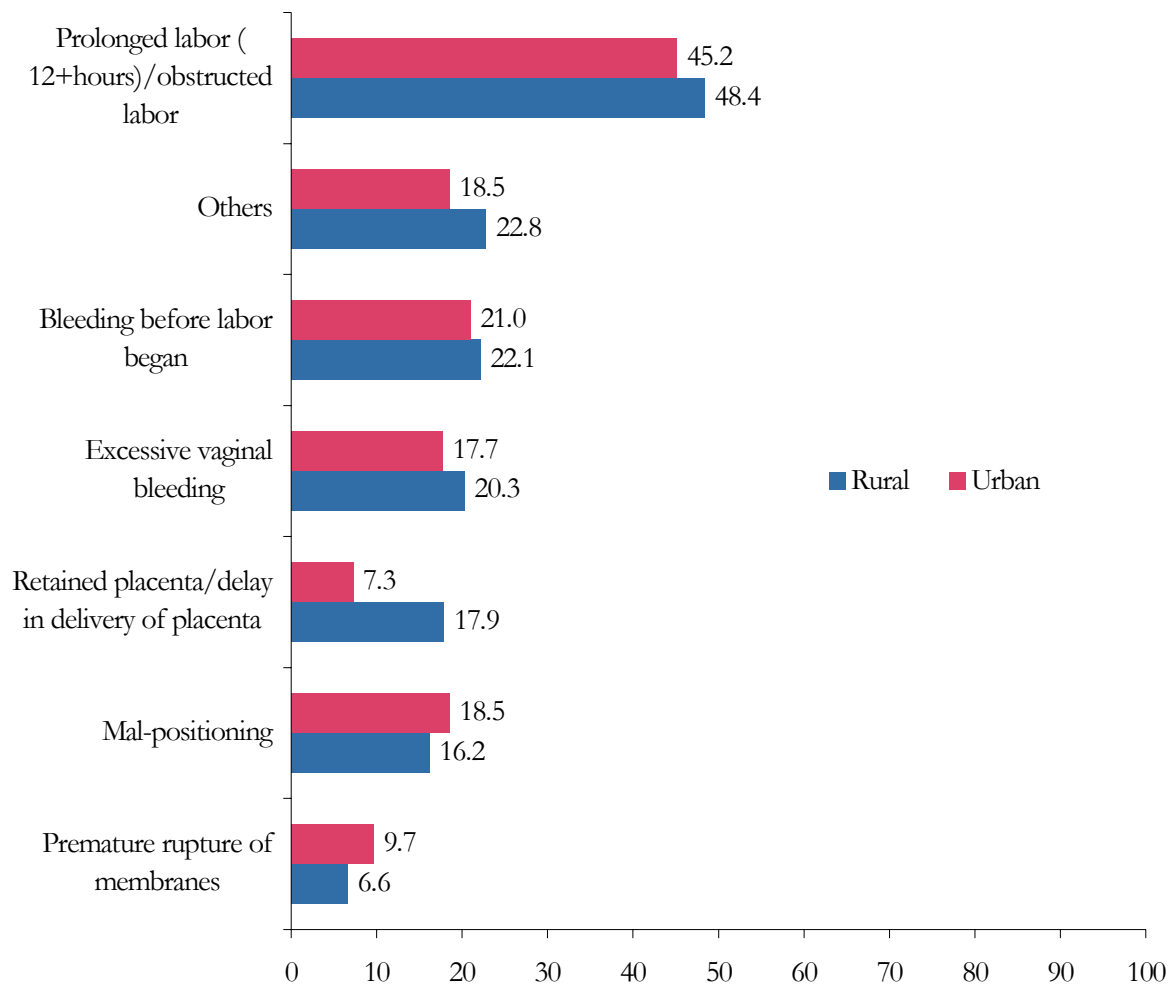

Figure 4.4 depicts the proportion of women in rural and urban areas $(15$ percent and 19 percent respectively) that were able to name three or more danger signs during delivery. However, a large number of women in urban and rural areas (36 percent and 27 percent respectively) were unable to name even one danger sign. 
Figure 4.4: $\quad$ Percentage of married women by knowledge of danger signs during delivery

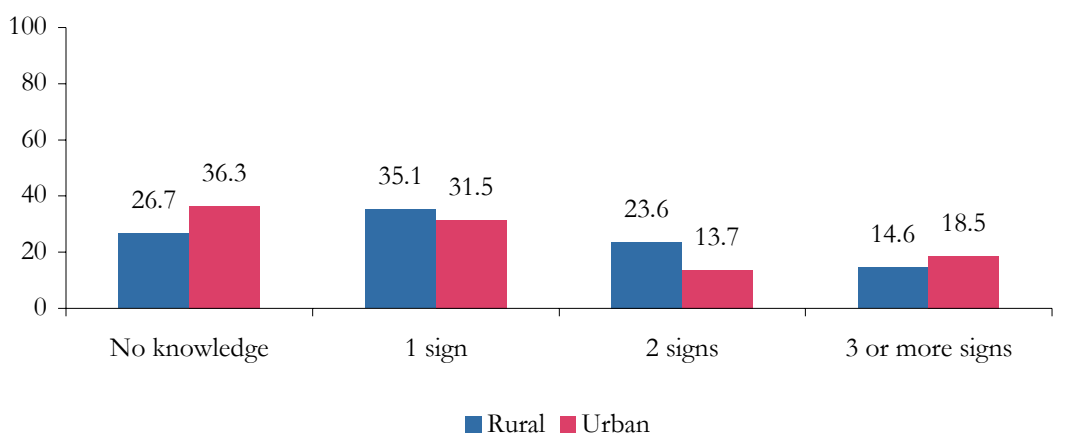

\section{Knowledge of Danger Signs during the Postpartum Period}

The postpartum period is defined as the 40 days after childbirth. According to figure 4.5 , respondents in both urban and rural areas regarded, 'excessive vaginal bleeding', 'high fever' and "offensive (foulsmelling) discharge from vagina" as being three major danger signs which can appear during the postpartum period.

Figure 4.5: $\quad$ Percentage distribution of married women who had knowledge about complication during postpartum period

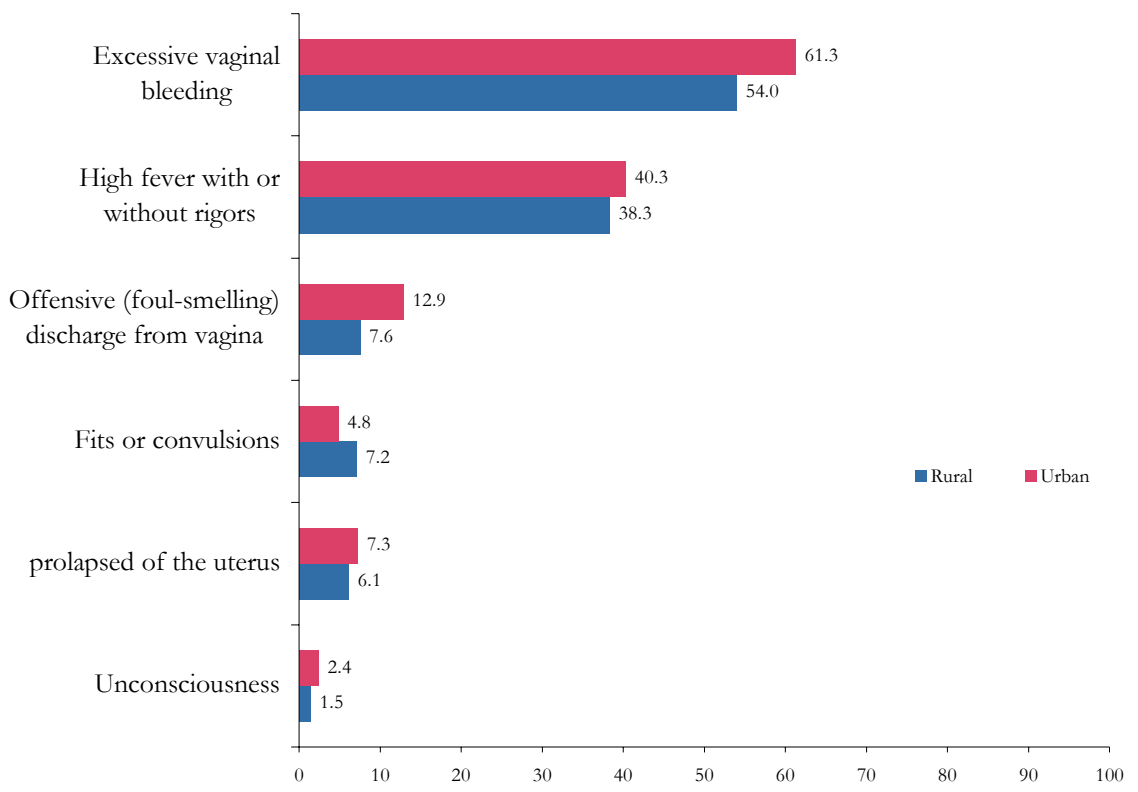

According to figure 4.6, a very low percentage of women ( 7 percent and 10 percent in urban and rural areas respectively) were able to name three or more danger signs during the postpartum period. More than 23 percent of the respondents in both urban and rural areas were unable to name a single danger signs during the postpartum period. 
Figure 4.6: $\quad$ Percentage distribution of women by number of known danger signs of postpartum period

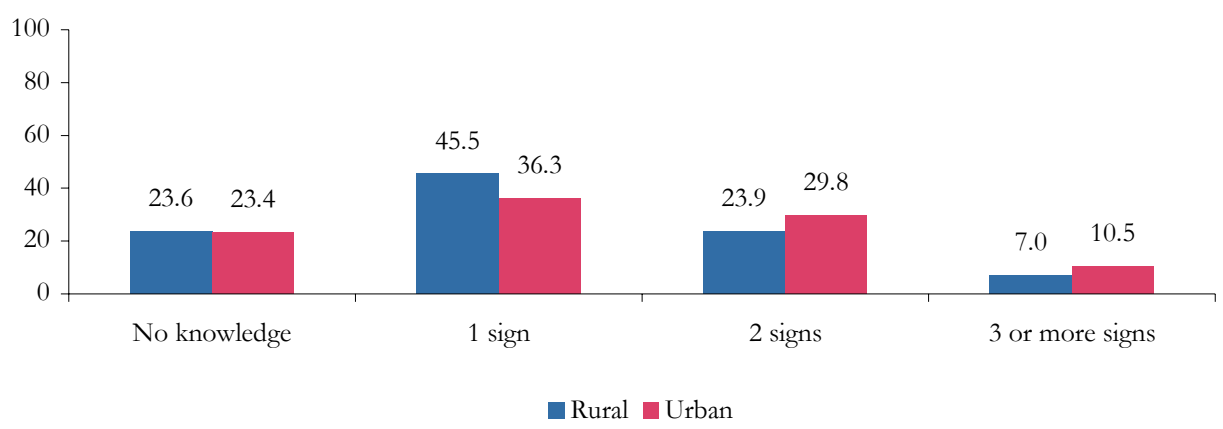

\section{Knowledge of Danger Signs in the Newborn}

For the purpose of this survey, the newborn period was defined as the first four weeks after birth.

Figure 4.7 outlines the percentage of respondents who believed that each complication listed required medical attention. About 60 percent respondents in urban areas and 46 percent in rural areas believed that "yellow skin color (jaundice)" was a danger sign in a newborn. "Fever/high fever (with or without rigors)" and "fits/abnormal/jerky movements" were the second and third most widely reported danger signs.

Figure 4.7: $\quad$ Percentage istribution of respondents who had knowledge about danger signs in newborns

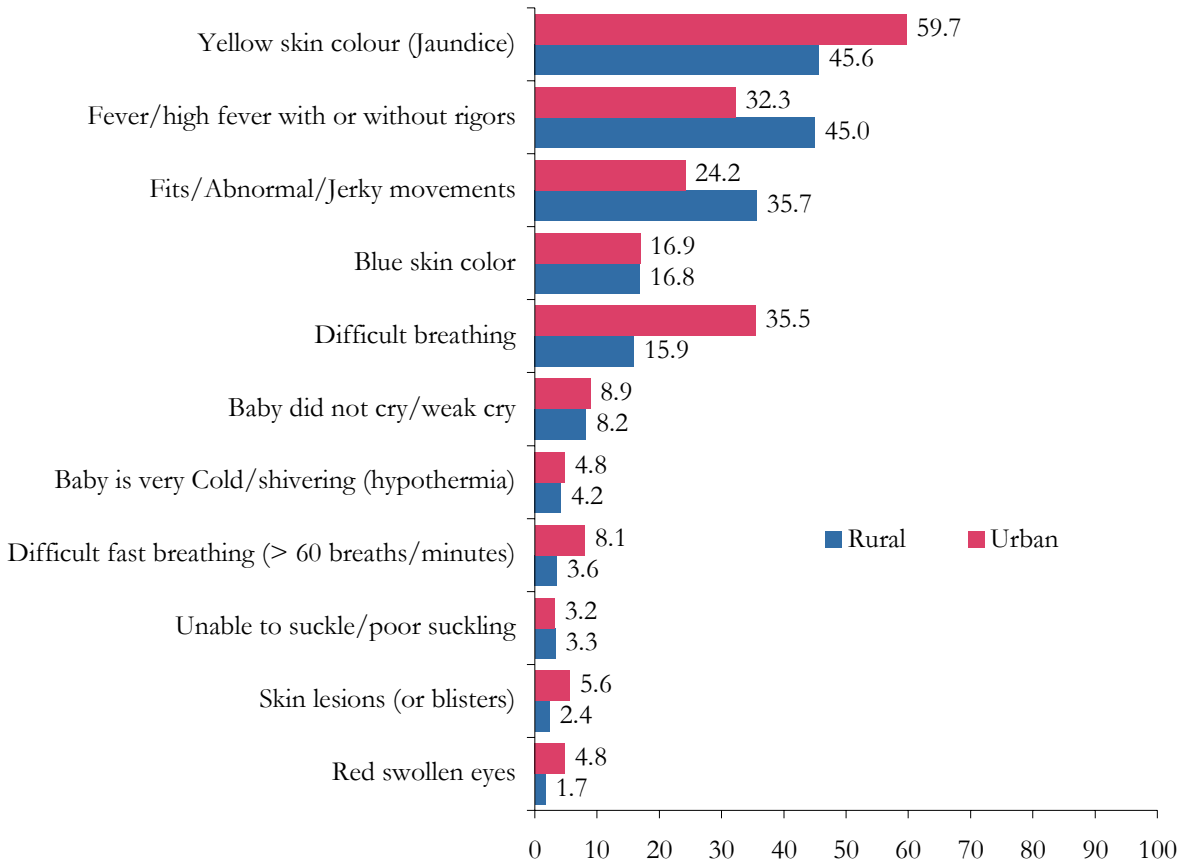

According to figure 4.8, approximately 27 percent of the women interviewed in rural areas, along with 39 percent in urban areas were able to name three or more danger signs in a newborn, while 14 percent and 18 percent in rural and urban areas respectively were unable to name a single danger sign. 
Figure 4.8: $\quad$ Percentage distribution of women by number of known danger signs in a newborn at birth

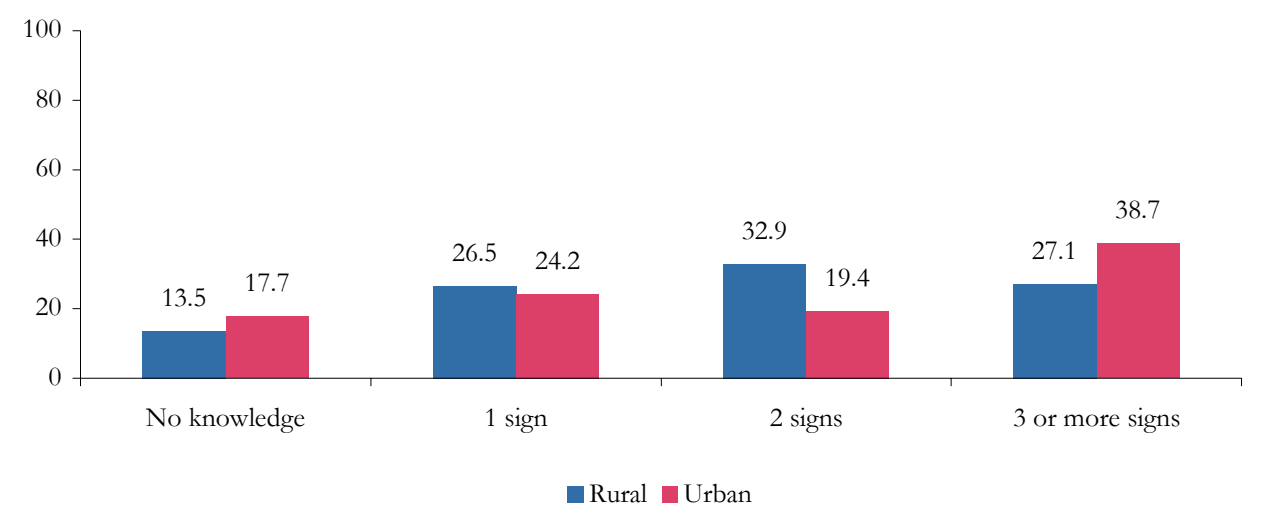

\section{Source of Information Regarding Danger Signs}

Finally, respondents were asked to indicate the source of their information regarding complications during pregnancy, delivery and the postpartum period. A very large percentage in both urban and rural areas indicated that they received their pregnancy, delivery and postpartum related information from their in-laws, family members and friends. About 21 percent of respondents in urban areas and 10 percent in rural areas said that they received their information from television. Very few respondents indicated other sources such as LHWs and DHQ/THQs as their source of information. This suggests that a majority of women obtain their information from sources which may be considered unreliable.

Figure 4.9: $\quad$ Source of information regarding danger signs during pregnancy

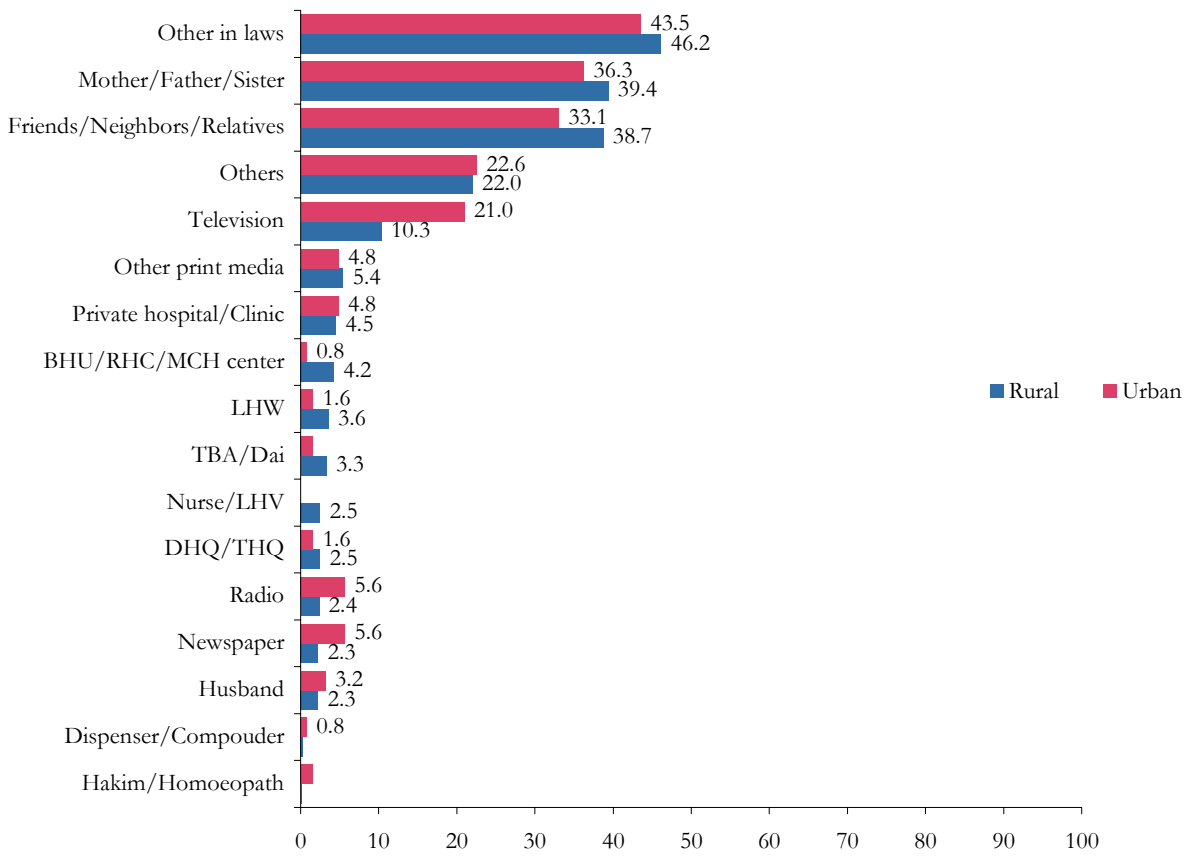




\section{Knowledge of Community Schemes for the Welfare of Women and Newborns}

In addition to being asked questions regarding the knowledge of danger signs, married women were also asked whether they were aware of any existing schemes in their respective communities designed to help women have a safe childbirth. The baseline focused on schemes pertaining to transportation, blood arrangements and funding; all of which help ensure that there are no delays at the time of delivery. Arrangement of transport to a health facility is a major cause of delay, which can lead to maternal and newborn mortality, and therefore the arrangement of transport ahead of time is necessary to eliminate that delay. Unfortunately, many households are unable to make such an arrangement due to the lack of transport facilities in their communities.

Table 4.1: $\quad$ Knowledge of existence and importance of transport, blood and finances by the community at the time of delivery

\begin{tabular}{lcccccc}
\multicolumn{1}{c}{ Community Services } & \multicolumn{2}{c}{ Rural } & \multicolumn{2}{c}{ Urban } & \multicolumn{2}{c}{ Total } \\
\cline { 2 - 7 } & Percent & Number & Percent & Number & Percent & Number \\
\hline $\begin{array}{l}\text { Existence of transport by the } \\
\text { community at delivery }\end{array}$ & 2.5 & 19 & 0.8 & 1 & 2.3 & 20 \\
\hline $\begin{array}{l}\text { Important to have community } \\
\text { provided transport facility }\end{array}$ & 99.1 & 747 & 99.2 & 123 & 99.1 & 870 \\
\hline $\begin{array}{l}\text { Existence of blood by the } \\
\text { community at time of delivery }\end{array}$ & 1.3 & 10 & & & 1.1 & 10 \\
\hline $\begin{array}{l}\text { Important to have community } \\
\text { provided blood facility }\end{array}$ & 99.9 & 753 & 99.2 & 123 & 99.8 & 876 \\
\hline $\begin{array}{l}\text { Existence of money by community } \\
\text { at the time of delivery }\end{array}$ & 0.3 & 2 & 0.8 & 1 & 0.3 & 3 \\
\hline $\begin{array}{l}\text { Important to have community } \\
\text { provided money facility }\end{array}$ & 99.6 & 751 & 98.4 & 122 & 99.4 & 873 \\
\hline
\end{tabular}

While 99 percent of the respondents believed that a community-based transport facility should exist, only 2 percent of the respondents in DG Khan were aware of such an arrangement in their communities. Similar trends were noted for blood and emergency fund arrangements at the time of delivery. Almost all the respondents interviewed agreed on the importance of arranging blood and money in advance for the time of delivery, but less than 1 percent actually reported having such arrangements in their communities. 



\section{Chapter}

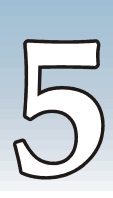

\section{Attitudes Towards Pregnancy, Delivery and the Postpartum Period}

This chapter explores the attitudes of married women towards pregnancy, delivery and the postpartum period. Determining these attitudes and beliefs is important for designing strategies and methods that bring about a change in the traditional ways of thinking.

\section{Attitudes Towards Age at Marriage}

When asked if they believed women should get married soon after puberty, more than 11 percent of the respondents in urban areas, and 29 percent in rural areas believed that women should in fact get married soon after puberty.

Table 5.1: $\quad$ Belief that women should get married soon after puberty

\begin{tabular}{lrrrrrr}
\multirow{2}{*}{ Get marry soon } & \multicolumn{2}{c}{ Rural } & \multicolumn{2}{c}{ Urban } & \multicolumn{2}{c}{ Total } \\
\cline { 2 - 7 } Yes & Percent & Number & Percent & Number & Percent & Number \\
\hline No & 29.0 & 219 & 11.3 & 14 & 26.5 & 233 \\
\hline No opinion & 67.5 & 509 & 87.9 & 109 & 70.4 & 618 \\
\hline Don't know & 2.0 & 15 & 0.8 & 1 & 1.8 & 16 \\
\hline Total & 1.5 & 11 & & & 1.3 & 11 \\
\hline
\end{tabular}

\section{Attitudes Towards Antenatal Care}

Women in both urban and rural areas of DG Khan were then asked if they believed pregnant women needed to have antenatal check-ups. Overall, prenatal care provides an opportunity to offer preventative care that will benefit the newborn as well as the mother. Prenatal care allows women to learn about hygiene, the benefits of breastfeeding, nutrition and general health (Mahmood, 2002). According to table 5.2, approximately 80 percent and 90 percent of the women in rural and urban areas respectively, indicated that antenatal care was necessary. Meanwhile, about 8 percent of the women in urban areas and 15 percent of the women in rural areas believed that antenatal care was not necessary. 
Table 5.2:

Importance of antenatal check-up

\begin{tabular}{lrrrrrrr} 
Have antenatal check-up & \multicolumn{2}{c}{ Rural } & \multicolumn{2}{c}{ Urban } & \multicolumn{2}{c}{ Total } \\
\cline { 2 - 6 } & Percent & Number & Percent & Number & Percent & Number \\
\hline Yes & 80.6 & 608 & 90.3 & 112 & 82.0 & 720 \\
\hline No & 15.1 & 114 & 8.1 & 10 & 14.1 & 124 \\
\hline Don't know & 4.2 & 32 & 1.6 & 2 & 3.9 & 34 \\
Total & 100.0 & 754 & 100.0 & 124 & 100.0 & 878
\end{tabular}

According to table 5.3, about one third of the women interviewed in DG Khan believed that antenatal check-ups should be obtained within the first three months of pregnancy, while about 10 percent believed that antenatal check-ups should be sought as soon as possible after pregnancy. A majority (23.5 percent) however, believed that antenatal care should be sought only when necessary.

Table 5.3:

Month of pregnancy when women should obtain antenatal care

\begin{tabular}{lrrrrrr} 
& \multicolumn{2}{c}{ Rural } & \multicolumn{2}{c}{ Urban } & \multicolumn{2}{c}{ Total } \\
\cline { 2 - 7 } 1 & Percent & Number & Percent & Number & Percent & Number \\
\hline 2 & 8.4 & 51 & 17.9 & 20 & 9.9 & 71 \\
\hline 3 & 3.6 & 22 & 14.3 & 16 & 5.3 & 38 \\
\hline 4 & 19.1 & 116 & 17.9 & 20 & 18.9 & 136 \\
\hline 5 & 7.6 & 46 & 3.6 & 4 & 6.9 & 50 \\
\hline 6 & 10.7 & 65 & 7.1 & 8 & 10.1 & 73 \\
\hline 7 & 5.3 & 32 & 1.8 & 2 & 4.7 & 34 \\
\hline 8 & 5.8 & 35 & 10.7 & 12 & 6.5 & 47 \\
\hline 9 & 1.3 & 8 & 0.9 & 1 & 1.3 & 9 \\
\hline $\begin{array}{l}\text { As soon as possible after } \\
\text { pregnancy }\end{array}$ & 1.0 & 6 & & & 0.8 & 6 \\
\hline When check-up is needed & 9.2 & 56 & 17.0 & 19 & 10.4 & 75 \\
\hline Don't know & 26.3 & 160 & 8.0 & 9 & 23.5 & 169 \\
\hline Total & 1.8 & 11 & 0.9 & 1 & 1.7 & 12 \\
\hline
\end{tabular}

Table 5.4 presents the number of antenatal visits respondents indicated a woman should receive during pregnancy. About one third of the women interviewed believed that between one and three antenatal visits must be obtained during pregnancy, while about 43 percent believed that antenatal visits should be made only when necessary. 
Table 5.4:

Number of antenatal visits considered necessary by respondents

\begin{tabular}{lrrrrrr}
\multirow{2}{*}{ Number } & \multicolumn{2}{c}{ Rural } & \multicolumn{2}{c}{ Urban } & \multicolumn{2}{c}{ Total } \\
1 & Percent & Number & Percent & Number & Percent & Number \\
2 & 2.8 & 17 & 1.8 & 2 & 2.6 & 19 \\
3 & 11.0 & 67 & 3.6 & 4 & 9.9 & 71 \\
4 & 20.4 & 124 & 15.2 & 17 & 19.6 & 141 \\
5 & 8.6 & 52 & 8.0 & 9 & 8.5 & 61 \\
6 & 3.0 & 18 & 3.6 & 4 & 3.1 & 22 \\
7 & 2.3 & 14 & 8.9 & 10 & 3.3 & 24 \\
8 & 0.5 & 3 & 5.4 & 6 & 1.3 & 9 \\
$9+$ & 1.2 & 7 & 1.8 & 2 & 1.3 & 9 \\
When check-up is & 3.1 & 19 & 16.9 & 19 & 5.2 & 38 \\
needed & 44.5 & 270 & 33.9 & 38 & 42.8 & 308 \\
Don't know & 2.6 & 16 & 0.9 & 1 & 2.4 & 17 \\
Total & 100.0 & 607 & 100.0 & 112 & 100.0 & 719
\end{tabular}

Figure 5.1 presents some interesting data regarding TT shots and iron/folate supplements. About 96 percent of the women surveyed in DG Khan believed that TT shots were necessary for pregnant women. All respondents surveyed in urban areas believed in the importance of TT shots, whereas the figure was 95 percent for rural areas. Unfortunately, respondents did not have similar sentiments regarding iron/folate supplements, as only 78 percent in urban and 61 percent in areas expressed the importance of taking these supplements during pregnancy to prevent anemia and other deficiencies.

Figure 5.1: $\quad$ Percentage of married women who thought it necessary to receive TT shots and take iron/folate tablets during pregnancy

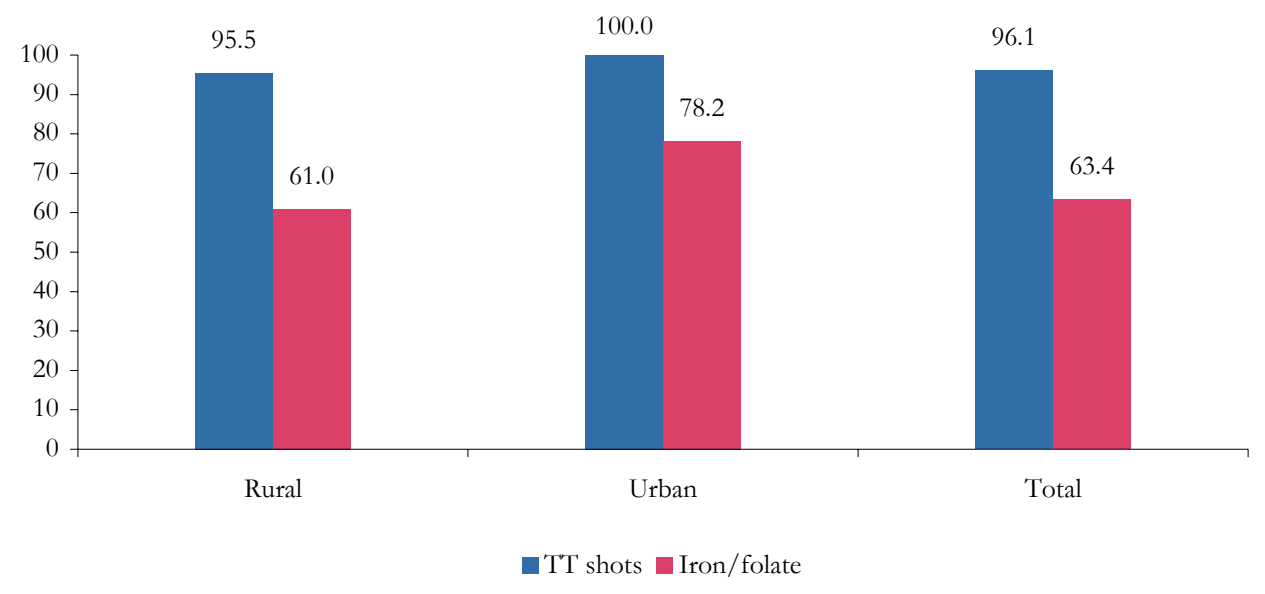




\section{Attitudes Towards Delivery}

Respondents were asked if pregnant women should receive delivery services from Skilled Birth Attendants (SBAs). Overall, more than 76 percent of the respondents in DG Khan believed that women should in fact receive delivery services from SBAs, while 21 percent disagreed with the idea.

Table 5.5: Respondents who believe that women should receive delivery services from health professional

\begin{tabular}{lrrrrrr} 
& \multicolumn{2}{c}{ Rural } & \multicolumn{2}{c}{ Urban } & \multicolumn{2}{c}{ Total } \\
\cline { 2 - 7 } Number & Percent & Number & Percent & Number & Percent & Number \\
\hline Yes & 74.5 & 561 & 88.7 & 110 & 76.5 & 671 \\
\hline No & 22.6 & 170 & 8.9 & 11 & 20.6 & 181 \\
\hline Don't know & 2.9 & 22 & 2.4 & 3 & 2.9 & 25 \\
Total & 100.0 & 753 & 100.0 & 124 & 100.0 & 877
\end{tabular}

Figure 5.2 indicates the proportion of respondents who believed women in their community obtained delivery services from skilled birth attendants. About 44 percent of the respondents in urban DG Khan and 22 percent of the respondents in rural DG Khan believed that a majority of the women in their communities obtained delivery services from SABs. It is interesting to note that more than 17 percent of the respondents in rural areas and 3 percent in urban areas reported that no one from their community obtained delivery services from SBAs.

Figure 5.2: $\quad$ Percentage of respondents who believe women in their community obtain delivery services from $S B A$ 's

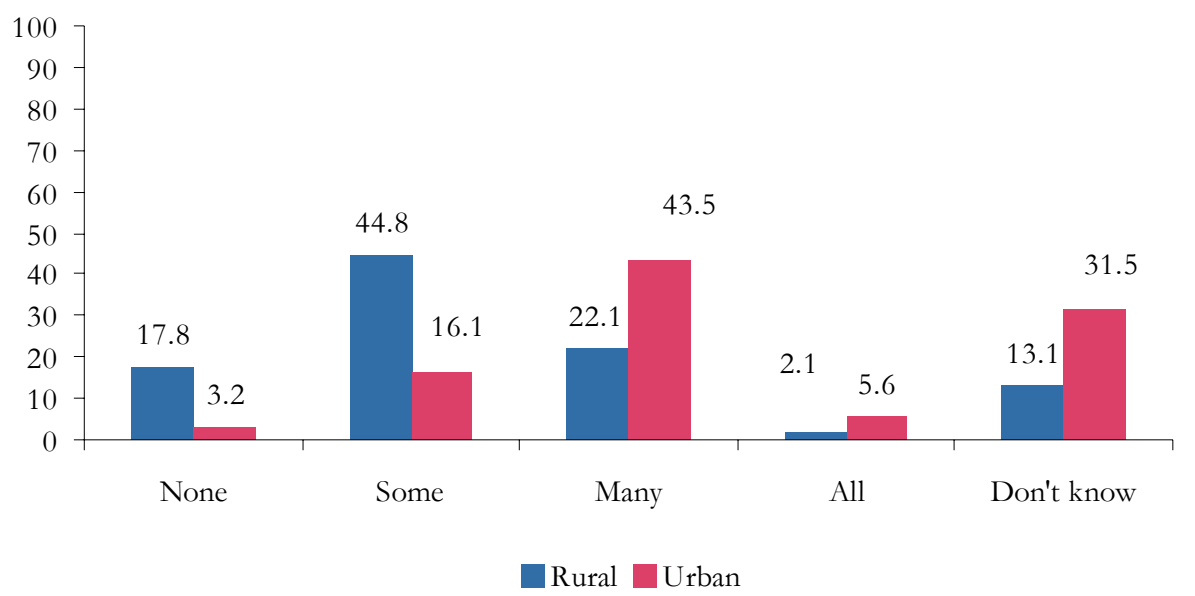

According to figure 5.3, approximately 71 percent of the respondents in urban areas and 38 percent in rural areas agreed that deliveries should be performed in hospitals, while 62 percent and 29 percent of the respondents in rural and urban areas respectively said that they should be carried out at home. 
Figure 5.3: $\quad$ Perception of respondents regarding place of delivery

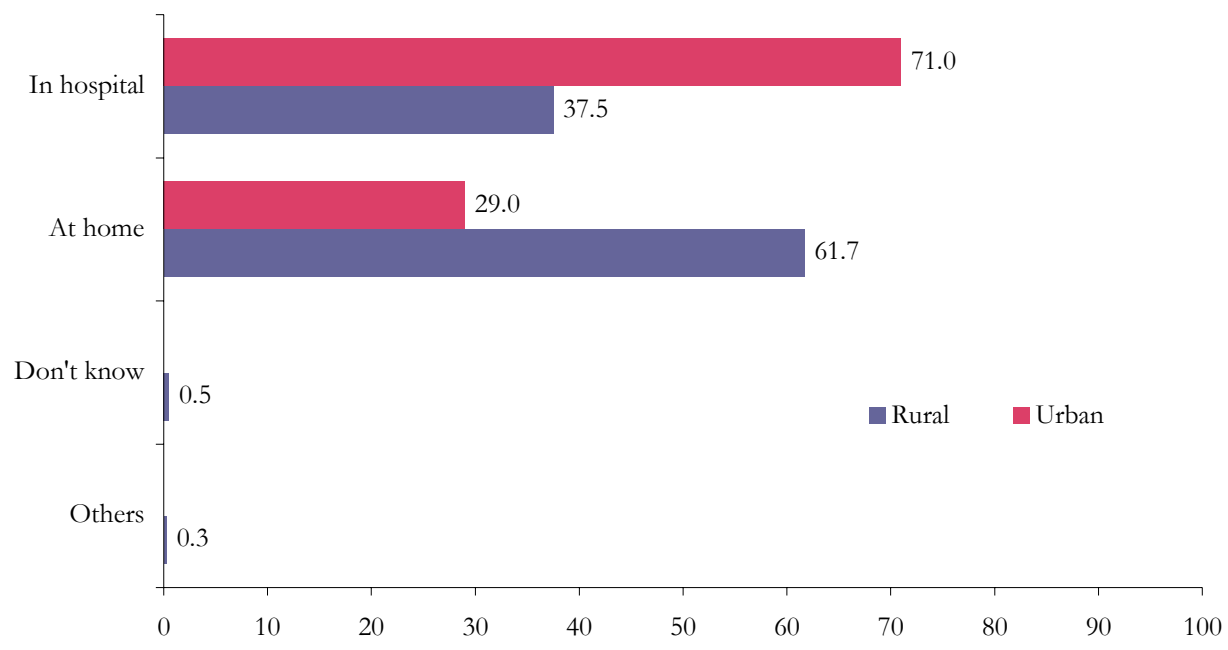

In a conservative society like DG Khan, husbands and in-laws play an important role in the decision to seek medical help. Overall, more than 70 percent of the respondents indicated that a woman's husband must make important decisions regarding the health of a pregnant woman, while nearly 20 percent indicated that other family members should make such decisions. In urban DG Khan, almost one-fifth of the respondents reported that pregnant women themselves should be allowed to make decisions regarding their own health, while only 4 percent of the respondents in rural areas shared that sentiment.

Table 5.6: $\quad$ Person who should make decisions regarding the health of pregnant women

\begin{tabular}{l|rrrrrr}
\multirow{2}{*}{\multicolumn{1}{c}{ Person }} & \multicolumn{2}{c}{ Rural } & \multicolumn{2}{c}{ Urban } & \multicolumn{2}{c}{ Total } \\
\cline { 2 - 7 } & Percent & Number & Percent & Number & Percent & Number \\
\hline Pregnant woman & 3.8 & 29 & 19.4 & 24 & 6.0 & 53 \\
\hline Husband & 72.8 & 549 & 61.3 & 76 & 71.2 & 625 \\
\hline Other family members & 20.2 & 152 & 18.5 & 23 & 19.9 & 175 \\
\hline TBA/Dai & 2.5 & 19 & 0.8 & 1 & 2.3 & 20 \\
\hline Don't know & 0.7 & 5 & & & 0.6 & 5 \\
Total & 100.0 & 754 & 100.0 & 124 & 100.0 & 878
\end{tabular}

Respondents were asked to indicate the mode of transportation they would use to reach a health facility. According to figure 5.4, in both urban and rural areas, two-thirds ( 66 percent) of the respondents said that they would use hired private transport, while more than one-fourth of the women in both urban and rural areas said that they would use their own transport. Only 3 percent in urban areas indicated that they plan to use community transport. Finally, about 2 percent of the sample women in both urban and rural areas indicated that no mode of transport was available to them, and that they would walk to a health facility at the time of delivery. 
Figure 5.4: $\quad$ Percentage of married women by mode of transport they would use to reach health facility

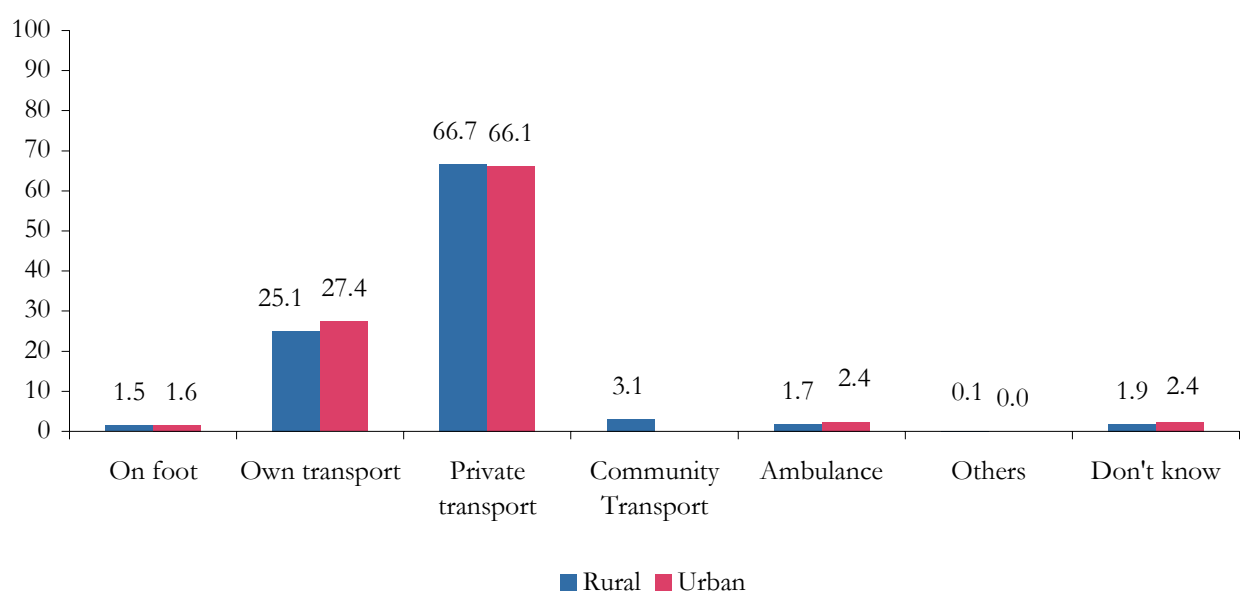

\section{Attitudes Towards Postpartum and Neonatal Care}

Table 5.7 shows that in rural areas of DG Khan, about half of the respondents indicated that postnatal care was not necessary, while nearly 41 percent were in favor of postnatal care. In urban areas however, 62 percent of the respondents believed postnatal care was necessary, while 31 percent disagreed with that sentiment.

Table 5.7: $\quad$ Necessity of a postnatal care

\begin{tabular}{|l|rrrrrrr} 
& \multicolumn{2}{c}{ Rural } & \multicolumn{2}{c}{ Urban } & \multicolumn{2}{c}{ Total } \\
\cline { 2 - 7 } Need postnatal & Percent & Number & Percent & Number & Percent & Number \\
\hline Yes & 40.6 & 306 & 62.1 & 77 & 43.6 & 383 \\
\hline No & 49.3 & 372 & 30.6 & 38 & 46.7 & 410 \\
\hline Don't know & 10.1 & 76 & 7.3 & 9 & 9.7 & 85 \\
\hline Total & 100.0 & 754 & 100.0 & 124 & 100.0 & 878
\end{tabular}

Women were asked about the postnatal care services used by women in their community after childbirth. According to figure 5.5, more than 45 percent of the respondents in rural areas believed that none of the women in their community received postnatal care. About 32 percent said that some of them received postnatal care, while only 4 percent said that most of the women in their community received postnatal care.

In urban areas, 23 percent of the respondents believed that none of the women in their community received postnatal care. About 24 percent said that some women received postnatal care, and 16 percent indicated that most of the women received postnatal care. 
Figure 5.5: $\quad$ Number of women who obtain postnatal care in their community

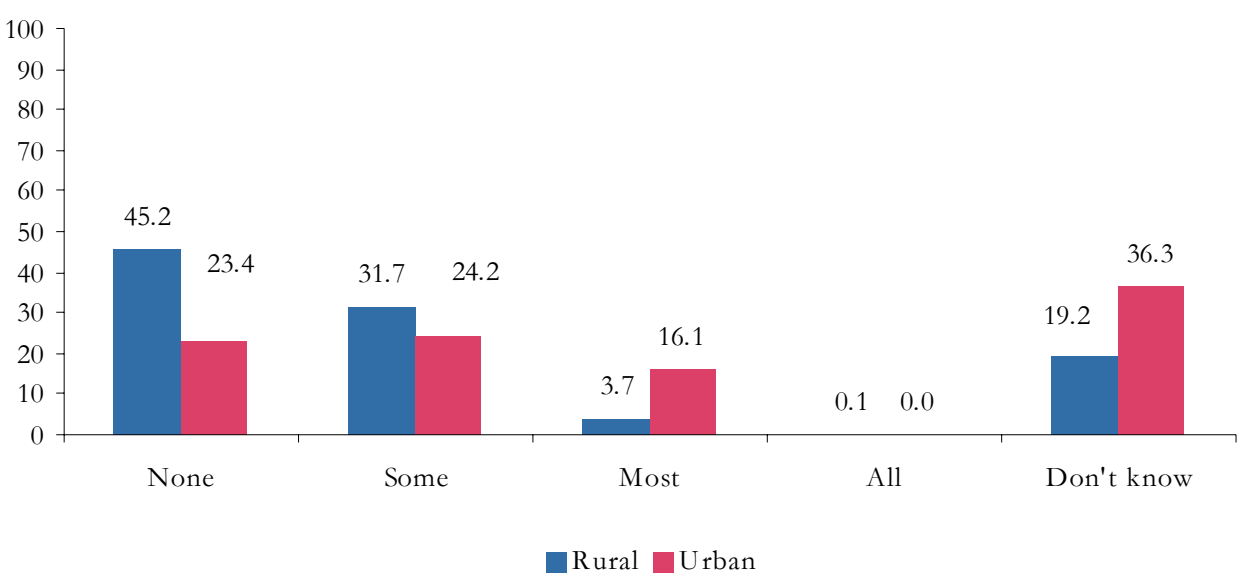

\section{Coverage of Lady Health Workers}

Women were asked if a Lady Health Worker (LHW) had been to their community. Overall two thirds of the respondents reported the presence of LHWs in their communities. In rural areas, almost 64 percent of the respondents indicated that an LHW had in fact been to their community, whereas in urban areas, more than 94 percent of the respondents indicated the same thing.

Table 5.8: $\quad$ Presence of lady bealth worker in the community

\begin{tabular}{lrrrrrr}
\multirow{2}{*}{ Has LHW in the area } & \multicolumn{2}{c}{ Rural } & \multicolumn{2}{c}{ Urban } & \multicolumn{2}{c}{ Total } \\
\cline { 2 - 7 } Yes & Percent & Number & Percent & Number & Percent & Number \\
\hline No & 63.5 & 479 & 94.4 & 117 & 67.9 & 596 \\
\hline Respondent herself is LHW & 34.5 & 260 & 2.4 & 3 & 30.0 & 263 \\
\hline Don't know & 1.2 & 9 & 2.4 & 3 & 1.4 & 12 \\
\hline Total & 0.8 & 6 & 0.8 & 1 & 0.8 & 7 \\
\hline
\end{tabular}

According to table 5.9, 86 percent of the women in rural areas indicated that an LHW visited their home during the last three months, while approximately 81 percent of the women in urban areas of DG Khan indicated the same. Only 14 percent of the women in rural areas and about 19 percent in urban areas said that a LHW had not visited their houses during the last three months.

Table 5.9: $\quad$ LHW ever visited home during last three months

\begin{tabular}{lrrrrrr} 
& \multirow{2}{*}{ Ever visited } & \multicolumn{2}{c}{ Rural } & \multicolumn{2}{c}{ Urban } & \multicolumn{2}{c}{ Total } \\
\cline { 2 - 7 } Yes & Percent & Number & Percent & Number & Percent & Number \\
\hline No & 86.4 & 414 & 81.2 & 95 & 85.4 & 509 \\
\hline Total & 13.6 & 65 & 18.8 & 22 & 14.6 & 87 \\
& 100.0 & 479 & 100.0 & 117 & 100.0 & 596
\end{tabular}





\section{Chapter}

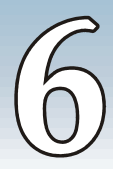

\section{Contraceptive Knowledge and Use}

Respondents were asked to name the ways in which a couple could delay or avoid a pregnancy. If the respondent did not spontaneously mention a particular method, the interviewer described different methods and asked the respondent to indicate if she recognized them. In the questionnaire, descriptions were included for six modern contraceptive methods and two traditional methods.

\section{Knowledge of Contraceptive Methods}

Many women are unaware of the different types of contraceptives that may be used to either delay or prevent pregnancy. Knowledge of contraception is an important step towards reproductive choice. Figure 6.1 shows the knowledge of both modern and traditional contraceptive methods among the respondents in rural areas of DG Khan. The most commonly known contraceptive methods in rural areas were the pill (88 percent), injections ( 87 percent) and IUD ( 77 percent). Only one-fourth of the respondents knew about condoms as a mean of contraception. Approximately three-quarters of the respondents had no knowledge of the traditional rhythm method.

Figure 6.1: $\quad$ Percentage of married women by knowledge of specific contraceptive method - Rural DG Khan

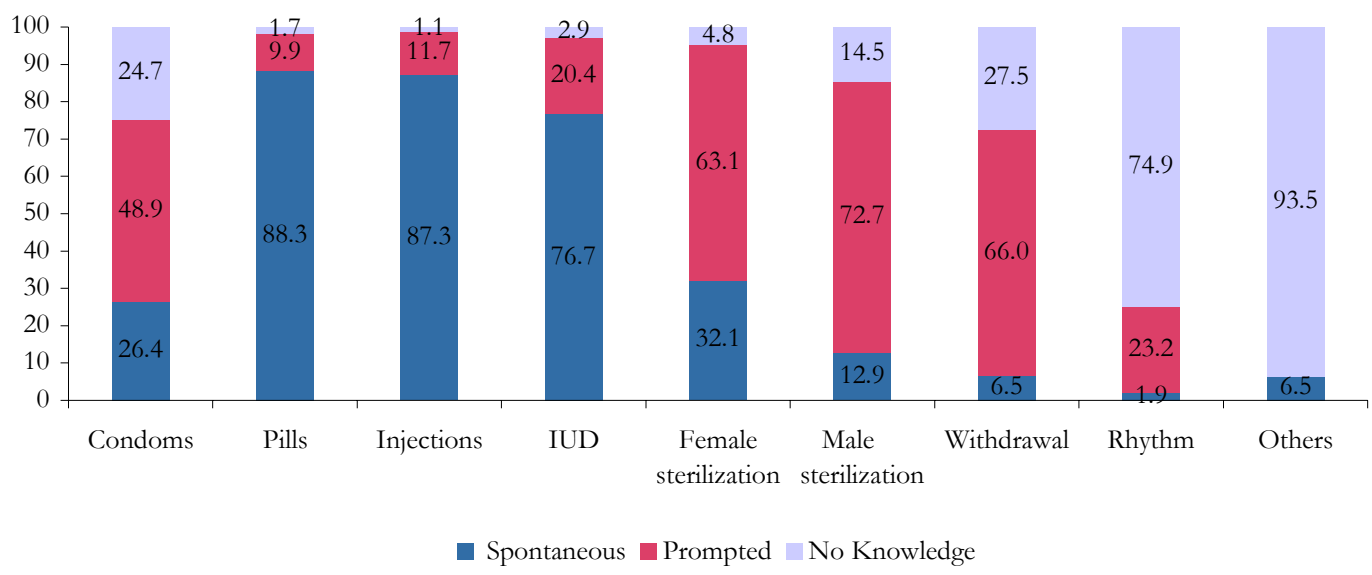

In urban areas, the most commonly known methods were the pill (92 percent), injections (85 percent) and IUD (72 percent). About 48 percent of the respondents in urban areas knew about condoms and 54 percent knew about female sterilization. 
Figure 6.2: $\quad$ Percentage of married women by knowledge of specific contraceptive method-

Urban DG Khan

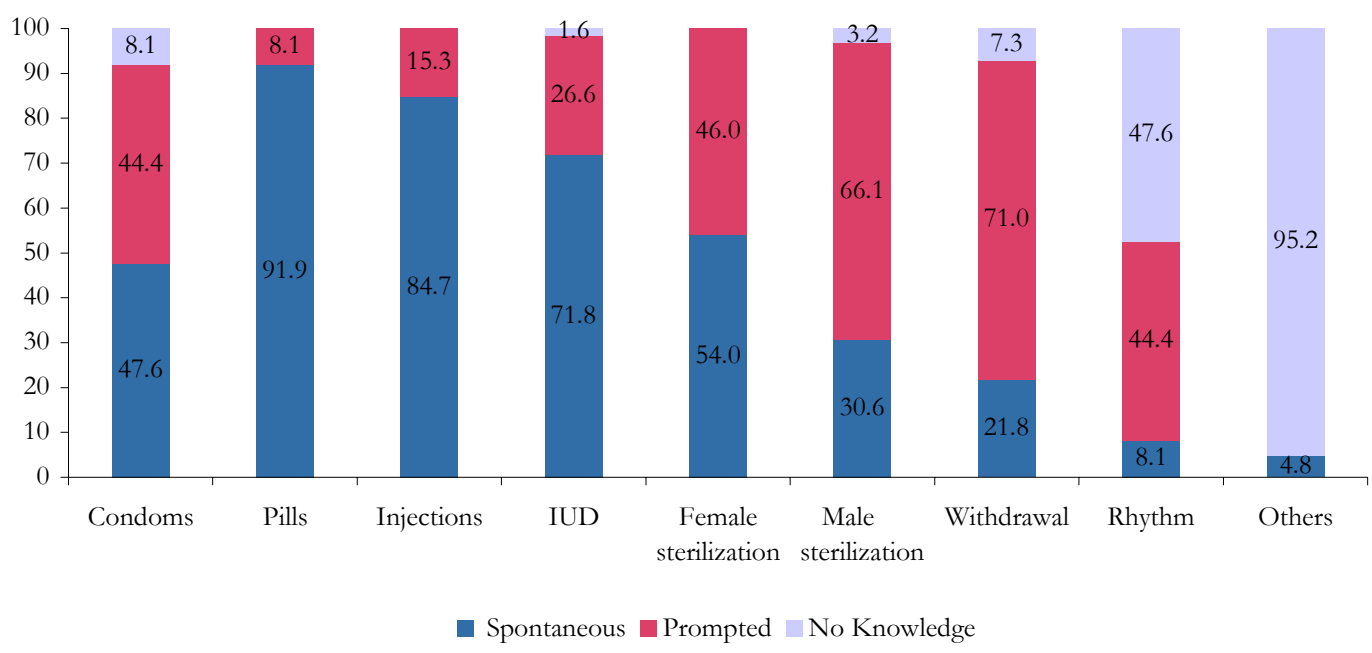

\section{Ever Use of Contraception}

Table 6.1 presents the percentage of respondents who had ever used contraception. Overall, more than 11 percent of the respondents said that they had used the contraceptive pill, while about 10 percent of the respondents each used condoms and injections. The percentage of male sterilizations was very low (slightly more than 1 percent) when compared to female sterilizations in both urban and rural areas of DG Khan.

Table 6.1: $\quad$ Ever used of specific contraceptive method

\begin{tabular}{lcccr}
\multicolumn{1}{c}{ Contraceptive method } & Place of residence & \multicolumn{2}{c}{ Total } \\
\cline { 2 - 4 } Any method & Rural & Urban & Percentage & Number \\
\hline Condoms & 37.5 & 52.4 & 39.6 & 348 \\
\hline Pills & 9.8 & 15.3 & 10.6 & 93 \\
\hline Injections & 10.3 & 17.7 & 11.4 & 100 \\
\hline IUD & 10.9 & 8.1 & 10.5 & 92 \\
\hline Female sterilization & 14.1 & 14.5 & 14.1 & 124 \\
\hline Male sterilization & 4.0 & 8.1 & 4.6 & 42 \\
\hline Withdrawal & 1.1 & 0.8 & 1.0 & 12 \\
\hline Rhythm & 7.2 & 14.5 & 8.2 & 72 \\
\hline
\end{tabular}




\section{Current use of Contraceptive methods}

Contraceptive prevalence is defined as the proportion of currently married women aged 15-49 years who were using some method of family planning at the time of the survey. Table 6.2 shows the percentage distribution of married women currently using specific family planning methods. Results indicate that more than 20 percent of the married women are using family planning methods; with 16 percent using modern methods and 4 percent using traditional methods. Among modern family planning methods, female sterilization is the most popular (4.6 percent) followed by IUD (3.6 percent) and condoms (3.4 percent). About 1.7 percent use pills, while 1.6 percent use injectables. The most commonly practiced traditional method is the withdrawal method ( 3.8 percent).

Table 6.2: $\quad$ Current use of specific contraceptive method

\begin{tabular}{lrrr}
\multicolumn{1}{c}{ Contraceptive Method } & Rural & Urban & All \\
Any method & 18.2 & 33.9 & 20.4 \\
\hline Any modern method & 14.5 & 25.0 & 15.9 \\
\hline Any traditional method & 3.3 & 8.9 & 4.1 \\
\hline Condom & 2.8 & 7.3 & 3.4 \\
\hline Pill & 1.3 & 4.0 & 1.7 \\
\hline Injectables & 1.9 & & 1.6 \\
\hline IUD & 3.4 & 4.8 & 3.6 \\
\hline Female sterilization & 4.0 & 8.1 & 4.6 \\
\hline Male sterilization & 1.1 & 0.8 & 1.0 \\
\hline Withdrawal & 3.1 & 8.1 & 3.8 \\
\hline Rhythm & 0.3 & 0.8 & 0.3 \\
\hline Other & 0.4 & & 0.3 \\
\hline Not currently using & 81.8 & 66.1 & 79.6 \\
\hline Number & 754 & 124 & 878 \\
\hline
\end{tabular}

\section{Source of Contraceptive Supplies}

Respondents were then asked where they last obtained their method of contraception. Table 6.3 shows the distribution of current users by most recent source of contraception.

A quarter in both urban and rural areas indicated that they obtained their contraception from THQ/DHQs. More than one fifth indicated that private clinics and hospitals were their main source of family planning methods. More than 9 percent in both urban and rural areas obtained contraception from BHU/RHC/MCH centers. LHWs were also cited as a source of contraception by nearly 8 percent of the sampled population 
Table 6.3:

Distribution of contraceptive users by source of supply

\begin{tabular}{lrrrrrr} 
& \multicolumn{2}{c}{ Rural } & \multicolumn{2}{c}{ Urban } & \multicolumn{2}{c}{ Total } \\
\cline { 2 - 7 } Source/Place & Percent & Number & Percent & Number & Percent & Number \\
\hline BHU/RHC//MCH center & 7.3 & 8 & 9.7 & 3 & 7.9 & 11 \\
\hline DHQ/THQ & 9.2 & 10 & 9.7 & 3 & 9.3 & 13 \\
\hline Private clinic/hospital & 25.7 & 28 & 22.6 & 7 & 25 & 35 \\
\hline Nurse/LHV & 22 & 24 & 19.4 & 6 & 21.4 & 30 \\
\hline FWC/RHS-A & 9.2 & 10 & 3.2 & 1 & 7.9 & 11 \\
\hline Mobile Team & 0.9 & 1 & 3.2 & 1 & 1.4 & 2 \\
\hline Medical Store & 0.9 & 1 & & & 0.7 & 1 \\
\hline General Store/shop & 6.4 & 7 & 9.7 & 3 & 7.1 & 10 \\
\hline Others & 8.3 & 9 & 12.9 & 4 & 9.3 & 13 \\
\hline Don't know & 0.9 & 1 & & & 0.7 & 1 \\
\hline Total & 9.2 & 10 & 9.7 & 3 & 9.3 & 13 \\
\hline
\end{tabular}

\section{Intentions of Future Use}

When the non-users of family planning methods were asked if they would like to use family planning methods in the future, the answers obtained were quite interesting. In rural areas, about 39 percent of the respondents indicated that they would like to use contraception in the future, while about 38 percent were unwilling to do so. In urban areas, more than 30 percent of the respondents indicated that they would like to use contraceptives in future, while half of the married women had no intentions of future use.

Figure 6.3: $\quad$ Percentage of women by future intention to use contraceptives

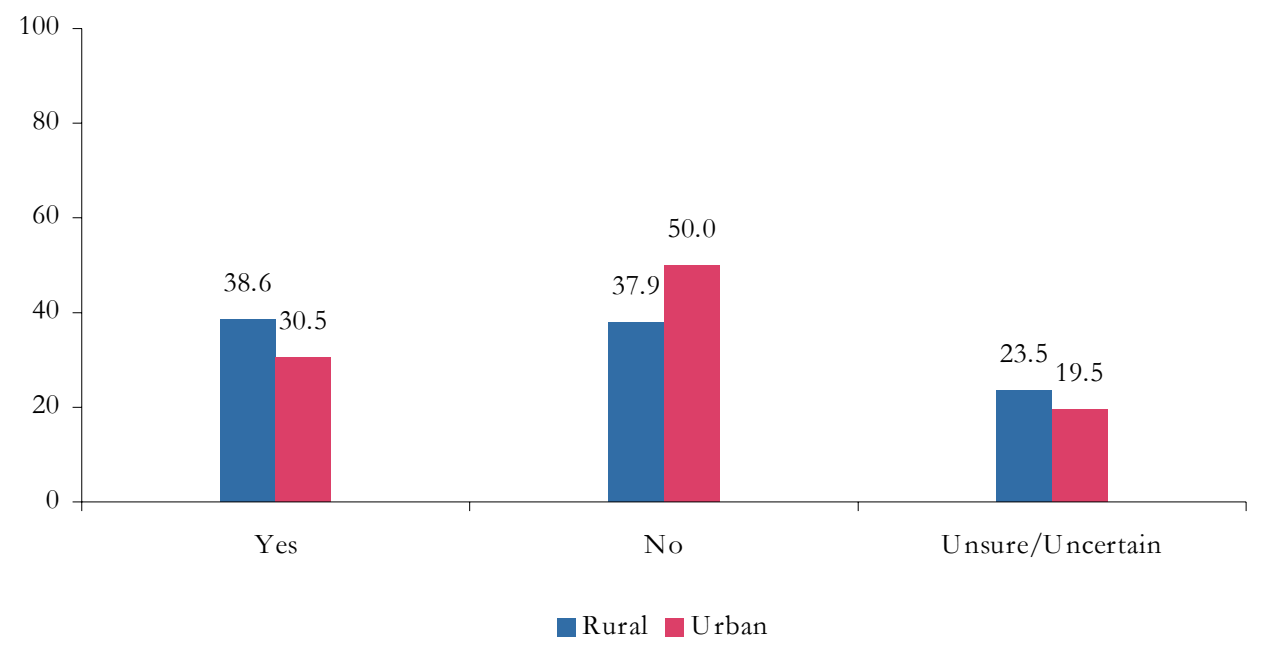




\section{Chapter}

\section{Behavior Regarding Maternal and Newborn Health}

Many of the women who were interviewed were currently pregnant. However, some women, especially those early in the pregnancy, had not yet experienced the full range of events that take place over the nine-month gestational period. Women who had recently given birth were able to provide a full range of information on these events, and thus constitute an important part of the sample population in terms of understanding the attitudes and behavior concerning maternal and newborn health. This chapter pertains to the respondents' last pregnancy, given that it was within the past three years. Respondents were asked several questions regarding their experience during their last pregnancy including antenatal and delivery care, complications during pregnancy and delivery, postnatal care, and problems in accessing health care.

Information on antenatal care, delivery services and postnatal care is of immense value in identifying subgroups of women who do not utilize such services, and it is useful in planning for future improvements in the services. Delivery services are described according to the person assisting and the rate of caesarean section. Information on postnatal care is collected from women who did not give birth in a health facility, and it describes the time since delivery when it was received, as well as from whom it was received.

\section{Gestational Age}

Respondents were asked to indicate the gestational age at the time at which their last pregnancy ended. Among the pregnancies resulting in live births, 83 percent of women had completed nine months, while 16 percent had completed ten months. Stillbirth mostly occurred in the third trimester, while the spontaneous and induced abortions occurred primarily within the first trimester. There was only one reported case of induced abortion in the district of DG Khan. 
Table 7.1: $\quad$ Pregnancy outcome by gestational age

\begin{tabular}{lcccc}
$\begin{array}{l}\text { Gestational age when } \\
\text { pregnancy ended }\end{array}$ & Live birth & Still birth & $\begin{array}{c}\text { Spontaneous } \\
\text { abortions }\end{array}$ & $\begin{array}{c}\text { Induced } \\
\text { abortions }\end{array}$ \\
\hline First trimester & & 8.3 & 69.7 & 100.0 \\
\hline Second trimester & 0.7 & 16.7 & 30.3 & \\
\hline 7 & 0.7 & 33.3 & & \\
\hline 8 & 82.6 & 33.3 & & 100.0 \\
\hline 9 & 16.0 & 8.3 & & 1 \\
\hline 10 & 100.0 & 100.0 & 100.0 & 33 \\
\hline Total & 455 & 12 & & \\
\hline Number of pregnancies & & & & \\
\hline
\end{tabular}

\section{Antenatal Care}

In this survey, antenatal care is defined according to the type of provider, the number of visits made, and the stage of pregnancy at the time of the first visit, including whether or not tetanus toxoid injection and iron/folate tablets were received. The survey also included questions regarding the antenatal care received by the respondent during their last pregnancy. Figure 7.1 shows that half of the married women in rural areas of DG Khan received antenatal care, while the other half did not receive any antenatal care during their last pregnancy. In urban areas, more than three quarters of the respondents received antenatal care during their last pregnancy. Less than 20 percent of rural and 48 percent of urban pregnant women had at least 3 ANC visits.

Figure 7.1: $\quad$ Percentage of respondents who obtained antenatal care

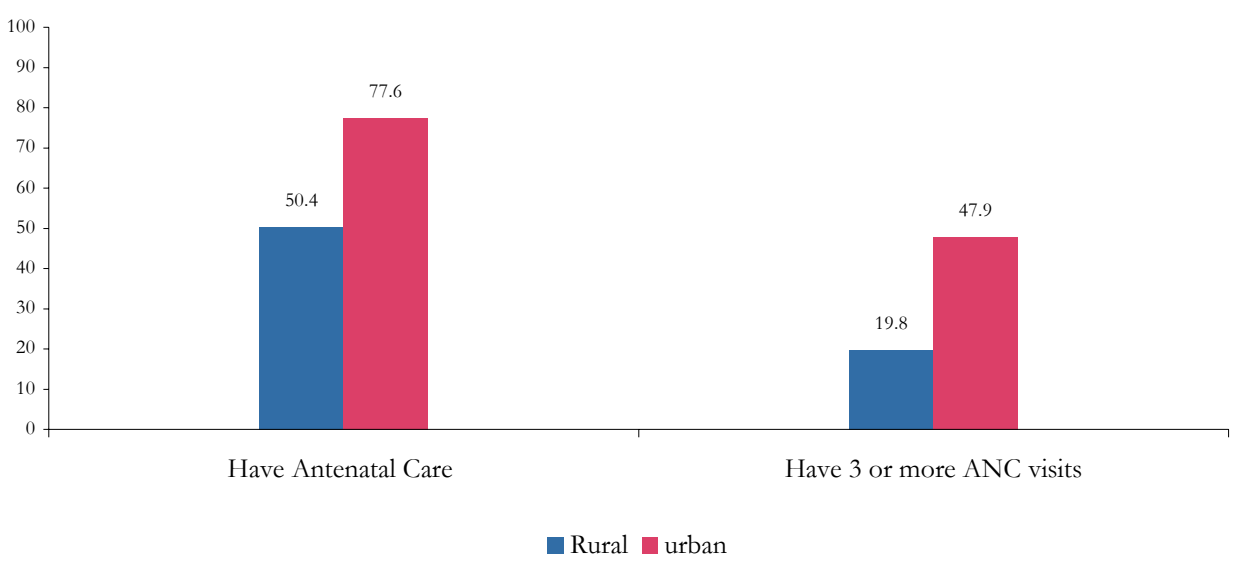


According to table 7.2, about 29 percent of the respondents in rural areas had their first antenatal check-up during their first trimester, 31 percent in their second trimester, while the rest sought antenatal care in their third trimester. In urban areas, 45 percent of the respondents had their first antenatal check-up in their first trimester, 21 percent in their second trimester and the rest sought care in their third trimester.

Table 7.2:

Gestational age at first antenatal check-up/ number of antenatal check-ups obtained

\begin{tabular}{|c|c|c|c|c|c|c|c|}
\hline \multirow{2}{*}{\multicolumn{2}{|c|}{ Check-ups }} & \multicolumn{2}{|c|}{ Rural } & \multicolumn{2}{|c|}{ Urban } & \multicolumn{2}{|c|}{ Total } \\
\hline & & Percent & Number & Percent & Number & Percent & Number \\
\hline \multirow{11}{*}{$\begin{array}{l}\text { Gestational age at } \\
\text { first antenatal care }\end{array}$} & 1 & 6.1 & 14 & 21.1 & 8 & 8.3 & 22 \\
\hline & 2 & 6.1 & 14 & 15.8 & 6 & 7.5 & 20 \\
\hline & 3 & 16.7 & 38 & 7.9 & 3 & 15.4 & 41 \\
\hline & 4 & 11.0 & 25 & 5.3 & 2 & 10.2 & 27 \\
\hline & 5 & 10.5 & 24 & 10.5 & 4 & 10.5 & 28 \\
\hline & 6 & 9.6 & 22 & 5.3 & 2 & 9.0 & 24 \\
\hline & 7 & 17.5 & 40 & 18.4 & 7 & 17.7 & 47 \\
\hline & 8 & 11.4 & 26 & 7.9 & 3 & 10.9 & 29 \\
\hline & 9 & 9.2 & 21 & 7.9 & 3 & 9.0 & 24 \\
\hline & 10 & 0.4 & 1 & & & 0.4 & 1 \\
\hline & Don't know & 1.3 & 3 & & & 1.1 & 3 \\
\hline \multirow{10}{*}{$\begin{array}{l}\text { No. of antenatal } \\
\text { check-ups during } \\
\text { pregnancy }\end{array}$} & 1 & 34.2 & 78 & 18.4 & 7 & 32.0 & 85 \\
\hline & 2 & 25.4 & 58 & 18.4 & 7 & 24.4 & 65 \\
\hline & 3 & 17.1 & 39 & 13.2 & 5 & 16.5 & 44 \\
\hline & 4 & 8.8 & 20 & 13.2 & 5 & 9.4 & 25 \\
\hline & 5 & 4.4 & 10 & 7.9 & 3 & 4.9 & 13 \\
\hline & 6 & 1.8 & 4 & 7.9 & 3 & 2.6 & 7 \\
\hline & 7 & 2.6 & 6 & 5.3 & 2 & 3.0 & 8 \\
\hline & 8 & 1.3 & 3 & 2.6 & 1 & 1.5 & 4 \\
\hline & 9 & 2.2 & 5 & 7.9 & 3 & 3.0 & 8 \\
\hline & Don't know & 1.3 & 3 & 2.6 & 1 & 1.5 & 4 \\
\hline Total & & 100.0 & 228 & 100.0 & 38 & 100.0 & 266 \\
\hline
\end{tabular}


According to figure 7.2, most of the women who went for ANC visits were accompanied by their husbands (42 percent), followed by other family members ( 32 percent), and mothers in law (18 percent).

Figure 7.2:

Persons accompanying pregnant women to antenatal check-ups

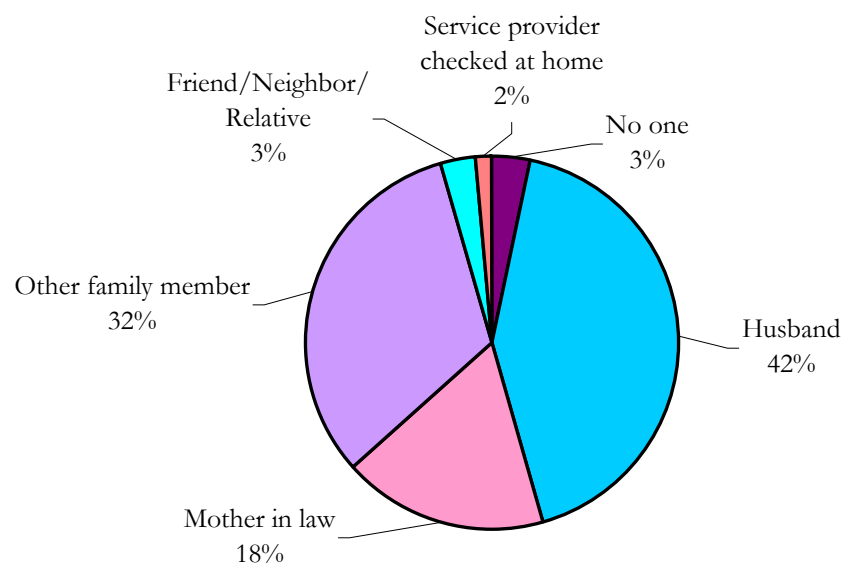

\section{Components of Antenatal care}

In Pakistan, it is recommended that every pregnant woman should receive the following services: height and weight measurements, blood pressure measurement, iron tablets, tetanus toxoid immunization, and abdominal examinations. In any antenatal care visit, a woman should be informed of the danger signs of pregnancy, and provide blood and urine samples for testing. Antenatal care can improve certain outcomes through the detection and management of possible complications. However, antenatal care has not been shown to reduce rates of maternal mortality. Antenatal care may improve birth weight and can also prevent, identify and treat iron deficiency and anemia in pregnant mothers.

Figure 7.3 shows the percentage distribution of services received by pregnant women during antenatal check-ups. In urban areas, 82 percent of the women surveyed were referred for an ultrasound test or had one performed at the place where they received the antenatal check-ups. Over 60 percent of the respondents had fetal heart activity checked, discussed past obstetric history with their health provider, and had their blood pressure measured during their antenatal check-ups. In rural areas, the fetal heart activity of almost 74 percent women was checked, and more than 61 percent were referred for ultrasound. Only half of the women in rural areas were asked for their obstetric history. As anemia is a common condition during pregnancy and can cause serious harm if unchecked, it is surprising that a large proportion of women in both rural and urban DG Khan were not checked for it. 
Figure 7.3: $\quad$ Services performed/questions asked during antenatal check-up

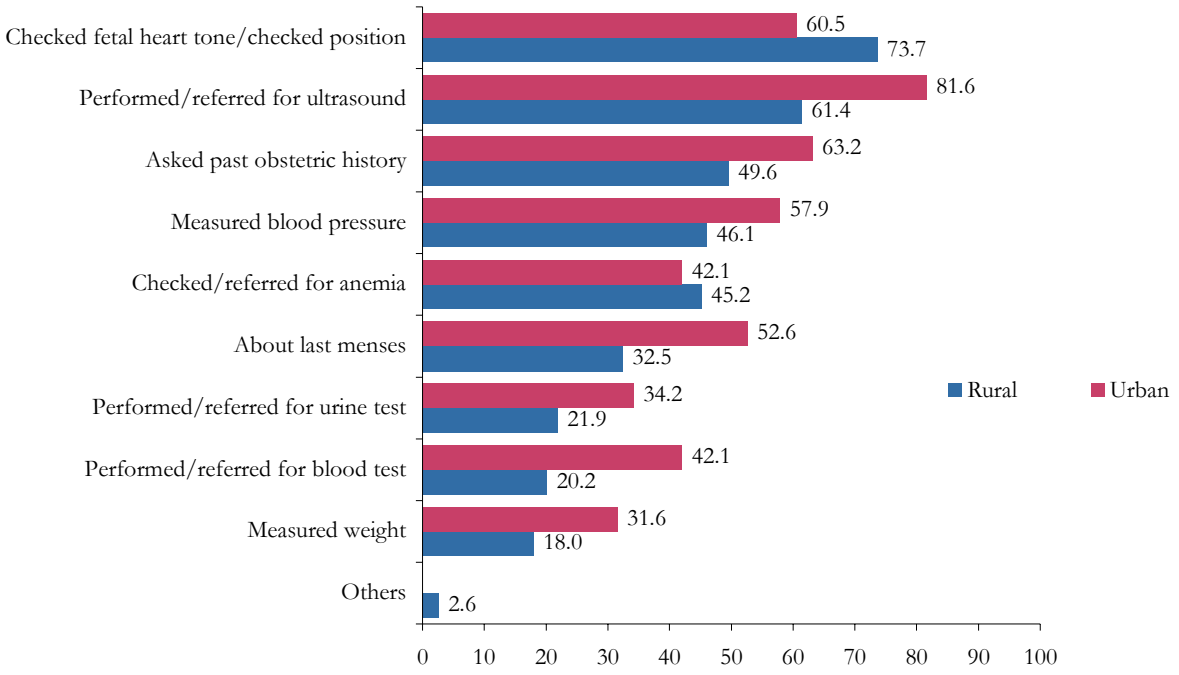

Figure 7.4 outlines the issues on which pregnant women were advised during their antenatal checkups. In urban areas, three quarters (76.3 percent) of the women interviewed received advice on nutrition, while three fifths (60.5 percent) received advice on tetanus toxoid injections. In rural areas, more than 69 percent of the respondents received advice on nutrition, while more than 44 percent received advice on TT injections. Some very important issues including birth preparedness, danger signs during pregnancy and breast-feeding were discussed with only 21 percent of the women in urban areas and 14 percent of the women in rural areas of DG Khan.

Figure 7.4: $\quad$ Percentage of pregnant women by issues discussed during antenatal check-up

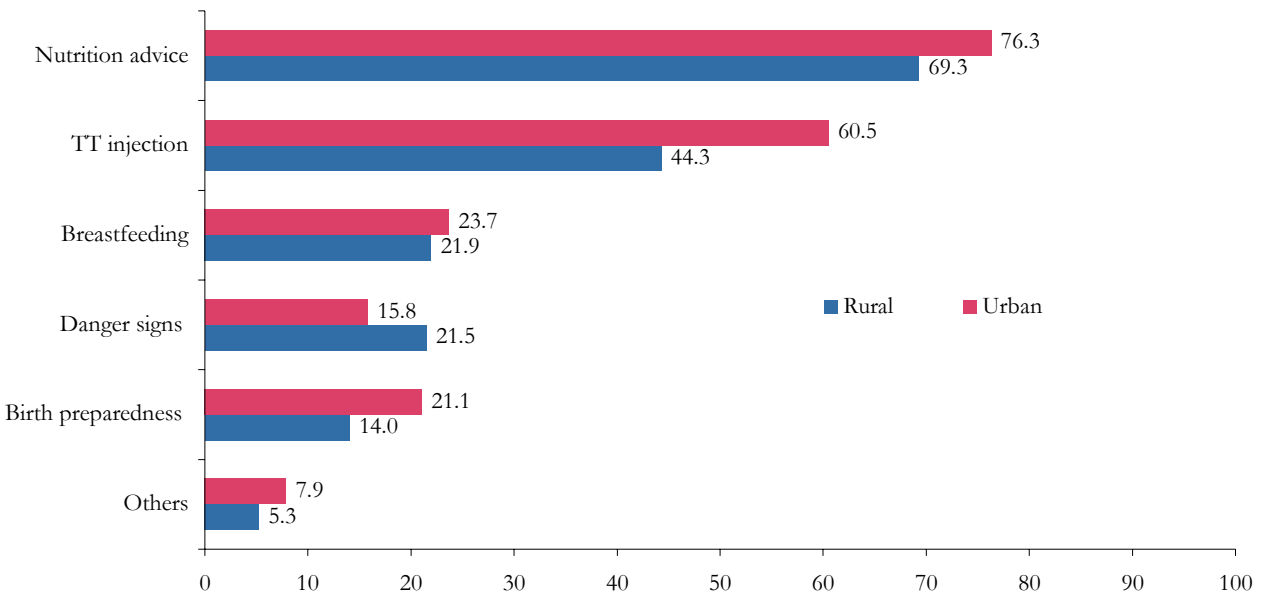




\section{TT Injections and Iron/Folate Tablets}

Respondents were also asked to state whether they took iron and folate supplements and received TT shots during their last pregnancy. The immunization of pregnant women is enforced by a program coordinated by the Expanded Program on Immunization (EPI) and the Maternal and Child Health Care $(\mathrm{MCH})$ departments at the district level. The program recommends that women should receive two tetanus toxoid (TT) injections during their first pregnancy. Booster injections are given once during each subsequent pregnancy to maintain full protection. In recent years, TT immunization has also been given to women before marriage, so that any pregnancy occurring within three years of their marriage would be protected against tetanus.

Figure 7.5 shows that in rural areas 56 percent of women received TT shots during their last pregnancy, while 44 percent did not receive TT shots. In urban areas almost 86 percent received TT shots during their last pregnancy, while about 14 percent did not. Figure 7.6 indicates that 29 percent of pregnant women residing in rural areas took iron/folate supplements, while about 71 percent did not take supplements during their last pregnancy. In urban areas, approximately 53 percent of pregnant women used iron/folate tablets during their last pregnancy while the remaining 47 percent did not.

When respondents were asked to indicate the importance of TT injections and iron/folate supplements, a higher percentage of women recognized the importance versus the percentage that actually took TT shots and iron/folate supplements during their pregnancies. It may be due to the fact that women may not have the decision-making power to obtain these supplements and vaccinations, and may be dependent upon husbands or family members/in-laws to make these important decisions for them.

Figure 7.5: $\quad$ Percentage of marred women by status of TT injections received during last pregnancy

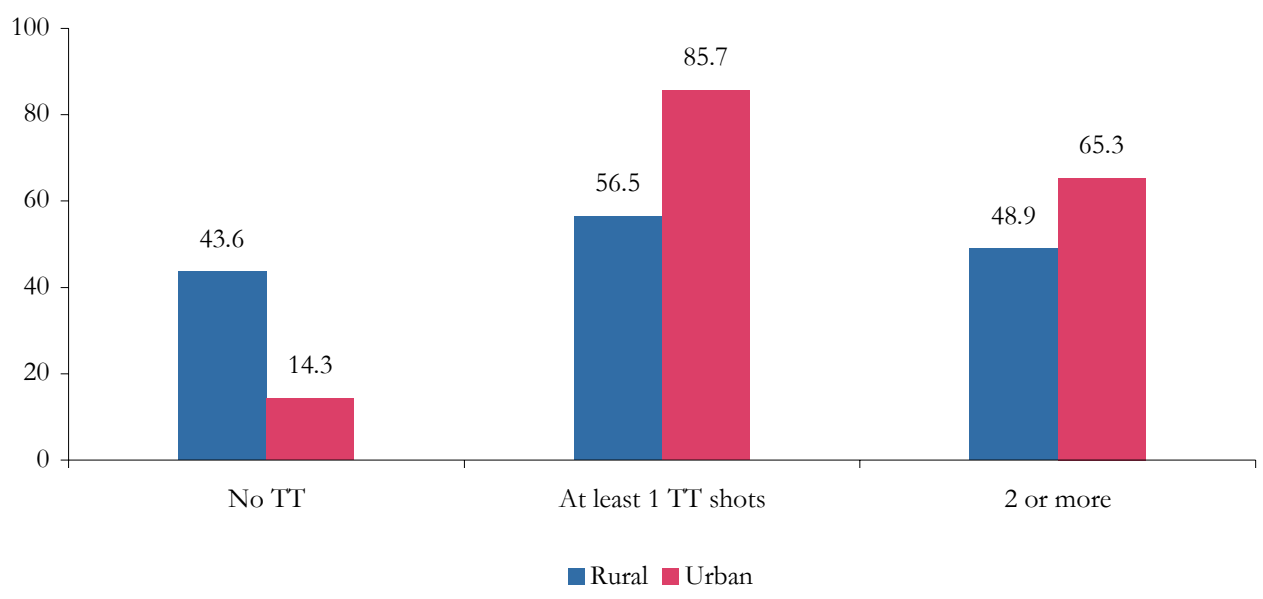


Figure 7.6: $\quad$ Percentage of married women by status of iron/folate tablets taken during the last pregnancy

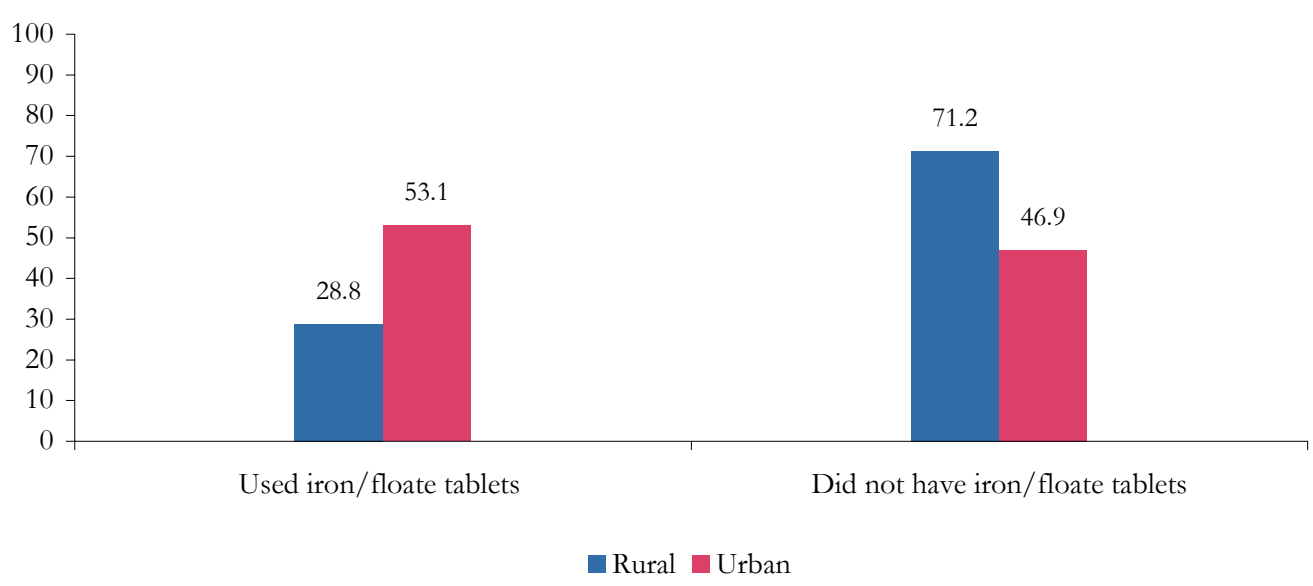

\section{Experience of Complications and Birth Preparedness}

\section{Complications During Pregnancy}

Women were asked to recall any signs and symptoms that they had experienced during their last pregnancy, provided it was within the past three years preceding the survey. In rural areas, almost three out of five respondents indicated that they had experienced some type of complication, while two out of five respondents in urban areas made the same claim.

According to figure 7.7, the complications experienced by respondents were reportedly higher in rural areas as compared to urban areas of DG Khan. In rural areas, 27 percent reported severe headaches, 26 percent suffered from blurring of vision, and 22 percent endured severe lower abdominal pain.

In urban areas, 16 percent had shortness of breath, and 12.2 percent each experienced severe headaches and blurring of vision. Almost 6 percent of the respondents in both areas reported heavy vaginal bleeding during their last pregnancy. It is possible that women perceive bleeding during pregnancy to be a normal symptom, and may therefore fail to report it as a complication. A very low percentage of women in DG Khan reported high blood pressure. 
Figure 7.7: $\quad$ Percentage of married women who experienced complications during their last pregnancy

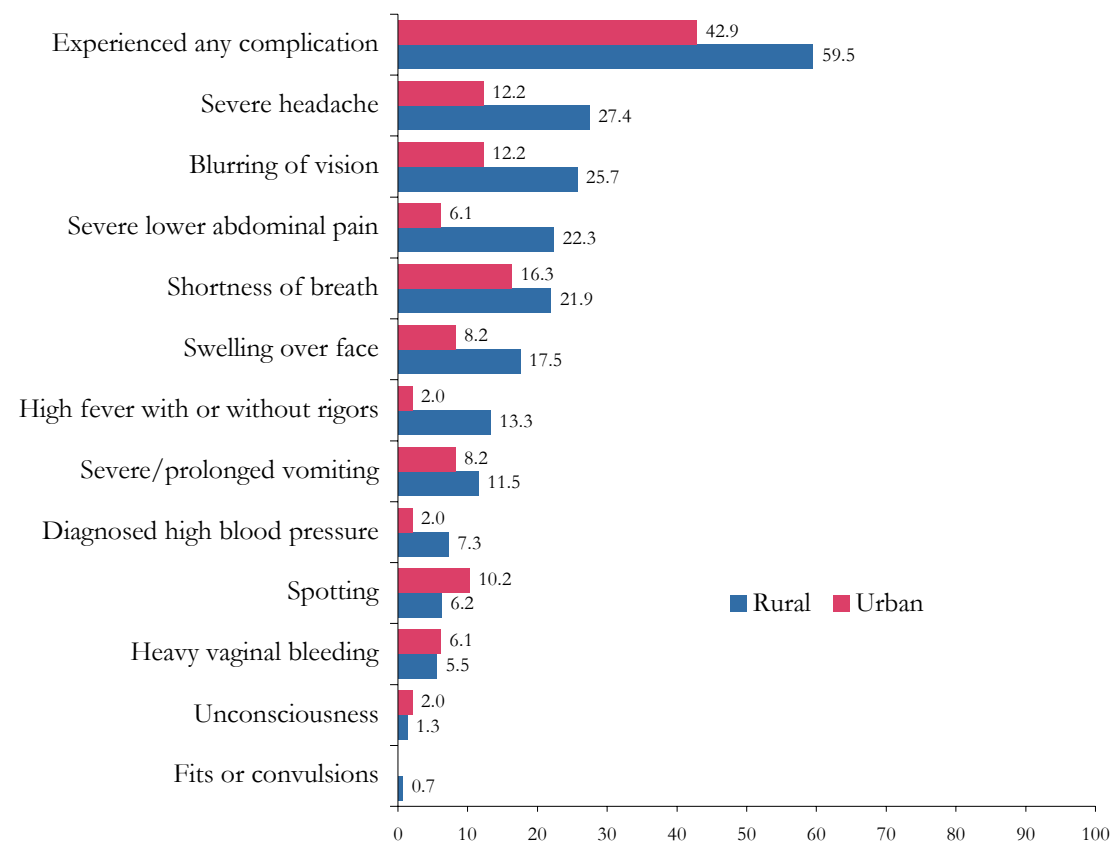

\section{Preparedness for Childbirth}

To ensure the safety of the mother and newborn at the time of delivery, certain preparations need to be made. These include deciding who is going to assist in the delivery, where the delivery is going to take place, how the woman is going to get to the place of delivery, and how much the delivery is going to cost. Delivery services, especially emergency obstetric care, are critical for pregnant women. Emergency care is important in the event that a pregnant mother experiences obstructed labor, pregnancy-induced hypertension, eclampsia or severe untreated anemia. Obstructed or prolonged labor is one of the more serious complications that can cause maternal death. Obstetric care can also prevent or treat complications that affect the neonate, such as birth asphyxia.

According to figure 7.8, 86 percent of the women in urban areas of DG Khan had prepared clothes for the baby, while 72 percent of their counterparts in rural areas did the same. Two-third of the sample population in urban areas and only 28 percent in rural areas had arranged money for an emergency delivery. Four out of five women in urban areas, along with two out of five women in rural areas arranged money for a normal delivery. About two thirds of the women in urban areas and onethird in rural areas knew the location of a nearby hospital. Moreover, 57 percent of the respondents in urban areas and 28 percent in rural areas had talked to a service provider before the delivery. About 49 percent of the women in urban areas, and only 16 percent in rural areas knew the cost of delivery or fee of the doctor. Figure 7.8 also shows that about half of the pregnant women in urban areas and only 14 percent in rural areas had arranged for transport at the time of delivery. 
Figure 7.8: $\quad$ Percentage of married women who made arrangements for their last delivery

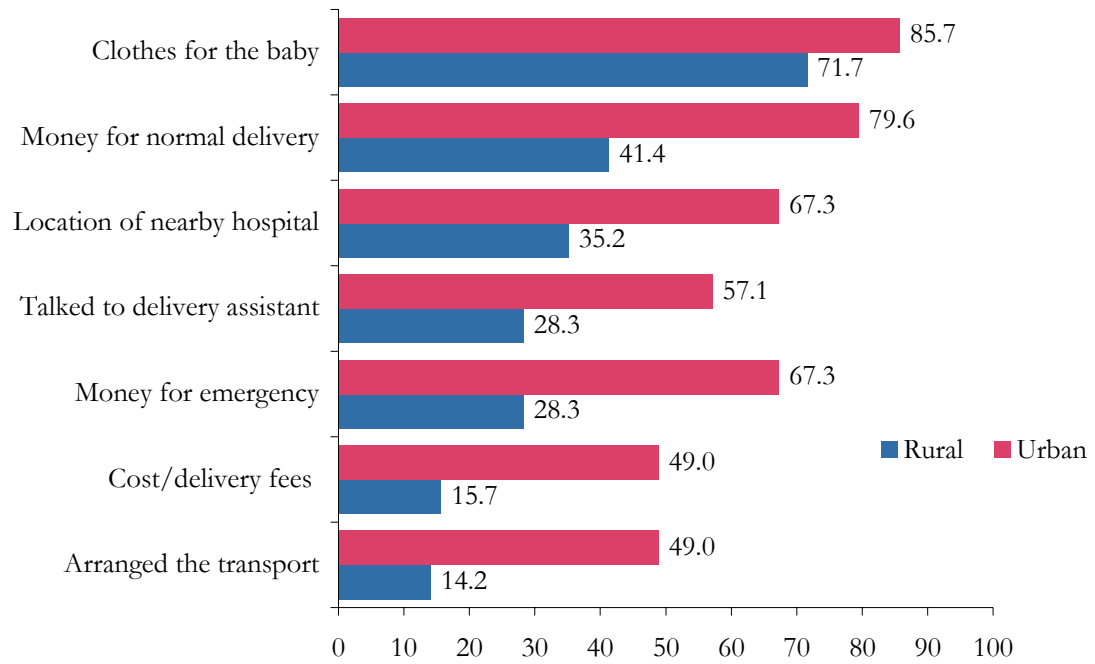

\section{Delivery Characteristics}

When asked about the characteristics of the delivery, more than 85 percent of the respondents indicated that they had a normal vaginal delivery. Overall, the percentages of caesarean section and assisted vaginal deliveries were only 4.4 percent and 3.4 percent respectively. In urban areas, 10 percent of the respondents reported caesarean section deliveries while about 12 percent reportedly had assisted vaginal deliveries. In rural areas, the caesarian section deliveries made up 3.8 percent of the deliveries, while 2.4 percent were assisted vaginal deliveries.

Table 7.3: $\quad$ Status of last delivery

\begin{tabular}{lrrrrrr}
\multicolumn{1}{c}{ Status } & \multicolumn{2}{c}{ Rural } & \multicolumn{2}{c}{ Urban } & \multicolumn{2}{c}{ Total } \\
& Percent & Number & Percent & Number & Percent & Number \\
\hline Normal vaginal delivery & 87.4 & 395 & 67.3 & 33 & 85.4 & 428 \\
\hline Assisted vaginal delivery & 2.4 & 11 & 12.2 & 6 & 3.4 & 17 \\
\hline Caesarean section & 3.8 & 17 & 10.2 & 5 & 4.4 & 22 \\
\hline Spontaneous abortion & 6.2 & 28 & 10.2 & 5 & 6.6 & 33 \\
\hline Induced abortion & 0.2 & 1 & & & 0.2 & 1 \\
Total & 100.0 & 452 & 100.0 & 49 & 100.0 & 501
\end{tabular}

Figure 7.9 depicts the outcome of the respondents' last delivery. The percentage of deliveries resulting in live births was slightly higher in rural areas (91.2 percent) when compared with urban areas (87.8 percent). The percentages of stillbirths were almost the same in both urban and rural areas of DG Khan. More than 10 percent of the respondents in urban areas, and 6.2 percent in rural areas reported that their last pregnancy ended in spontaneous abortions. 
Figure 7.9: $\quad$ Outcome of last pregnany

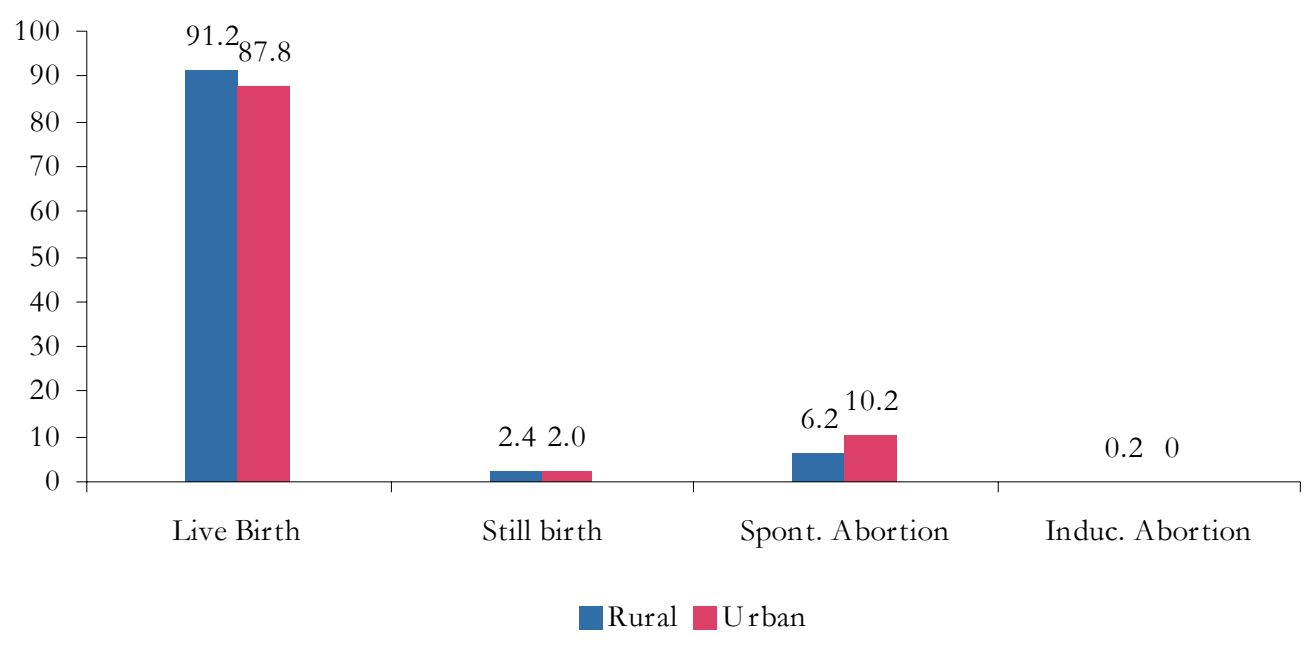

\section{Place of delivery}

Around 77 percent of the respondents in rural areas indicated that they delivered their baby at home. Only 4 percent of the women delivered their babies at government facilities (DHQ/THQ, RHCs, BHUs $/ \mathrm{MCH}$ ), and 19 percent at private hospitals. In urban areas, almost 55 percent of the women said that they delivered their babies at private hospitals/clinics, while 43 percent indicated that they delivered at home. Only 2 percent of respondents in urban areas used government health facilities for their delivery.

Figure 7.10: $\quad$ Place of delivery

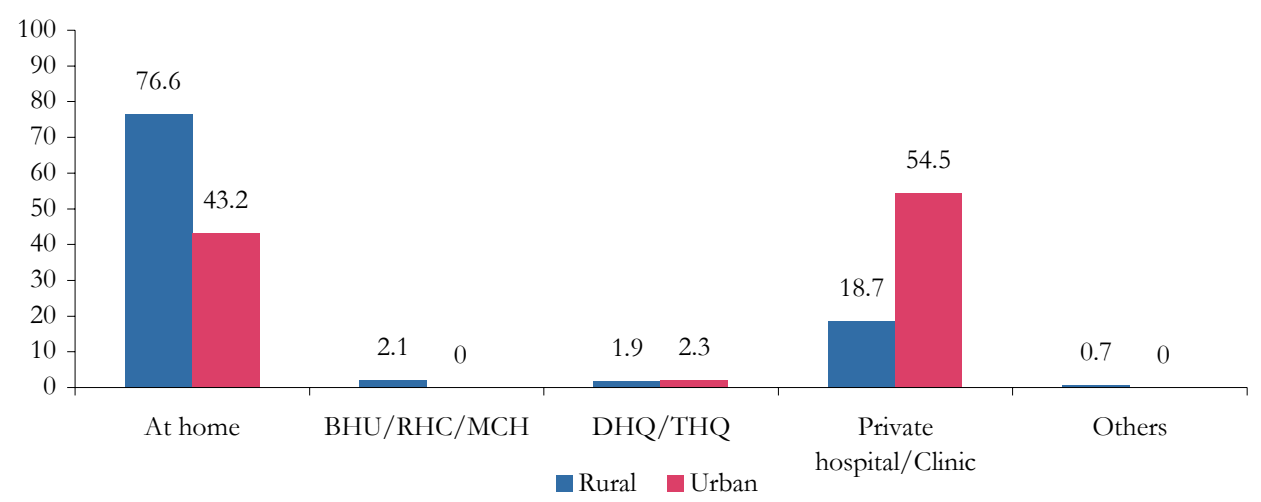




\section{Assistance during Delivery}

Among those who delivered at home, TBAs assisted more than 82 percent of the deliveries in D G Khan. Female relatives assisted about 14 percent of the deliveries, and less than 2 percent were assisted by a LHW/nurse/midwife (figure 7.11).

Figure 7.11: $\quad$ Percentage of married women who delivered their last child at home by type of delivery attendant

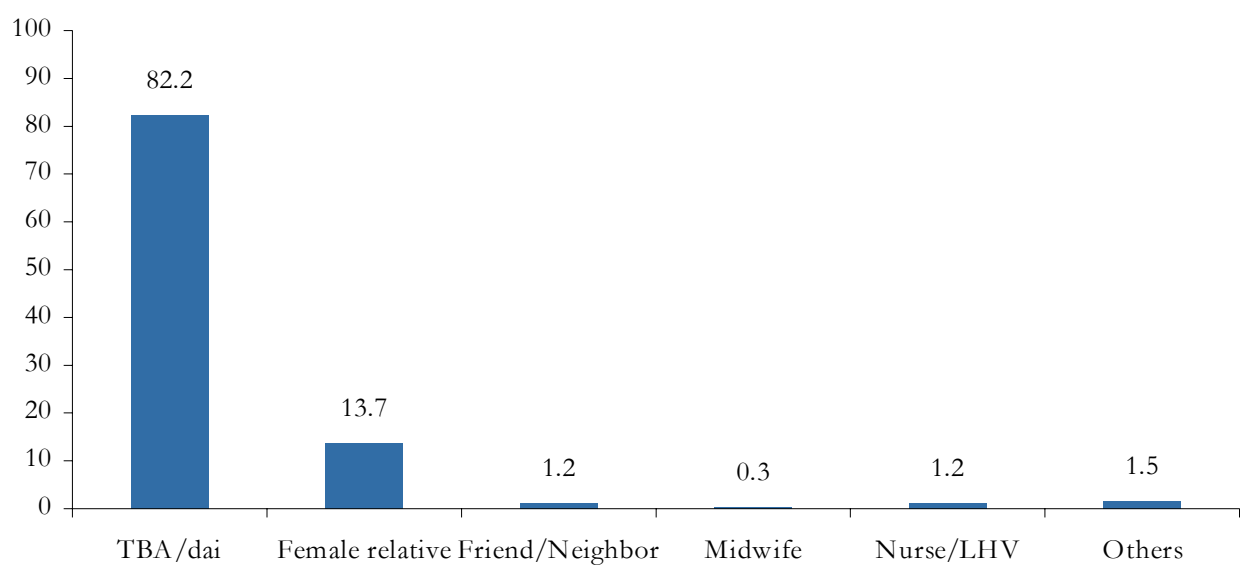

Figure 7.12 outlines the main reasons for choosing a TBA to assist with deliveries. In DG Khan, half of the married women reported that TBAs were chosen because they had already been used for earlier deliveries. More than one fifth of the respondents indicated that family choice was the main reason for choosing a TBA over a health professional. Approximately one-eighth of the women believed that TBAs were more knowledgeable than health professionals when it cames to deliveries. According to figure $7.12,9$ percent of the respondents cited geographical proximity as the main reason for choosing a TBA, while 5 percent of the respondents indicated that the low cost was the motivating factor.

Figure 7.12: $\quad$ Main reason for using a $\mathrm{TB} A$ / dai to assist with the last delivery

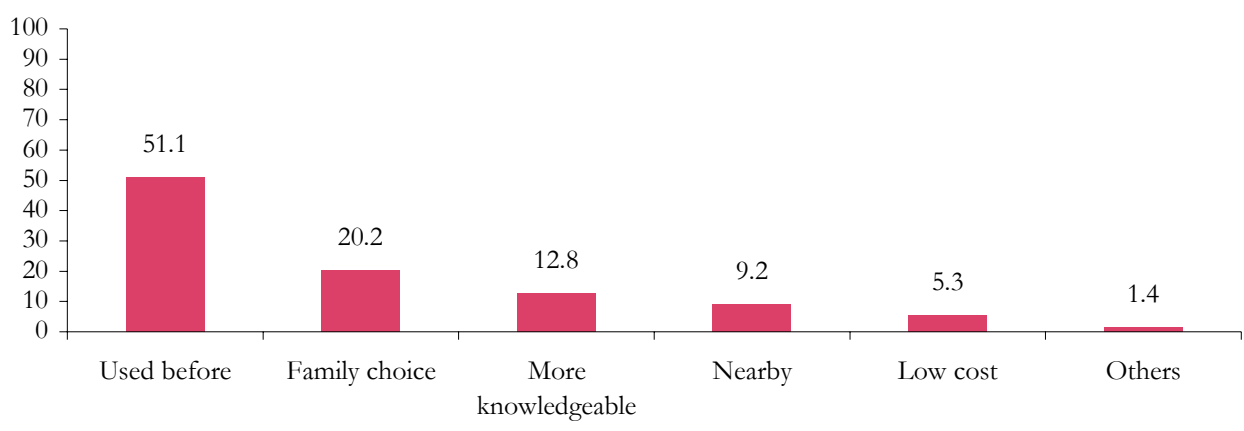




\section{Clean Delivery Practices}

Respondents were asked to state if the TBAs followed safe health practices such as washing their hands with soap prior to deliveries. More than 68 percent of the women surveyed in rural areas and over 74 percent in urban areas said that the TBA who assisted with the delivery washed her hands with soap.

Figure 7.13: $\quad$ Percentage of delivery attendants who reportedly washed their hands before conducting the delivery/type of thread used to tie the cord

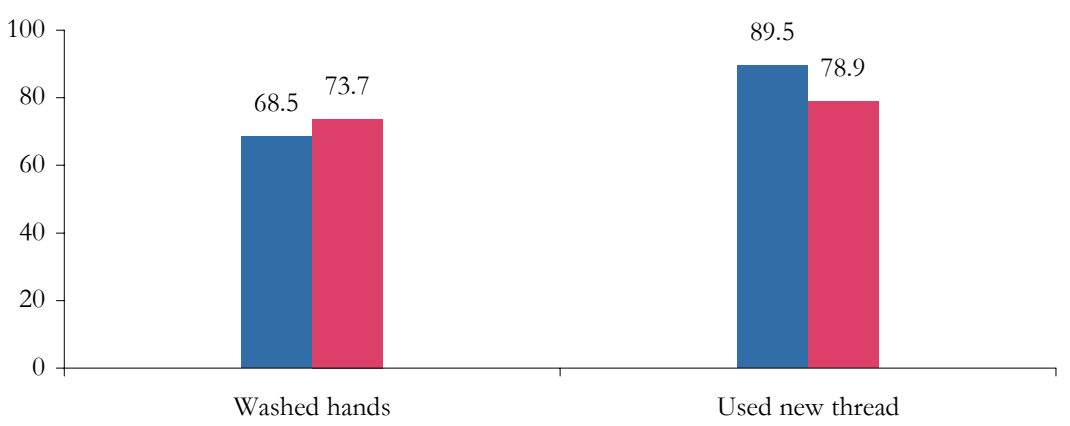

n Rural urban

Figure 7.14 outlines the type of instrument used to cut the cord at delivery. More than 86 percent of rural and 68 percent of urban respondents reported that their TBA used a new blade to cut the cord. In urban areas, more than a quarter of the respondents also reported that their TBA used scissors or a knife to cut the cord. About 90 percent of the respondents in rural areas and around 79 percent of the respondents in urban areas reported that their TBAs used a new thread to tie the cord.

Figure 7.14: $\quad$ Percentage of delivery attendants who reported instruments used for cutting the cord

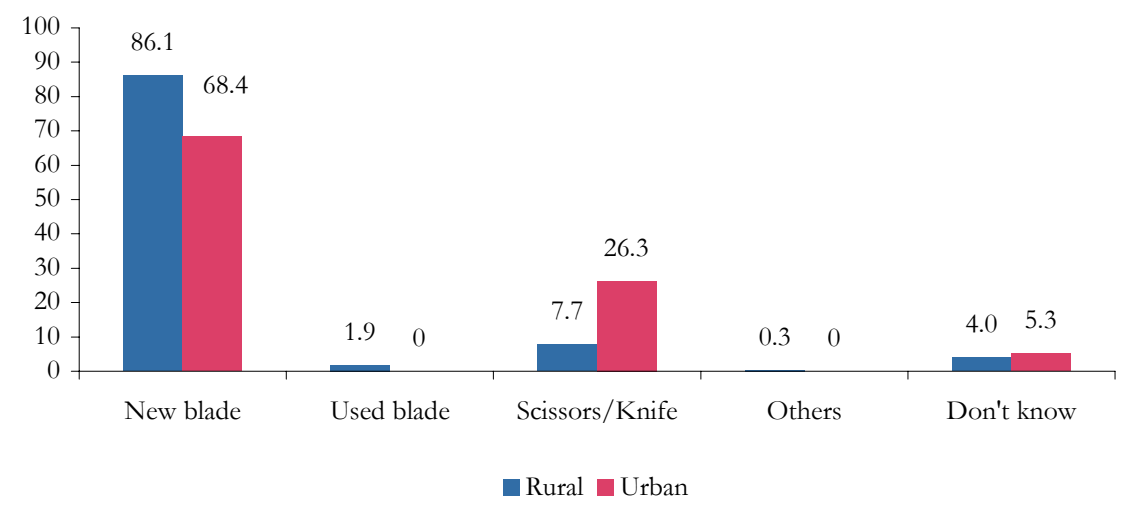




\section{Complications during Childbirth}

During the baseline survey, severe complications during childbirth were also discussed, and respondents were asked to indicate the complications they may have experienced. Table 7.4 indicates the percentage of severe complications that were experienced by respondents during childbirth. More than 20 percent of the respondents in rural areas indicated that they experienced 'excruciatingly abnormal pain' during their last pregnancy, whereas only 8 percent in urban areas reported the same. 'Prolonged labor', 'premature rupture of membranes' and 'excessive bleeding' were also among the commonly reported complications.

Table 7.4: $\quad$ Type of complications experienced during the last delivery

\begin{tabular}{|c|c|c|c|c|}
\hline \multirow{2}{*}{ Complications } & \multirow{2}{*}{ Rural } & \multirow{2}{*}{ Urban } & \multicolumn{2}{|c|}{ Total } \\
\hline & & & Percentage & Number \\
\hline Prolonged/obstructed labor & 15.0 & 12.2 & 14.8 & 74 \\
\hline Bleeding before labor began & 4.4 & 8.2 & 4.8 & 24 \\
\hline Excruciating abnormal pain & 20.4 & 8.2 & 19.2 & 96 \\
\hline Premature rupture of membranes & 8.2 & 12.2 & 8.6 & 43 \\
\hline Delay in delivery of placenta/retained placenta & 3.5 & & 3.2 & 16 \\
\hline Excessive postpartum bleeding on day of delivery & 4.6 & 4.1 & 4.6 & 23 \\
\hline Tear in vagina, cervix or uterus & 1.3 & 4.1 & 1.6 & 8 \\
\hline Prolapsed uterus & 0.7 & 2.0 & 0.8 & 4 \\
\hline Fever & 3.3 & & 3.0 & 15 \\
\hline Abnormal position of fetus & 3.1 & 2.0 & 3.0 & 15 \\
\hline
\end{tabular}

\section{Decision-making within family}

Delays in seeking care, in reaching adequate health facilities and in receiving appropriate care at health facilities are recognized barriers to care for pregnant women, and these factors may be especially pronounced for young and older pregnant mothers. Timely and appropriate care provides an opportunity to prevent or manage the direct causes of maternal mortality such as hemorrhage, obstructed labor, infection and hypertensive disorders. It also reduces fetal and neonatal deaths related to obstetric complications.

Table 7.5 shows that 17 percent of the respondents in rural areas indicated that their husbands were the ones who made the decision to seek treatment for delivery-related complications compared to only 15 percent in urban areas. In urban centers, more than 38.5 percent of the pregnant women indicated that they themselves decided when to seek medical attention compared to only 9 percent of the rural respondents. In rural areas more than 37 percent of the respondents reported that service providers (TBA/dai) made the decision for such treatments. 
Table 7.5:

Person who made decision to seek health care / mode of transport used to reach the bealth facility

\begin{tabular}{|c|c|c|c|c|c|c|c|}
\hline & \multirow{2}{*}{ Measures taken } & \multicolumn{2}{|c|}{ Rural } & \multicolumn{2}{|c|}{ Urban } & \multicolumn{2}{|c|}{ Total } \\
\hline & & Percent & Number & Percent & Number & Percent & Number \\
\hline \multirow{6}{*}{$\begin{array}{l}\text { Person who } \\
\text { made } \\
\text { decision to } \\
\text { seek health } \\
\text { care }\end{array}$} & Self & 8.7 & 10 & 38.5 & 5 & 11.7 & 15 \\
\hline & Husband & 17.4 & 20 & 15.4 & 2 & 17.2 & 22 \\
\hline & Mother in law & 10.4 & 12 & & & 9.4 & 12 \\
\hline & Other family member & 9.6 & 11 & 7.7 & 1 & 9.4 & 12 \\
\hline & TBA/Dai & 37.4 & 43 & 7.7 & 1 & 34.4 & 44 \\
\hline & Others & 16.5 & 19 & 30.8 & 4 & 18 & 23 \\
\hline \multirow{5}{*}{$\begin{array}{l}\text { Mode of } \\
\text { transport to } \\
\text { reach health } \\
\text { care service }\end{array}$} & Service provider visited home & 47.8 & 55 & 7.7 & 1 & 43.8 & 56 \\
\hline & On foot & 3.5 & 4 & & & 3.1 & 4 \\
\hline & Own transport & 17.4 & 20 & 53.8 & 7 & 21.1 & 27 \\
\hline & Private transport & 30.4 & 35 & 38.5 & 5 & 31.3 & 40 \\
\hline & Others & 0.9 & 1 & & & 0.8 & 1 \\
\hline
\end{tabular}

\section{Availability of Transport}

The mode of transport to a health facility was also an issue that was discussed during the survey. Table 7.5 shows most respondents indicated that they used private/hired transport to reach health facilities (30 percent in rural areas and 39 percent in urban centers). About 54 percent of the urban and 17 percent of the rural respondents stated that they had their own mode of transport. However, 48 percent in rural and 8 percent in urban areas, stated that they had a health provider visit their homes. Due to the small number of cases, these percentages must be read with caution.

Whatever the mode of transport used, almost one-third (32 percent) of the pregnant women were able to reach a health facility within 15 minutes. About 28 percent reached a health facility between 16-30 minutes, while 6 percent took 1-2 hours to reach a facility. One-third took 30 to 60 minutes, while about 7 percent took more than one hour to reach a health facility. Figure 7.15 shows the distribution of respondents by the time they took to reach a facility.

Figure: 7.15: $\quad$ Time taken to reach the health facility for childbirth

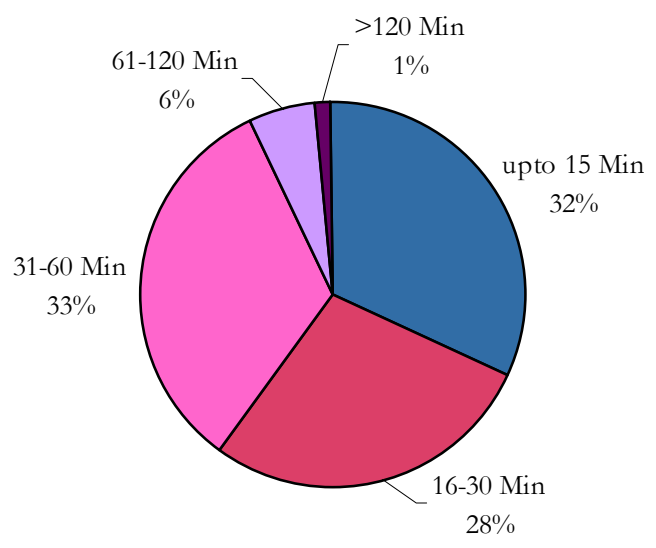


Figure 7.16 shows the median time taken to find transport at the time of delivery, travel to a health facility, and to obtain medical attention upon reaching the facility. In the district of DG Khan, it took respondents an average of 30 minutes to locate transport at the time of delivery, another 30 minutes of travel time to reach a health facility, and about 10 minutes to obtain delivery services upon arrival at the facility.

Figure 7.16:

Median time to get the transport, to reach the health facility and to obtain the treatment after reaching the facility

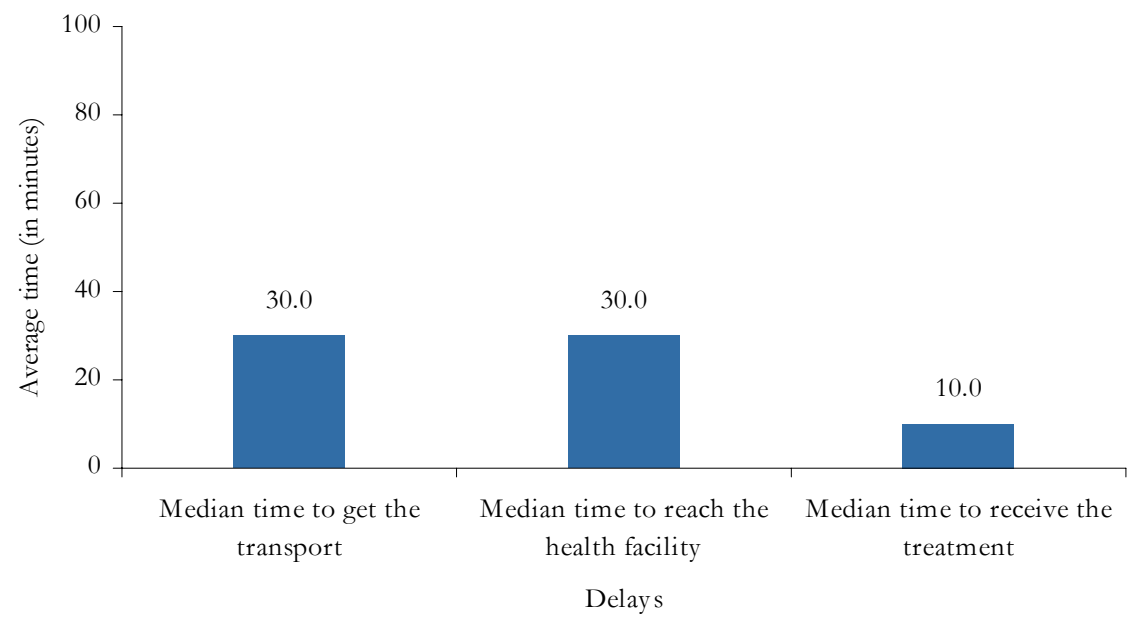

\section{Postpartum Care}

The postpartum period is a critical time for both the mother and the newborn. Respondents were asked about the quality and level of postpartum care they received after their last delivery. Table 7.6 shows that 77 percent of the respondents in rural areas, along with 46 percent of the respondents in urban areas, did not receive any postnatal check-ups after their last delivery. Only a quarter of the respondents in urban areas and 13 percent of their rural counterparts received postnatal care. Of those who received postnatal care services, 21 percent in rural and 27 percent in urban areas received it within the twenty-four hours following childbirth. 
Table 7.6 also shows that about 23 percent of the women surveyed in rural areas, and 14 percent in urban areas reported having experienced complications during the postpartum period.

Table 7.6:

History of postpartum care

\begin{tabular}{|c|c|c|c|c|c|c|c|}
\hline \multirow{2}{*}{ History } & & \multicolumn{2}{|c|}{ Rural } & \multicolumn{2}{|c|}{ Urban } & \multicolumn{2}{|c|}{ Total } \\
\hline & & Percent & Number & Percent & Number & Percent & Number \\
\hline \multirow{3}{*}{ Had postnatal check-ups } & Yes & 12.6 & 53 & 25.0 & 11 & 13.8 & 64 \\
\hline & No & 77.2 & 325 & 45.5 & 20 & 74.2 & 345 \\
\hline & $\begin{array}{l}\text { Delivered } \\
\text { in hospital }\end{array}$ & 10.2 & 43 & 29.5 & 13 & 12.0 & 56 \\
\hline $\begin{array}{l}\text { No. of days after delivery, } \\
\text { had first check-up }\end{array}$ & Same day & 20.7 & 11 & 27.3 & 3 & 21.8 & 14 \\
\hline \multirow{2}{*}{$\begin{array}{l}\text { Experienced complications } \\
\text { during postpartum period }\end{array}$} & Yes & 22.6 & 102 & 14.3 & 7 & 21.8 & 109 \\
\hline & No & 77.4 & 350 & 85.7 & 42 & 78.2 & 392 \\
\hline Total & & 100.0 & 452 & 100.0 & 49 & 100.0 & 501 \\
\hline
\end{tabular}

\section{Newborn/Infant Care}

The care provided to a newborn upon birth is crucial to the baby's health. Survey questions regarding initial infant and childcare help determine the cause of newborn morbidity and mortality.

\section{Child Care during Delivery}

Respondents were asked to indicate where the child was placed immediately after delivery. About half (48 percent) of the respondents in rural areas said that their newborns were placed on a piece of cloth immediately after delivery, while 12 percent of their urban counterparts said the same. About one sixth (16.3 percent) of respondents in both areas said that newborns were put with the mother immediately after delivery. More than 14 percent of the rural respondents and almost 12 percent of the urban respondents reported that their newborns were placed on the floor immediately after delivery.

Table 7.7: $\quad$ History of newborn care

\begin{tabular}{|c|c|c|c|c|c|c|c|}
\hline \multirow{2}{*}{\multicolumn{2}{|c|}{ History }} & \multicolumn{2}{|c|}{ Rural } & \multicolumn{2}{|c|}{ Urban } & \multicolumn{2}{|c|}{ Total } \\
\hline & & Percent & Number & Percent & Number & Percent & Number \\
\hline \multirow{6}{*}{$\begin{array}{l}\text { Placed child } \\
\text { immediately after } \\
\text { delivery }\end{array}$} & On floor & 14.3 & 59 & 11.6 & 5 & 14.1 & 64 \\
\hline & On mattress & 9.2 & 38 & 30.2 & 13 & 11.2 & 51 \\
\hline & On a piece of cloth & 48.1 & 198 & 11.6 & 5 & 44.6 & 203 \\
\hline & Put with the mother & 16.3 & 67 & 16.3 & 7 & 16.3 & 74 \\
\hline & Others & 2.4 & 10 & 2.3 & 1 & 2.4 & 11 \\
\hline & Don't know & 9.7 & 40 & 27.9 & 12 & 11.4 & 52 \\
\hline \multirow{3}{*}{$\begin{array}{l}\text { Child dried up/ } \\
\text { cleaned before } \\
\text { giving bath }\end{array}$} & Yes & 87.9 & 362 & 76.7 & 33 & 86.8 & 395 \\
\hline & No & 1.9 & 8 & & & 1.8 & 8 \\
\hline & Don't know & 10.2 & 42 & 23.3 & 10 & 11.4 & 52 \\
\hline
\end{tabular}


It is not very common to weigh a newborn in a district where most of the births take place at home. For those women who did not have their newborns weighed, a question was asked about the size of the baby at the time of birth. Figure 7.17 depicts the percentage distribution of babies by their size at birth. About 87 percent of the mothers reported that the size of their babies at the time of birth was normal, and 13 percent reported that their baby was smaller than average.

Figure 7.17: $\quad$ Percentage of newborns according to their size (small, normal and big) at birth

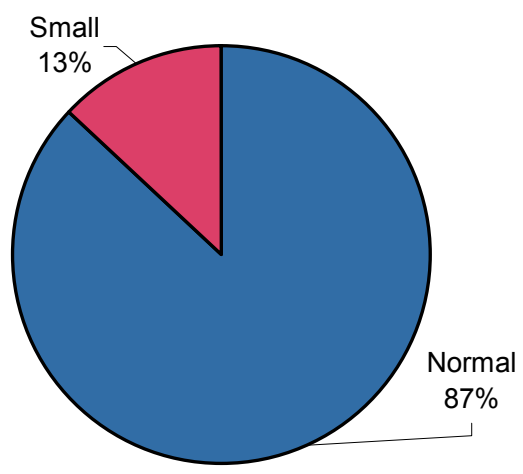

A question on the practice of bathing babies after the birth was also asked, and figure 7.18 shows the responses. It shows that less than 39 percent of the babies were bathed within the first hour of birth. However, 42 percent of the newborns were bathed after the recommended time of six hours following birth.

Figure 7.18: $\quad$ Duration between the time of birth and the first bath given to a newborn

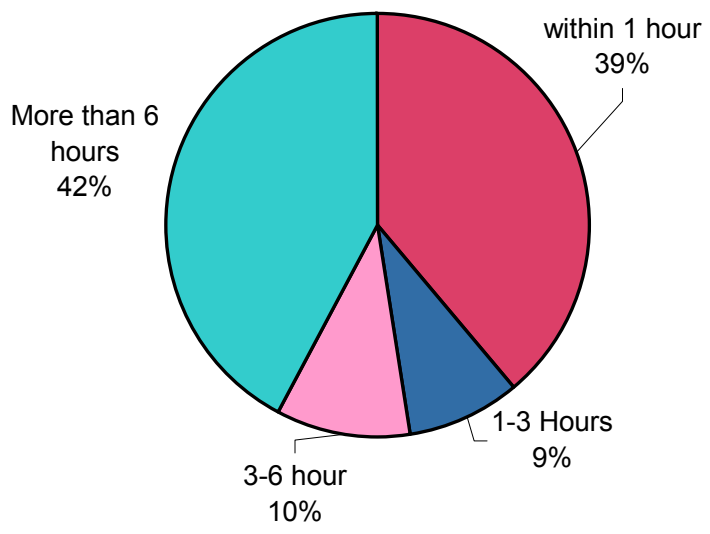




\section{Colostrum and Breastfeeding}

According to figure 7.19 three-quarters of the women in urban areas, and 61 percent of the women in rural areas indicated that they gave colostrums to their newborns. As well, approximately three quarters of the women in urban areas and two thirds of the women in rural areas provided their newborns with food supplements other than breast milk within the first three days following delivery.

\section{Newborn Medical Check-ups}

Respondents were also asked if any medical/physical check-ups were conducted on their newborns shortly after delivery. About 61 percent respondents in rural areas along with 28 percent in urban areas indicated that they did not have any medical or physical examinations carried out on their newborns.

Figure 7.19: $\quad$ Newborn feeding and health indicators

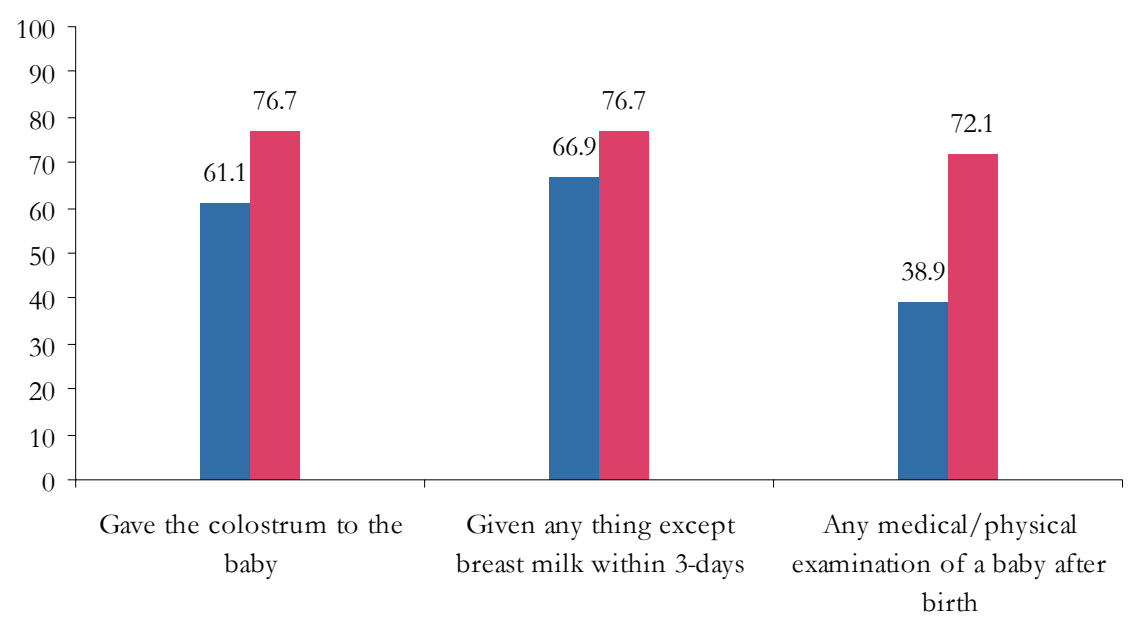

Rural Urban

Respondents were asked to recall any complications or symptoms they noted in their newborns soon after delivery. According to figure 7.20, 'difficult breathing' and 'weak cry' were the most widely observed complications in newborns soon after birth. Figure 7.21 shows the symptoms or complications that appeared in newborns within the first seven days after birth. 'Yellow skin color (jaundice)' was the most commonly noted symptom in newborns within the first seven days of birth. 
Figure 7.20: $\quad$ Percent of newborns with appeared signs/symptoms soon after delivery

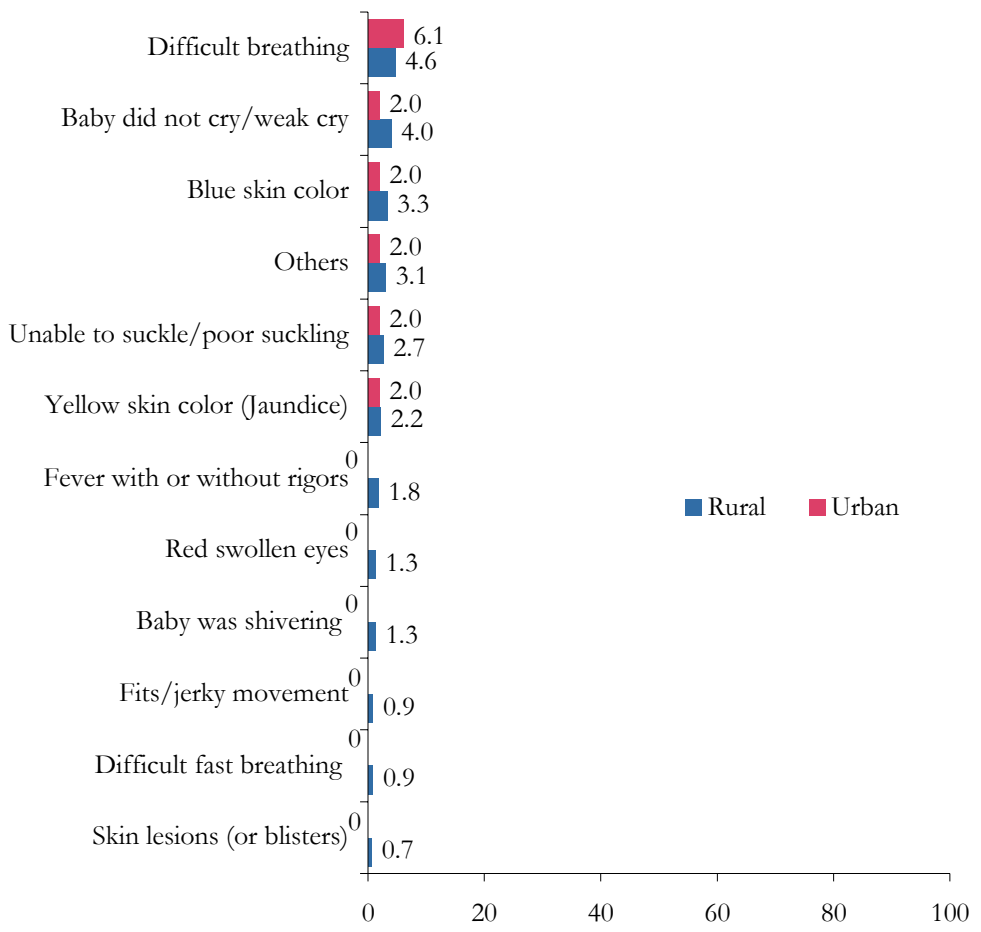

Figure 7.21: $\quad$ Percentage of newborns with danger signs/symptoms within 7-days after last delivery

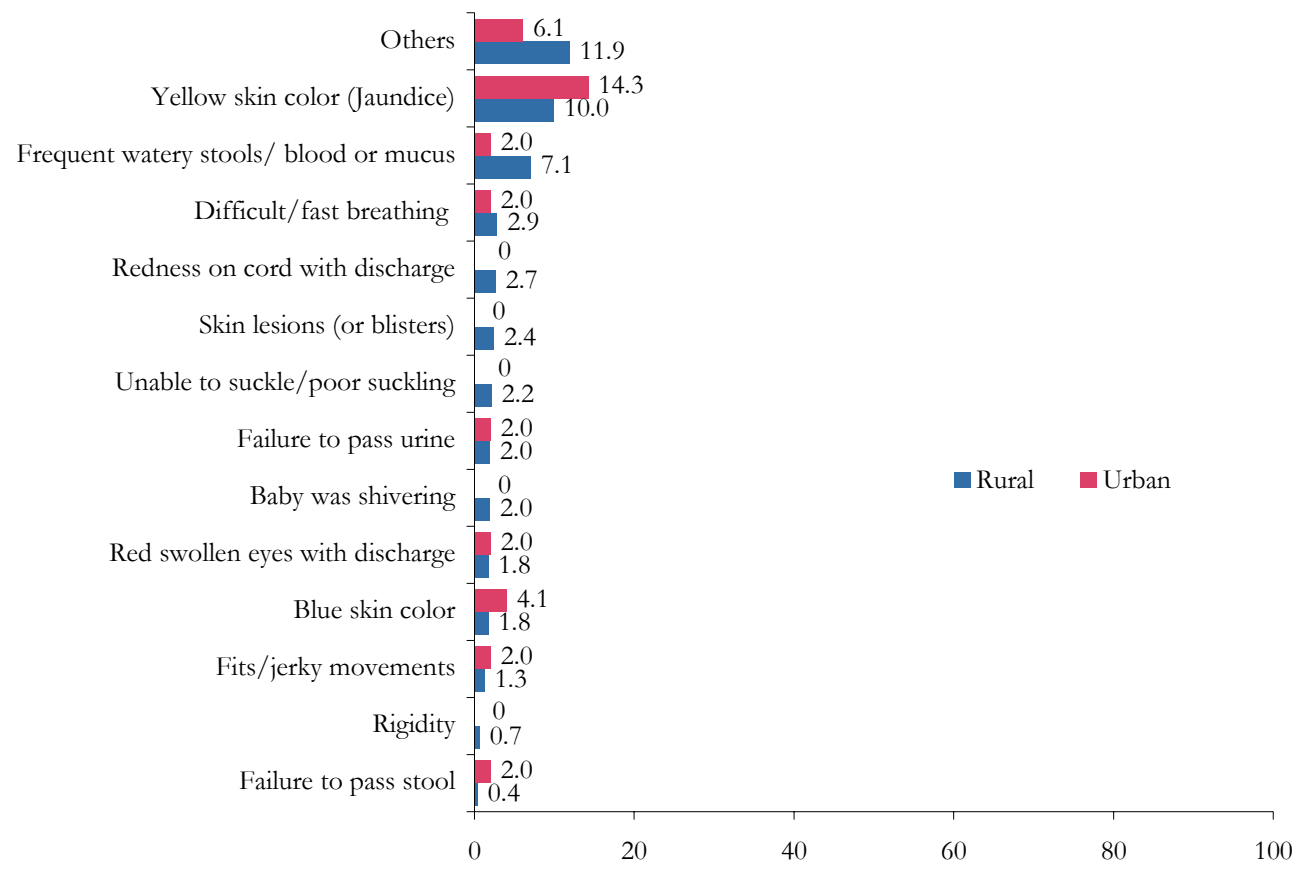


Respondents were asked to indicate where they sought treatment for their newborn when the abovementioned complications were noted. The responses are presented in figure 7.22. About 55 percent of the respondents in rural areas and 47 percent of the respondents in urban areas said that they sought treatment at private hospitals/clinics. Around 19 percent in rural areas and 33 percent in urban areas failed to get any treatment at all.

Figure 7.22: $\quad$ Place where treatment was sort for newborn complications

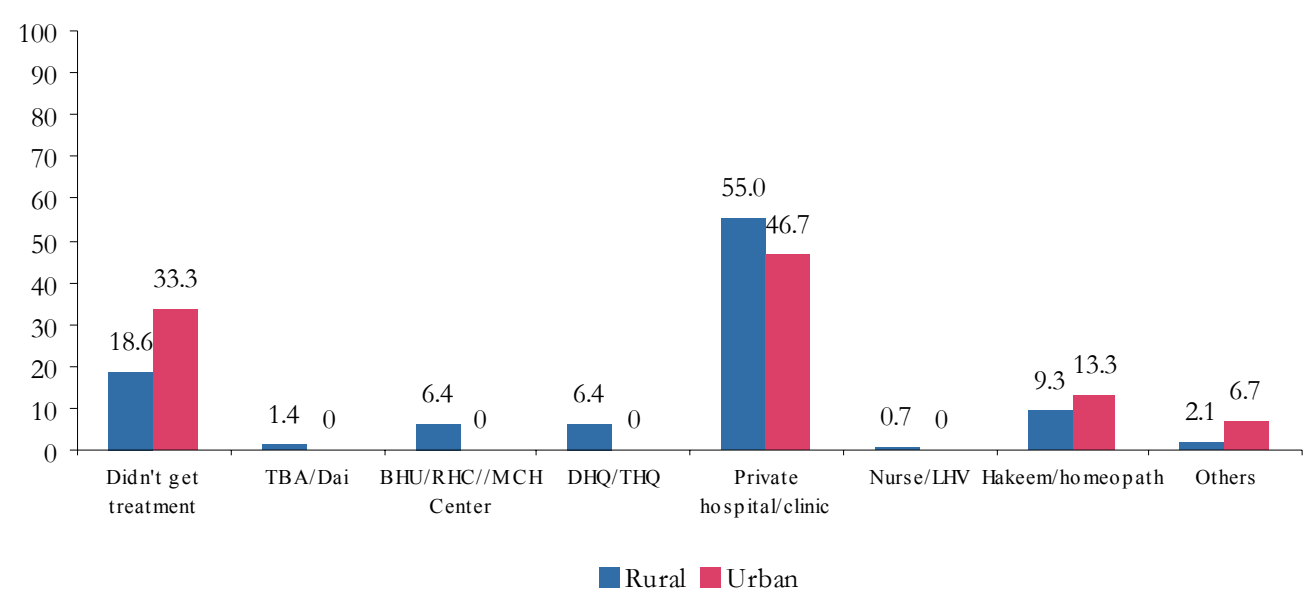

Respondents were asked to indicate the health status of their last child. Figure 7.23 shows that about 96 percent of the children born in rural areas, along with 93 percent of the children born in urban areas were alive at the time of the survey. About 74 percent of the women in rural areas along with 70 percent of their counterparts in urban areas were still breastfeeding their children at the time of survey. Approximately 38 percent of the women in rural areas, and about half of the women in urban areas reported that their children under three years of age had had at least one episode of diarrhea during two weeks preceding the survey.

Figure 7.23: $\quad$ Status of last live birth

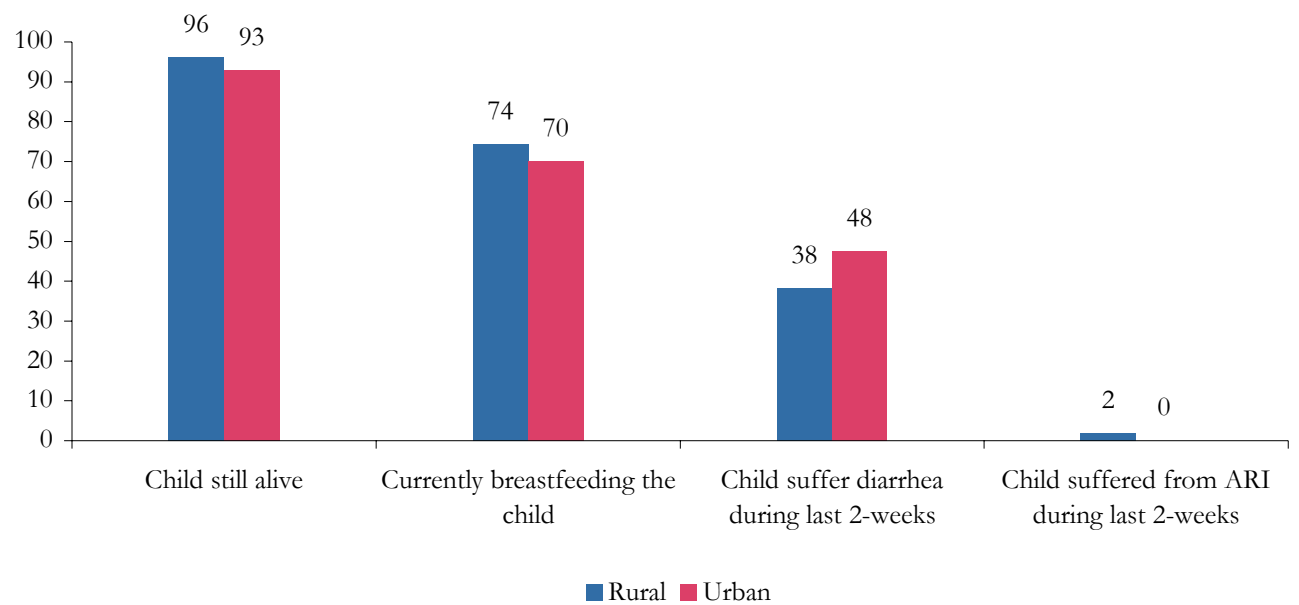




\section{Chapter 8)}

\section{Conclusions}

The baseline household survey conducted in DG Khan is an essential tool in the process of understanding the different attitudes towards, and misconceptions regarding, pregnancy and neonatal care. Since PAIMAN is intended to improve the health of all pregnant women as well as their newborn children, it is important to understand the obstacles that stand in the way of good health. Since the baseline survey is based largely on the opinions and experiences of married women of reproductive age (MWRA), the information obtained is from the very individuals who are to be the primary recipients of the work done through PAIMAN.

In DG Khan, the overall age-sex distribution shows a sex ratio of 104 males to 100 females, which is much better than the sex ratio of 108 to 100 obtained in the 1998 Population Census. This may be due to the improvement in the overall enumeration of the female population in individual households. Another sign of progress is that marital status clearly demonstrates a delay in the age at which females marry, which is an improvement in the status of women compared to 1998 Population Census. However, women still tend to get married earlier than men. The overall average number of children ever born has decreased from 4.8 to 4.2 since the 1998 Census. This reduction can be seen in almost all age groups. The number of living children has increased from 3.4 to 3.7 .

Findings also show that half of the respondents of DG Khan have no access to any one of the three media channels; television, radio or newspapers. In order to educate and inform this segment of the population regarding maternal and infant mortality and birth preparedness, more grassroots methods must be adopted. These grassroots efforts may include inter-personal communication through community workers, community gatherings, speeches and health education sessions. The majority of the women interviewed in both urban and rural areas believed that television was the most trustworthy form of media.

Regarding antenatal care, an overwhelming majority believed it necessary for women to receive antenatal check-ups, while 15 percent and 8 percent of the married women in rural and urban areas respectively felt it was not necessary. The findings show that half of all pregnant women in rural areas, and more than three-quarters of the women in urban areas went for antenatal check-ups during their last pregnancy. However, less than 50 percent of married women went for 3 or more antenatal checkups. Therefore, it becomes quite clear that while many women do want to receive antenatal check-ups, and feel that it is a necessary part of neonatal care, many are not able to access this service. Less than 20 percent of the pregnant women were informed of the signs of pregnancy complications during antenatal visits.

Respondents were asked to indicate which complications they believed were dangerous and required medical attention. Surprisingly, a very small percentage believed that most complications required a 
doctor's care. The findings show that a quarter of the married women in urban areas knew three or more danger signs during pregnancy, compared to more than 22 percent in rural areas. More than a quarter of women in both urban and rural areas were unable to name a single sign of complications during pregnancy.

The baseline findings show that about 56 percent of the married women in rural areas and about 86 percent in urban centers indicated that they did in fact receive TT shots during their last pregnancy. A very large portion of the rural women (71 percent) and urban women (47 percent) indicated that they took no iron or folate supplements during their pregnancy.

The baseline findings also show that more than three quarters of the women in rural areas indicated that they delivered their baby at home. Only 4 percent of women delivered their babies at government facilities and 18 percent at private hospital in rural areas. In urban areas more than half of the women said that they delivered their babies at private hospitals/clinics and 43 percent did so at home. Only 2 percent of respondents availed government health facilities in urban areas. This shows that the use of government health facilities is very low in DG Khan.

Caesarean section deliveries appear to make up a higher percentage in urban than rural areas (10.2 percent versus 3.8 percent respectively). Normally caesarean sections are performed only for certain medical reasons and for complicated deliveries. More than 20 percent of the respondents in rural areas indicated that they experienced excruciatingly abnormal pain during their last delivery, whereas only 8.2 percent in urban centers reported the same thing. Prolonged labor, premature ruptures of membranes and excessive bleeding were some other complications that were reported.

Married women in DG Khan generally undervalue the importance of postnatal care. About half of the respondents in rural areas and about one-third in urban areas did not feel postnatal care was necessary. Furthermore, a quarter of the respondents in urban and about one-third in rural areas of DG Khan, believed that only some women in their area received postnatal care.

As in the case of pregnancy, many women are not aware of the complications that may arise during delivery. The findings show that only 15 percent of the women recognize at least three danger signs during delivery. It becomes very difficult to save a pregnant woman who does not recognize danger signs during pregnancy and therefore fails to seek medical assistance in time. Deliveries can only be made safe if married women are educated regarding the danger signs, which may be noted during the delivery, so that they can decide when to seek treatment. Innovative approaches are therefore needed to make these communities more aware of issues regarding maternal and newborn health.

Although baseline survey findings indicate that excessive vaginal bleeding is the most known danger sign during the postpartum period, not all women are aware of this fact. Unfortunately, many women are also unaware of danger signs that may appear in newborns, especially in the first seven days after delivery. The postpartum period is a critical time for mothers and newborns. A very large portion of the married women interviewed did not receive any postnatal check-ups after their last pregnancy. More than 77 percent of the population in rural areas received no postnatal check-up, whereas the figure was 45.5 percent even in urban areas. Among those who went for postnatal care, 22 percent went within 24 hours after the childbirth. 
A very large percentage in both urban and rural areas indicated that they received their pregnancy related information from their in-laws, family members and friends. Only 3.6 percent in rural areas indicated that a Lady Health Worker was the source of their information. District Headquarter Hospitals and Tehsil Headquarter Hospitals were also a source of information for 2.5 percent of the rural and 1.6 percent of the urban population in DG Khan.

Arrangement of transport to a health facility is a major cause of delay and can often lead to maternal and newborn mortality. It is very important to arrange transport ahead of time in order to eliminate that delay. Unfortunately, many households are unable to do so due to a lack of transportation in their communities. Most communities do not have any arrangements made for transport, provision of blood and finances for women at the time of need during delivery. This is a major obstacle to safe birth practices, as women are then forced to deliver at home, and may be exposed to infections and complications. Birth preparedness promotes the arrangement of such aspects.

We hope that the data may be used by health officials, NGOs, and other concerned stakeholders to improve the situation regarding maternal and newborn health in DG Khan. PAIMAN will use this information to guide its own interventions and to monitor its progress. 


\section{References}

Caldwell, J., Routes to Low Mortality in Poor Countries. Population and Development Review, Vol. 12, No. 2. (Jun., 1986), pp. 171-220.

Federal Bureau of Statistics, "Socio-Economic Indicators at District Level, Punjab," Statistics Division, Government of Pakistan, (2002).

Hollander, D., Antenatal Education Helps Turkish Women Adopt Health-Promoting Behaviour. International Family Planning Perspectives, Vol. 30, No. 1. (Mar., 2004), pp. 45-46.

JHPIEGO/Maternal and Neonatal Health Program, "Monitoring Birth Preparedness and Complication Readiness: Tools and Indicators for Maternal and Newborn Health," (2004).

Mahmood, Arshad, Determinants of Neonatal and Post-Neonatal Mortality in Pakistan. The Pakistan Development Review, Vol. 41, No. 4, Part II (Winter 2002), pp. 723-744.

Mahmood, Arshad, Socioeconomic Factors, Personal Illness Control and Infant and Child Mortality in Pakistan. Pakistan Population Review, Vol. 3, No. 1 (1992), pp. 67-86.

Martin, Linda G.; J. Trussell; Florentina Reyes Salvail; Nasra M. Shah, Co-variates of Child Mortality in the Philippines, Indonesia, and Pakistan: An Analysis Based on Hazard Models. Population Studies, Vol. 37, No. 3. (Nov., 1983), pp. 417-432.

Nawaz, Shuja, The Mass Media and Development in Pakistan. Asian Survey, Vol. 23, No. 8. (Aug., 1983), pp. 934-957.

Ringheim, Karin, When the Client is Male: Client-Provider Interaction from a Gender Perspective, International Family Planning Perspectives, Vol. 28, No. 3 (Sept., 2002), pp. 170-175.

Robbins, P.T., Global Approaches to Development. Sociology of Development, University of London, (2001), pp. 29-37.

Sathar, Zeba; Nigel Crook; Christine Callum; Shahnaz Kazi, Women's Status and Fertility Change in Pakistan. Population and Development Review, Vol. 14, No. 3. (Sep., 1988), pp. 415432.

Simmons, George B., Family Planning Programs or Development: How Persuasive is the New Wisdom? International Family Planning Perspectives, Vol. 5, No. 3. (Sep., 1979), pp. 101-110.

Syed, Sabiha H., Communications Channels and Family Planning in Pakistan. Studies in Family Planning, Vol. 10, No. 2. (Feb., 1979), pp. 53-60.

www.unesco.org 